\title{
Photometric Calibrations
}

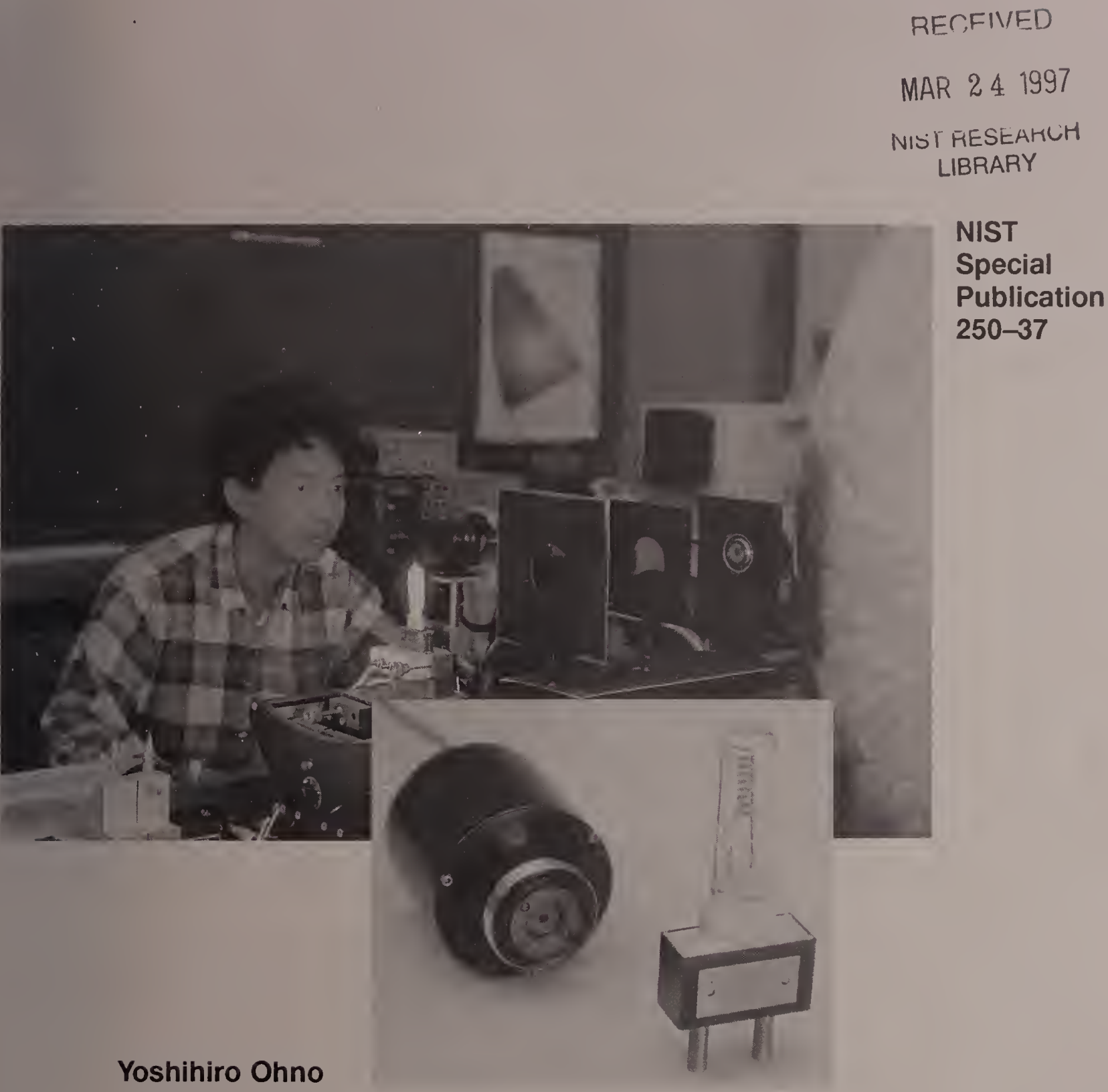

U.S. Department of Commerce Technology Administration

National Institute of Standards and Technology 



\section{NIST MEASUREMENT SERVICES: Photometric Calibrations}

\section{Yoshihiro Ohno}

Optical Technology Division

Physics Laboratory

National Institute of Standards and Technology

Gaithersburg, MD 20899

January 1997

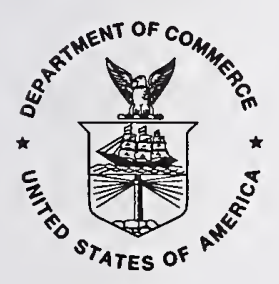

U.S. Department of Commerce

Michael Kantor, Secretary

Technology Administration

Mary L. Good, Under Secretary for Technology

National Institute of Standards and Technology

Arati Prabhakar, Director 
National Institute of Standards and Technology Special Publication 250-37

Natl. Inst. Stand. Technol. Spec. Publ. 250-37, 90 pages (Jan. 1997)

CODEN: NSPUE2

\section{U.S. GOVERNMENT PRINTING OFFICE}

WASHINGTON: 1997 


\section{PREFACE}

The calibration and related measurement services of the National Institute of Standards and Technology are intended to assist the makers and users of precision measuring instruments in achieving the highest possible levels of accuracy, quality, and productivity. NIST offers over 300 different calibrations, special tests, and measurement assurance services. These services allow customers to directly link their measurement systems to measurement systems and standards maintained by NIST. These services are offered to the public and private organizations alike. They are described in NIST Special Publication (SP) 250, NIST Calibration Services Users Guide.

The Users Guide is supplemented by a number of Special Publications (designated as the "SP250 Series") that provide detailed descriptions of the important features of specific NIST calibration services. These documents provide a description of the: (1) specifications for the services; (2) design philosophy and theory; (3) NIST measurement system; (4) NIST operational procedures; (5) assessment of the measurement uncertainty including random and systematic errors and an error budget; and (6) internal quality control procedures used by NIST. These documents will present more detail than can be given in NIST calibration reports, or than is generally allowed in articles in scientific journals. In the past, NIST has published such information in a variety of ways. This series will make this type of information more readily available to the user.

This document, SP250-37 (1996), NIST Measurement Services: Photometric Calibrations, is a revision of SP250-15 (1987). It covers the calibration of standards of luminous intensity, luminous flux, illuminance, luminance, and color temperature (test numbers $37010 \mathrm{C}-37100 \mathrm{~S}$ in SP250, NIST Calibration Services Users Guide). Inquiries concerning the technical content of this document or the specifications for these services should be directed to the author or to one of the technical contacts cited in SP250.

NIST welcomes suggestions on how publications such as this might be made more useful. Suggestions are also welcome concerning the need for new calibrations services, special tests, and measurement assurance programs.

Stanley D. Rasberry

Director

Measurement Services
Katharine B. Gebbie

Director

Physics Laboratory 


\section{ABSTRACT}

The National Institute of Standards and Technology supplies calibrated standards of luminous intensity, luminance, and color temperature, and provides calibration services for submitted artifacts for luminous intensity, luminance, color temperature, total luminous flux, and luminance. The procedures, equipment, and techniques used to perform these calibrations are described. Detailed estimates and procedures for determining uncertainties of the reported values are also presented.

Key words : Calibration; Candela; Color temperature; Illuminance; Lumen; Luminance; Luminous flux; Luminous intensity; Lux; Photometry; Standards; Total flux; Unit 


\section{TABLE OF CONTENTS}

Abstract

1. Introduction

1.1 Photometry, physical photometry, and radiometry …................................. 1

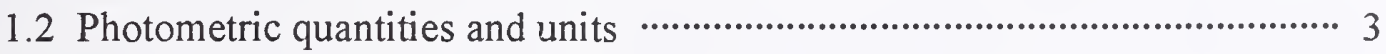

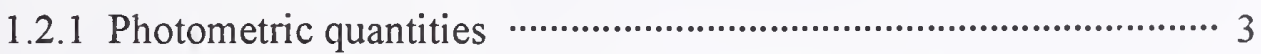

1.2.2 Relationship between the SI units and English units …................... 6

1.3 NIST photometric units …................................................................... 7

1.3.1 NIST luminous intensity unit …….............................................. 7

1.3.2 NIST luminous flux unit ……..................................................... 9

2. Outline of the calibration services

3. Luminous intensity (candela) calibrations ……........................................................... 12

3.1 NIST illuminance unit and the NIST candela ……...................................... 12

3.1.1 Principles of the detector-based candela realization …….................. 12

3.1.2 Design of the NIST standard photometers …................................... 13

3.1.3 Calibration of the NIST standard photometers …............................. 14

3.1.4 Spectral mismatch correction …………........................................ 14

3.1.5 Correction for the photometer temperature ……............................ 15

3.1.6 Linearity of the NIST standard photometers …............................. 16

3.1.7 Uncertainty of the NIST illuminance unit and the candela realization ….......................................................................... 16

3.1.8 Long-term stability of the NIST standard photometers …............ 17

3.2 Artifacts for calibration …….................................................................. 19

3.2.1 Type of test lamps and their characteristics …….......................... 19

3.2.2 Alignment of test lamps ……................................................... 22

3.2.3 Operation and handling of test lamps ….................................... 23

3.3 Equipment for calibration ……............................................................ 23

3.3.1 Photometry bench ………………………................................... 23

3.3.2 Electrical power supply …...................................................... 24

3.4 Calibration procedures ………………………................................... 25

3.5 Uncertainty of calibration 
4. Illuminance calibrations

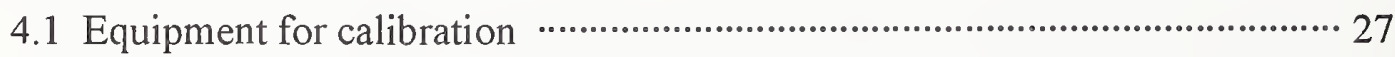

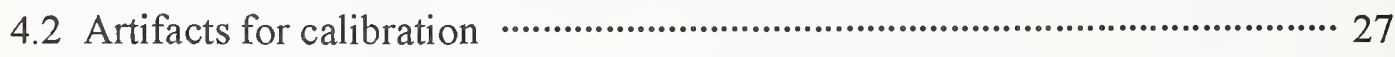

4.2.1 Types of photometers and illuminance meters ……........................ 27

4.2.2 Operation and handling of photometers and illuminance meters $\cdots 28$

4.3 Calibration procedures …………....................................................... 28

4.3.1 Illuminance responsivity of photometers …….............................. 28

4.3.2 Illuminance meter calibration …………....................................... 29

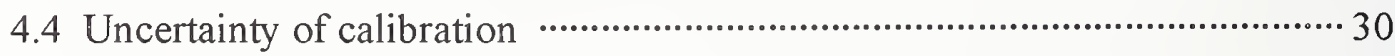

5. Total luminous flux calibrations

5.1 NIST luminous flux unit ………….................................................... 32

5.1.1 Principles of the integrating sphere method ……............................ 32

5.1.2 Design of the NIST integrating sphere for the lumen realization $\cdots 33$

5.1.3 Correction for the spatial nonuniformity of the sphere

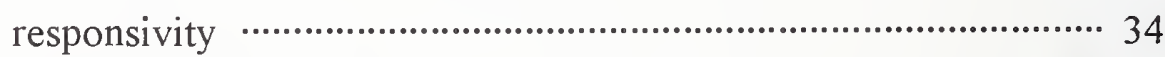

5.1.4 Incident angle dependence correction ………................................ 36

5.1.5 Spectral mismatch correction ………........................................... 36

5.1.6 Calibration of the primary standard lamps …................................... 37

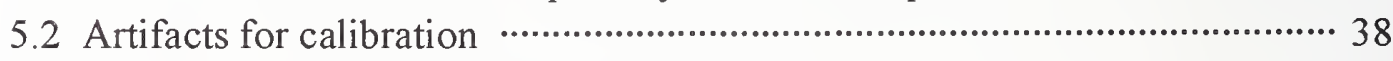

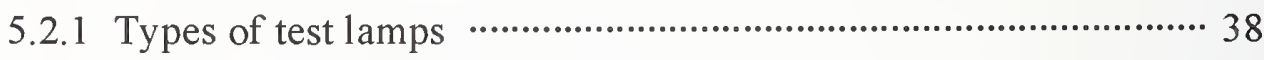

5.2.2 Operation and handling of test lamps ………............................... 39

5.3 Equipment for calibration ……………………….................................. 40

5.3.1 2 m integrating sphere ……................................................ 40

5.3.2 Electrical facility for incandescent lamps …….............................. 42

5.3.3 Electrical facility for fluorescent lamps …….................................. 43

5.4 Calibration procedures

5.4.1 Correction for the sphere detector temperature …………………... 44

5.4.2 Self-absorption correction ………................................................. 44

5.4.3 Spectral mismatch correction …………………............................. 44

5.4.4 Correction for the spatial nonuniformity of the sphere response $\cdots 46$

5.4.5 Determination of luminous flux ……………............................... 46

5.5 Uncertainty of calibration

6. Luminance calibrations

6.1 NIST luminance unit ………………………......................................... 49

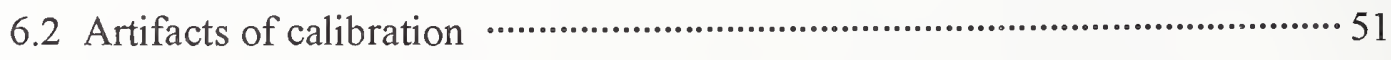

6.3 Equipment for calibration ………........................................................... 51 
TABLE OF CONTENTS (continued)

6.4 Calibration of luminance sources ………………...................................... 52

6.5 Calibration for luminance meters ……....................................................... 53

6.6 Calibration for opal glass ….................................................................. 55

6.6.1 Calibration procedures …….................................................... 55

6.6.2 Use of opal glass standards for luminance coefficient ……............... 56

6.6.3 Uncertainty of calibration …........................................................... 57

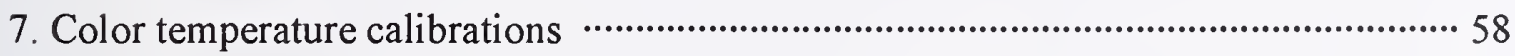

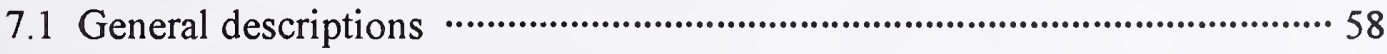

7.2 NIST color temperature scale ………………...................................... 59

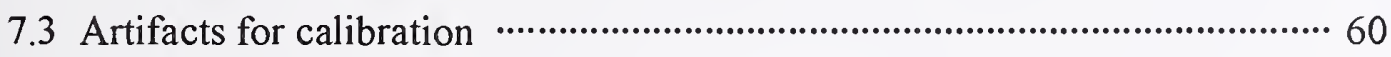

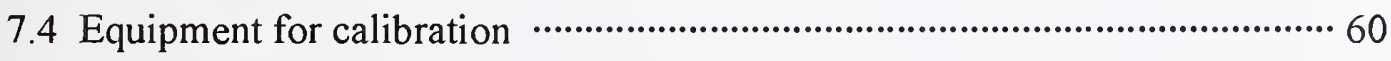

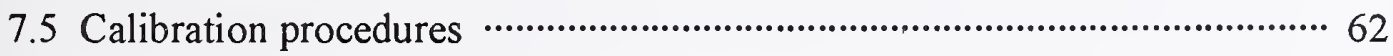

7.6 Uncertainty of calibration

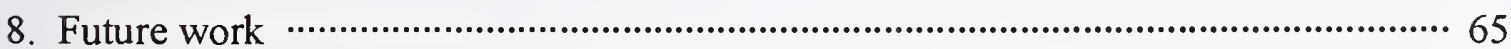

8.1 Total spectral radiant flux scale realization ……………………………….....6 65

8.2 Luminous flux calibration of other discharge lamps ………........................... 65

8.3 Issuing calibrated standard lamps …………................................................. 66

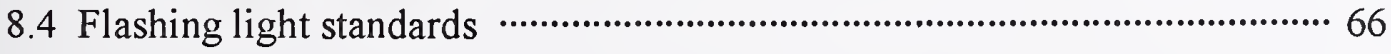

Acknowledgments

References

Appendix A - State of the NIST photometric units in international intercomparisons - A1

Appendix B - SP250, Optical Radiation Measurements, Chapter 7 …….................. A2

Appendix C - Samples of calibration reports 


\section{LIST OF FIGURES}

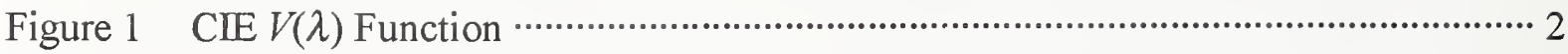

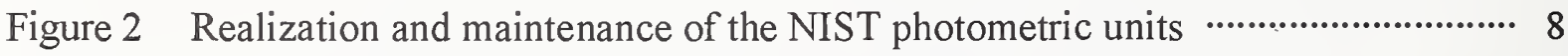

Figure 3 Construction of the High Accuracy Cryogenic Radiometer ….............................. 9

Figure 4 Geometry for the detector-based candela realization ……..................................... 12

Figure 5 Design of the NIST standard photometer …..................................................... 13

Figure 6 Polynomial fit for the spectral mismatch correction factors …............................. 15

Figure 7 The temperature dependence of the photometers' illuminance responsivity $\cdots \cdots \cdot 15$

Figure 8 Linearity of one of the NIST standard photometers …....................................... 16

Figure 9 Drift of the illuminance responsivity of the NIST standard photometers over

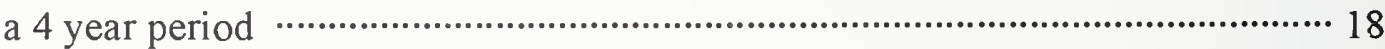

Figure 10 Appearance of the luminous intensity standard lamps and their electrical

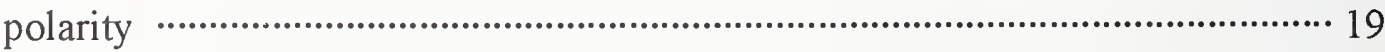

Figure 11 Aging characteristics of a typical Airway Beacon type lamp at $2856 \mathrm{~K} \cdots \cdots \cdots \cdot 20$

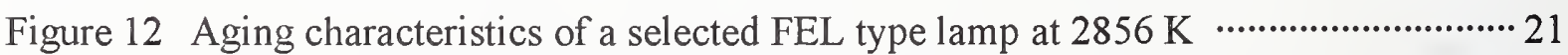

Figure 13 Spatial nonuniformity of a typical FEL type lamp …........................................ 21

Figure 14 Alignment of the bi-post base socket using a jig and a laser beam ……............... 22

Figure 15 Alignment of the distance origin using a jig and a laser beam ……........................ 22

Figure 16 NIST Photometry Bench ……................................................................... 24

Figure 17 Geometry of the simulation model ….............................................................. 32

Figure 18 Geometry of the integrating sphere for the luminous flux unit realization ……... 34

Figure 19 SRDF of the NIST integrating sphere. $(\theta=0$ is at the detector. $\phi=0$ is the plane passing through the sphere bottom.) ……………….................................. 35

Figure 20 NIST $2 \mathrm{~m}$ integrating sphere set up for routine calibrations …............................. 40

Figure 21 Spectral characteristics of the NIST integrating sphere ……………………........ 41

Figure 22 Spectral mismatch correction factor of the NIST $2 \mathrm{~m}$ integrating sphere as a function of the color temperature of a Planckian source ………….................. 42

Figure 23 Measurement circuit for a rapid start fluorescent lamp ….................................. 43

Figure 24 Arrangement for NIST luminance unit realization …........................................ 49

Figure 25 Relative spectral responsivity of the reference luminance meter …….................. 52

Figure 26 Configuration for opal glass calibration ……................................................... 55

Figure 27 Realization of the NIST spectral irradiance scale and the color temperature

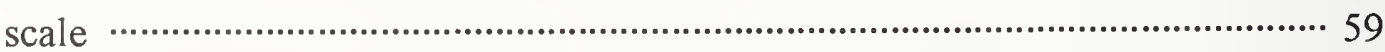

Figure 28 Configuration for color temperature calibration …............................................. 61

Figure 29 Color temperature correction values for the NIST diode-array spectroradiometer 


\section{LIST OF TABLES}

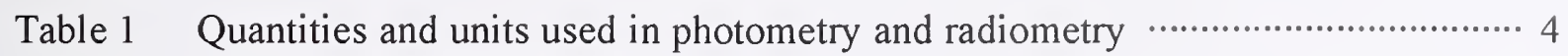

Table 2 English units and definition

Table 3 Conversion between English units and SI units ……............................................ 6

Table 4 NIST Photometric Calibration Services ……........................................................ 11

Table 5 Uncertainty budget for the NIST illuminance unit realization ………................... 17

Table 6 . Uncertainty budget for the NIST candela realization …….................................. 17

Table 7 Uncertainty budget for luminous intensity calibrations (typical) ……………......26

Table 8 Uncertainty budget for illuminance responsivity calibration (typical) $\cdots(. . . \cdots \cdots . . . . .31$

Table 9 Uncertainty budget for the calibration of an illuminance meter (an example) $\cdots \cdot 31$

Table 10 Uncertainty budget for the NIST 1995 luminous flux unit ………...................... 38

Table 11 Uncertainty budget for total luminous flux calibrations of standard incandescent lamps (typical) ……………………....................................... 48

Table 12 Uncertainty budget for total luminous flux calibrations of $4 \mathrm{ft}$ linear fluorescent lamps (typical) ………………………………………………... 48

Table 13 Uncertainty budget for the NIST luminance unit realization ……....................... 50

Table 14 Uncertainty budget for luminance source calibrations (typical) …....................... 53

Table 15 Uncertainty budget for luminance meter calibrations (typical) …....................... 54

Table 16 Uncertainty budget for opal glass calibrations ……............................................ 57

Table 17 The uncertainty of the spectral irradiance calibration with respect to the

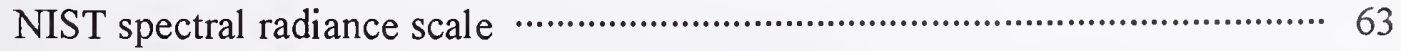

Table 18 The uncertainty budget for the NIST color temperature calibration ………….... 64 



\section{Introduction}

This document supersedes the NBS Special Publication 250-15 (1987). In 1992, a new candela was realized based on an absolute cryogenic radiometer, and the old NIST gold-point blackbody-based unit [1] was replaced by the new detector-based unit [2]. A group of eight standard photometers with calibrations based on the cryogenic radiometer holds the NIST candela, and replaces the lamp scheme formerly used. Further, the photometric calibration procedures have been revised to utilize the detector-based methods [3].

This document describes the new photometric calibration procedures for luminous intensity (candela; cd), illuminance (lux; $1 \mathrm{x}$ ), total luminous flux (lumen; $1 \mathrm{~m}$ ), luminance (cd/ $\mathrm{m}^{2}$ ) and color temperature (kelvin; K). Throughout this document, uncertainty statements follow the NIST policy given by Taylor and Kuyatt [4], which prescribes the use of an expanded uncertainty with a coverage factor $k=2$ for uncertainties of all NIST calibrations.

Descriptions for the individual standards and calibrations available from NIST, as of April 1996, are listed and explained in Section 2. Updated information about calibration services and prices are published periodically in the NIST Calibration Services Users Guide (SP250) [5] and Fee Schedule (SP250 Appendix).

The material presented in this document describes photometric calibration facilities and procedures as they existed at the time of publication. Further improvement of photometric calibration facilities and procedures are underway. Some of these on-going projects are described in Section 8.

\subsection{Photometry, physical photometry, and radiometry}

The primary aim of photometry is to measure visible optical radiation, light, in such a way that the results correlate with what the visual sensation is to a normal human observer exposed to that radiation. Until about 1940, visual comparison techniques of measurements were predominant in photometry, whereby an observer was required to match the brightness of two visual fields viewed either simultaneously or sequentially. This method of photometry is so-called visual photometry, and is seldom used today.

In modern photometric practice, measurements are made with photodetectors. This is referred to as physical photometry. In order to achieve the aim of photometry, one must take into account the characteristics of human vision. The relative spectral responsivity of the human eye was first defined by CIE (Commission Internationale de l'Éclairage) in 1924 [6], and redefined as part of colorimetric standard observers in 1931 [7]. It is called the spectral luminous efficiency function for photopic vision, or the $V(\lambda)$ function, defined in the domain $360 \mathrm{~nm}$ to $830 \mathrm{~nm}$, and is normalized to one at its peak, $555 \mathrm{~nm}$ (Fig. 1). This model gained wide acceptance, republished by CIE in 1983 [8] and published by CIPM (Comité International des Poids et Mesures) in 1982 [9] to supplement the 1979 definition of candela. The tabulated values of the function at $1 \mathrm{~nm}$ increments are available in reference $[8,10]$. In most cases, the 
region $380 \mathrm{~nm}$ to $780 \mathrm{~nm}$ is used for calculation with negligible errors because the $V(\lambda)$ function falls below $10^{-4}$ outside this region. Thus, a photodetector having a spectral responsivity matched to the $V(\lambda)$ function replaced the role of human eyes in photometry.

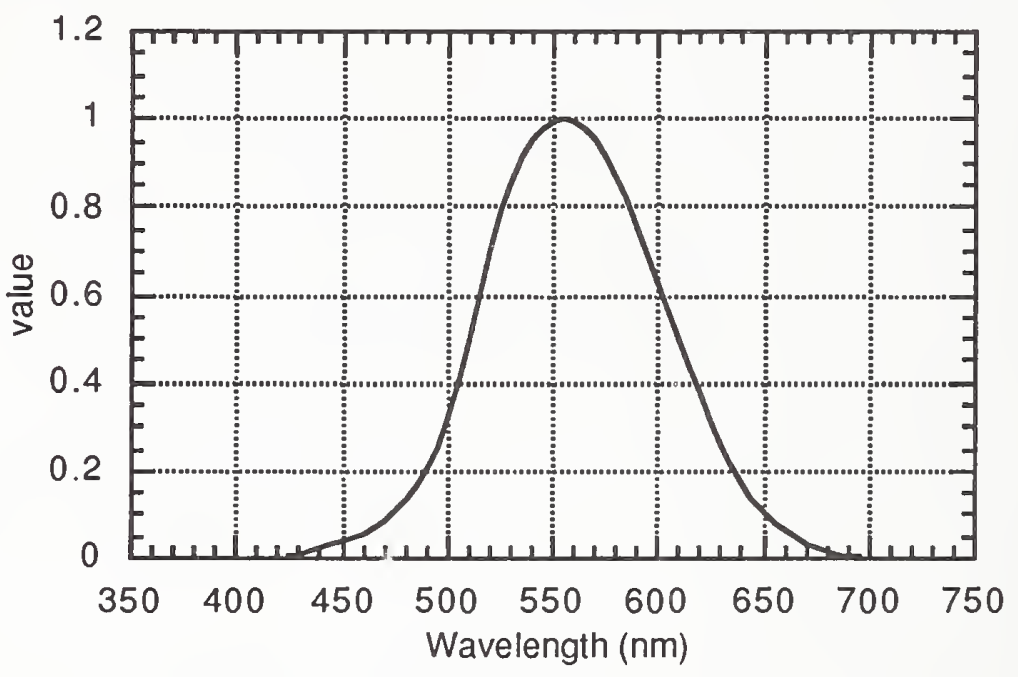

Figure 1 CIE $V(\lambda)$ Function.

Radiometry concerns physical measurement of optical radiation as a function of its wavelength. As specified in the definition of the candela by CGPM (Conférence Générale des Poids et Mesures) in 1979 [11] and CIPM in 1982 [9], a photometric quantity $X_{\mathrm{v}}$ is defined in relation to the corresponding radiometric quantity $X_{\mathrm{e}, \lambda}$ by the equation:

$$
X_{\mathrm{v}}=K_{\mathrm{m}} \int_{360 \mathrm{~nm}}^{830 \mathrm{~nm}} X_{\mathrm{e}, \lambda} V(\lambda) \mathrm{d} \lambda
$$

The constant, $K_{\mathrm{m}}$, relates the photometric quantities and radiometric quantities, and is called the maximum spectral luminous efficacy (of radiation) for photopic vision. The value of $K_{\mathrm{m}}$ is given by the 1979 definition of candela which defines the spectral luminous efficacy of light at the frequency $540 \times 10^{12} \mathrm{~Hz}$ (at the wavelength $555.016 \mathrm{~nm}$ in standard air) to be $683 \mathrm{~lm} / \mathrm{W}$. The value of $K_{\mathrm{m}}$ is calculated as $683 \times V(555.000 \mathrm{~nm}) V(555.016 \mathrm{~nm})=683.002 \mathrm{~lm} / \mathrm{W}[8] . K_{\mathrm{m}}$ is normally rounded to $683 \mathrm{~lm} / \mathrm{W}$ with negligible errors [9]. Various photometric and radiometric quantities are described in the next section.

It should be noted that the $V(\lambda)$ function is based on the CIE standard photometric observer for photopic vision, which assumes additivity of sensation and a $2^{\circ}$ field of view at relatively high luminance levels (higher than $\sim 1 \mathrm{~cd} / \mathrm{m}^{2}$ ). The human vision in this level is called photopic vision. The spectral responsivity of human vision deviates significantly at very low levels of luminance (less than $\sim 10^{-2} \mathrm{~cd} / \mathrm{m}^{2}$ ). This type of vision is called scotopic vision. Its 
spectral responsivity, peaking at $507 \mathrm{~nm}$, is designated by the $V^{\prime}(\lambda)$ function, which was defined by CIE in 1951 [12], recognized by CIPM (Comité International des Poids et Mesures) in 1976 [13], and republished by CIPM in 1982 [9]. The human vision in the region between photopic vision and scotopic vision is called mesopic vision. While active research is being conducted [14], there is no internationally accepted spectral luminous efficiency function for the mesopic region yet. In current practice, almost all photometric quantities are given in terms of photopic vision, even at low light levels, except for special measurements for research purposes. This document, therefore, does not deal with quantities specified in terms of scotopic or mesopic vision. Further details of definitions outlined in this section are given in Reference [8].

To better understand the international metrology system, it is useful to know the relationship between such organizations as CGPM, CIPM, CCPR (Comité Consultatif de Photométrie et Radiométrie), BIPM (Bureau International des Poids et Mesures), and CIE. These are all abbreviations of their French names as appeared before. In English, their names would be: CGPM, General Conference of Weights and Measures; CIPM, International Committee for Weights and Measures; CCPR, Consultative Committee of Photometry and Radiometry; BIPM, International Bureau of Weights and Measures; and CIE, International Commission on Illumination. All the SI units are officially defined by CGPM which is the decision-making body for the Treaty of the Meter (Convention du Mètre), signed in 1875. The decisions of CGPM legally govern the global metrology system among those countries signatory to the Treaty of the Meter or agreeing to its usage. CIPM is a committee under CGPM, charged with the management of the international system of units and related fundamental units, consisting of many subcommittees for each technical field. CCPR is a subcommittee under CIPM, that discusses and recommends the units in photometry and radiometry. It consists of representatives of interested national standardizing laboratories. CCPR also holds international intercomparisons of photometric units and radiometric scales. BIPM is a metrology laboratory under the supervision of CIPM, with staff and facilities in Paris. CIE, on the other hand, is originally an academic society in the field of lighting science and was organized to promote uniformity and quality in optical measurements. Many definitions developed by CIE, such as the $V(\lambda)$ function, the color matching functions, and the standard illuminants, have been adopted by CGPM and by ISO (International Organization for Standardization) as international standards. CIE has recently been recognized officially by ISO as a standards-creating body in the field of optical radiation. NIST staff play active roles in CCPR and CIE activities.

\subsection{Photometric quantities and units}

\subsubsection{Photometric quantities}

The base unit of all photometric quantities is the candela. The candela was first defined by CGPM in 1948 , based on the radiation from platinum at the temperature of its solidification. It 
became one of the base SI (Système International) units when SI was established in 1960. Most recently, the candela was redefined by CGPM in 1979 [9] as

"The candela is the luminous intensity, in a given direction, of a source that emits monochromatic radiation of frequency $540 \times 10^{12}$ hertz and that has a radiant intensity in that direction of $(1 / 683)$ watt per steradian."

Table 1 lists photometric quantities and their corresponding radiometric quantities side by side, with units and symbols. The precise definition of each quantity is given by CCPR [10] and CIE [15].

Table 1. Quantities and units used in photometry and radiometry

\begin{tabular}{lllll}
\hline Photometric quantity & Unit & $\begin{array}{c}\text { relationship } \\
\text { with lumen }\end{array}$ & Radiometric Quantity & Unit \\
\hline Luminous flux & $\mathrm{lm}$ (lumen) & & Radiant flux & $\mathrm{W}$ (watt) \\
Luminous intensity & $\mathrm{cd}$ (candela) & $1 \mathrm{~m} \mathrm{sr}^{-1}$ & Radiant intensity & $\mathrm{W} \mathrm{sr}$ \\
Illuminance & $1 \mathrm{x}$ (lux) & $1 \mathrm{~m} \mathrm{~m}^{-2}$ & Irradiance & $\mathrm{W} \mathrm{m}^{-2}$ \\
Luminance & $\mathrm{cd} \mathrm{m} \mathrm{m}^{-2}$ & $1 \mathrm{~m} \mathrm{sr}^{-1} \mathrm{~m}^{-2}$ & Radiance & $\mathrm{W} \mathrm{sr}^{-1} \mathrm{~m}^{-2}$ \\
Luminous exitance & $1 \mathrm{~m} \mathrm{~m}^{-2}$ & & Radiant exitance & $\mathrm{W} \mathrm{m}^{-2}$ \\
Luminous exposure & $1 \mathrm{x} \mathrm{s}$ & & Radiant exposure & $\mathrm{W} \mathrm{m}^{-2} \mathrm{~s}$ \\
Luminous energy & $\mathrm{lm} \mathrm{s}$ & & Radiant energy & $\mathrm{J} \mathrm{(joule)}$ \\
Color temperature & $\mathrm{K}$ (kelvin) & & Radiance temperature & $\mathrm{K}$ \\
\hline
\end{tabular}

Although the candela is defined as an SI base unit, luminous flux (lumen) is perhaps the most fundamental photometric quantity, as the four other photometric quantities are defined in terms of lumen with appropriate geometric factors.

Luminous flux $\left(\Phi_{\mathrm{v}}\right)$ is the time rate of flow of light as weighted by $V(\lambda)$. It is defined as

$$
\Phi_{\mathrm{v}}=K_{\mathrm{m}} \int_{\lambda} \Phi_{\mathrm{e}, \lambda} V(\lambda) \mathrm{d} \lambda
$$

where $\Phi_{\mathrm{e}, \lambda}$ is the spectral concentration of radiant flux in (W/nm) as a function of wavelength $\lambda$ in nm.

Luminous intensity $\left(I_{\mathrm{v}}\right)$ is the luminous flux (from a point source) emitted per unit solid angle in a given direction. It is defined as

$$
I_{\mathrm{v}}=\frac{\mathrm{d} \Phi_{\mathrm{v}}}{\mathrm{d} \Omega}
$$

where $\mathrm{d} \Phi_{\mathrm{v}}$ is the luminous flux leaving the source and propagating in an element of solid angle $\mathrm{d} \Omega$ containing the given direction. 
Illuminance $\left(E_{\mathrm{v}}\right)$ is the density of the luminous flux incident on a given point of a surface or a plane. It is defined as

$$
E_{\mathrm{v}}=\frac{\mathrm{d} \Phi_{\mathrm{v}}}{\mathrm{d} A}
$$

where $\mathrm{d} \Phi_{\mathrm{v}}$ is the luminous flux incident on an element $\mathrm{d} A$ of the surface containing the point.

Luminance $\left(L_{\mathrm{v}}\right)$ is the luminous flux from an element of a surface surrounding a given point, emitted into a small solid angle containing the given direction, per unit area of the element projected on a plane perpendicular to that given direction. It is defined as

$$
L_{\mathrm{v}}=\frac{\mathrm{d}^{2} \Phi_{\mathrm{v}}}{\mathrm{d} \Omega \mathrm{d} A \cos \theta}
$$

where $\mathrm{d} \Phi_{\mathrm{v}}$ is the luminous flux emitted (reflected or transmitted) by an elementary beam passing through the given point and propagating in the solid angle $\mathrm{d} \Omega$ containing the given direction; $\mathrm{d} A$ is the area of a section of that beam containing the given point; $\theta$ is the angle between the normal to that section and the direction of the beam.

Luminous exitance $\left(M_{\mathrm{v}}\right)$ is the density of luminous flux leaving a surface at a point. The equation is the same as equation (4), with $\mathrm{d} \Phi_{\mathrm{v}}$ meaning the luminous flux leaving a surface. This quantity is rarely used in the general practice of photometry.

Luminous exposure $\left(H_{\mathrm{v}}\right)$ is the time integral of illuminance $E_{\mathrm{v}}(t)$ over a given duration $\Delta$, as defined by

$$
H_{\mathrm{v}}=\int_{\Delta t} E_{\mathrm{v}}(t) \mathrm{d} t
$$

Luminous energy $\left(Q_{\mathrm{v}}\right)$ is the time integral of the luminous flux $\left(\Phi_{\mathrm{v}}\right)$ over a given duration $\Delta t$, as defined by

$$
Q_{\mathrm{v}}=\int_{\Delta t} \Phi_{\mathrm{v}}(t) \mathrm{d} t
$$

Color temperature $\left(T_{\mathrm{c}}\right)$ is the temperature of a Planckian radiator with radiation of the same chromaticity as that of the light source in question. However, the chromaticity coordinates of most lamps do not fall on the Planckian locus, and in actual lamp calibrations, either distribution temperature or correlated color temperature is used. "Color temperature" is often used informally for the correlated color temperature.

Distribution temperature $\left(T_{\mathrm{d}}\right)$ is the temperature of a blackbody with a spectral power distribution closest to that of the light source in question, and it is a useful concept for quasiPlanckian sources.

Correlated color temperature $\left(T_{\mathrm{cp}}\right)$ is a concept used for sources with a spectral power distribution significantly different from that of Planckian radiation, for example, discharge lamps. 
Correlated color temperature is the temperature of the Planckian radiator whose perceived color most closely resembles that of the light source in question. The distribution temperature and correlated color temperature are explained further in Section 7.

General information (definitions, symbols, and expressions) on many other physical quantities and units including photometric and radiometric quantities are given in Reference [16].

\subsubsection{Relationship between SI units and English units}

Under NIST policy [17], results of all NIST measurements are reported in SI units. However, the English units shown in Table 2 are still rather widely used. For all the photometric measurements and calculations, use of the SI units shown in Table $\mathbf{1}$ is recommended, and use of non-SI units is discouraged [18]. The definitions of the English units are described below for conversion purposes only.

Table 2. English units and definition

\begin{tabular}{lll}
\hline Unit & Quantity & Definition \\
\hline foot-candle (fc) & illuminance & lumen per square foot $\left(\mathrm{lm} \mathrm{ft}^{-2}\right)$ \\
foot-Lambert (fL) & luminance & $1 / \pi$ candela per square foot $\left(\pi^{-1} \mathrm{~cd} \mathrm{ft}^{-2}\right)$ \\
\hline
\end{tabular}

It should be noted that the definition of foot-Lambert is such that the luminance of a perfect diffuser is $1 \mathrm{fL}$ when illuminated at $1 \mathrm{fc}$. In SI units, the luminance of a perfect diffuser would be $1 / \pi\left(\mathrm{cd} / \mathrm{m}^{2}\right)$ when illuminated at $11 \mathrm{x}$. For convenience of changing from English units to SI units, the conversion factors are listed in Table 3. For example, $1000 \mathrm{~lx}$ is the same illuminance as $92.9 \mathrm{fc}$, and $1000 \mathrm{~cd} / \mathrm{m}^{2}$ is the same luminance as $291.9 \mathrm{fL}$. Conversion factors to and from some other units are given in Reference [19].

Table 3. Conversion between English units and SI units

\begin{tabular}{lcc}
\hline To obtain the value in & multiply the value in & by \\
\hline $\mathrm{lx}$ from $\mathrm{fc}$ & $\mathrm{fc}$ & 10.764 \\
$\mathrm{fc}$ from $\mathrm{lx}$ & $\mathrm{lx}$ & 0.09290 \\
$\mathrm{~cd} / \mathrm{m}^{2}$ from $\mathrm{fL}$ & $\mathrm{fL}$ & 3.4263 \\
$\mathrm{fL}$ from cd $\mathrm{m}^{2}$ & $\mathrm{~cd} / \mathrm{m}^{2}$ & 0.29186 \\
$\mathrm{~m}$ (meter) from feet & feet & 0.30480 \\
$\mathrm{~mm}$ (millimeter) from inch & inch & 25.400 \\
\hline
\end{tabular}




\subsection{NIST photometric units}

\subsubsection{NIST Luminous intensity unit}

Until 1991, the NIST luminous intensity unit was derived from the NIST spectral irradiance scale [20], which was based on a gold-point blackbody, and therefore, dependent on the temperature scale. In 1990, the international temperature scale was revised [21], and the gold point temperature changed from $1337.58 \mathrm{~K}$ to $1337.33 \mathrm{~K}$. Due to this change, the magnitude of NIST luminous intensity unit increased by $0.35 \%$.

In 1992 at NIST, a new luminous intensity unit (candela) was realized based on the absolute responsivity of detectors (using a $100 \%$ Q.E. silicon detectors [2] and subsequently a cryogenic electrical substitution radiometer [3]). The old luminous intensity unit was replaced with the new unit in 1992.

The new candela is realized and maintained on a group of eight photometers (referred to as the NIST standard photometers) which are calibrated for illuminance responsivity in A/x. These standard photometers also embody the NIST illuminance unit, and allow luminous intensity to be determined from measured illuminance and distance.

The realization and maintenance of the photometric units at NIST are shown in Figure 2. The NIST cryogenic radiometer [22] acts as the absolute radiometric base at the top of the chain. The radiometer (called HACR; High Accuracy Cryogenic Radiometer) is cooled by liquid helium to $5 \mathrm{~K}$, and works on the principle of electrical substitution. The construction of the HACR is shown in Figure 3. Based on laser-beam power measurements with the HACR at several wavelengths, the NIST detector spectral responsivity scale is maintained on silicon photodiode light-trapping detectors [23]. The measurement uncertainty in the calibration of a light-trapping detector against the HACR is $0.06 \%$ (relative expanded uncertainty, $k=22^{\dagger}$ ) in the visible region [23]. The spectral responsivity scale is transferred to other detectors using the Spectral Comparator Facility (SCF) [25], where the absolute spectral responsivity $s(\lambda)(\mathrm{A} / \mathrm{W})$ of each of the NIST standard photometers is determined. The illuminance responsivity [A/lx] of each photometer is then calculated from $s(\lambda)$, the area of the aperture, and other correction factors. The relative expanded uncertainty of the illuminance responsivity determination is $0.39 \%$ [2]. The standard photometers are recalibrated annually utilizing the detector spectral responsivity scale. The details of the candela realization are described in Section 3.1 and in Reference [2].

$\uparrow$ Throughout this paper, all uncertainty values are given as an expanded uncertainty with coverage factor $k=2$, thus a two standard deviation estimate. Uncertainties of fundamental units given as a combined standard uncertainty in other documents are restated as an expanded uncertainty $(k=2)$. 


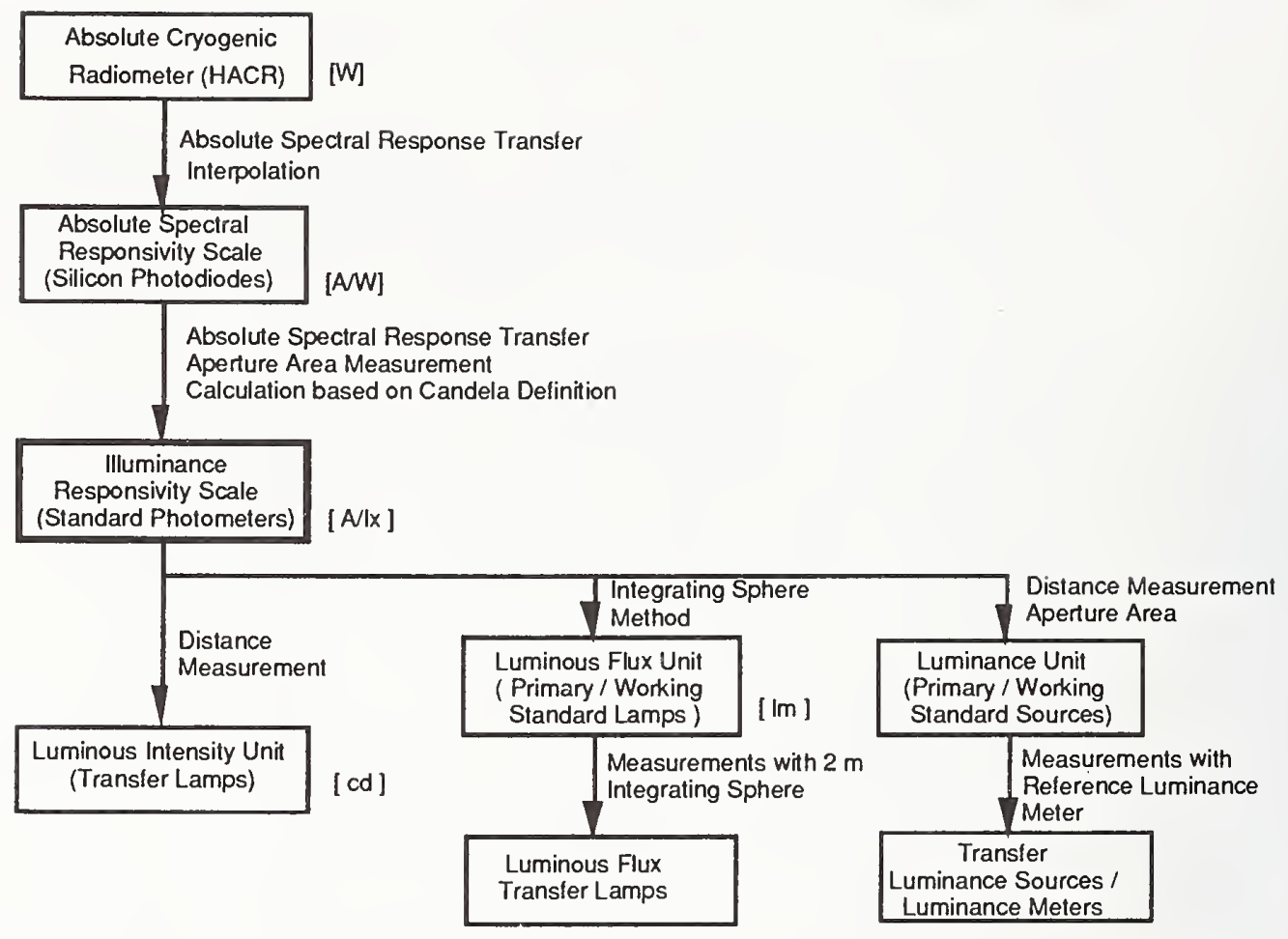

Figure 2 Realization and maintenance of the NIST photometric units.

As the result of the candela realization in 1992, the magnitude of the NIST luminous intensity unit changed (increased) by approximately $0.3 \%$. With the effect of the change of the international temperature scale in 1990 included, the magnitude of the NIST candela is larger (measured values are smaller) by approximately $0.6 \%$ than that reported before 1990 . At the latest CCPR international intercomparison [26] in 1985, the NIST candela was $0.6 \%$ smaller than the world mean. The changes of the NIST candela occurred in the direction to reduce its difference from the world mean At the time of the 1985 intercomparison, the candela and the lumen standards disseminated in different countries varied by $\pm 1 \%$. The most recent status of the differences in the magnitude of photometric units for different countries in the world was last published by BIPM in 1988 [27], the copy of which is attached in the Appendix A. The next international intercomparison of photometric units by CCPR is planned to be completed by 1998. In the mean time, NIST occasionally conducts bilateral intercomparisons of photometric units with other national laboratories [28]. 


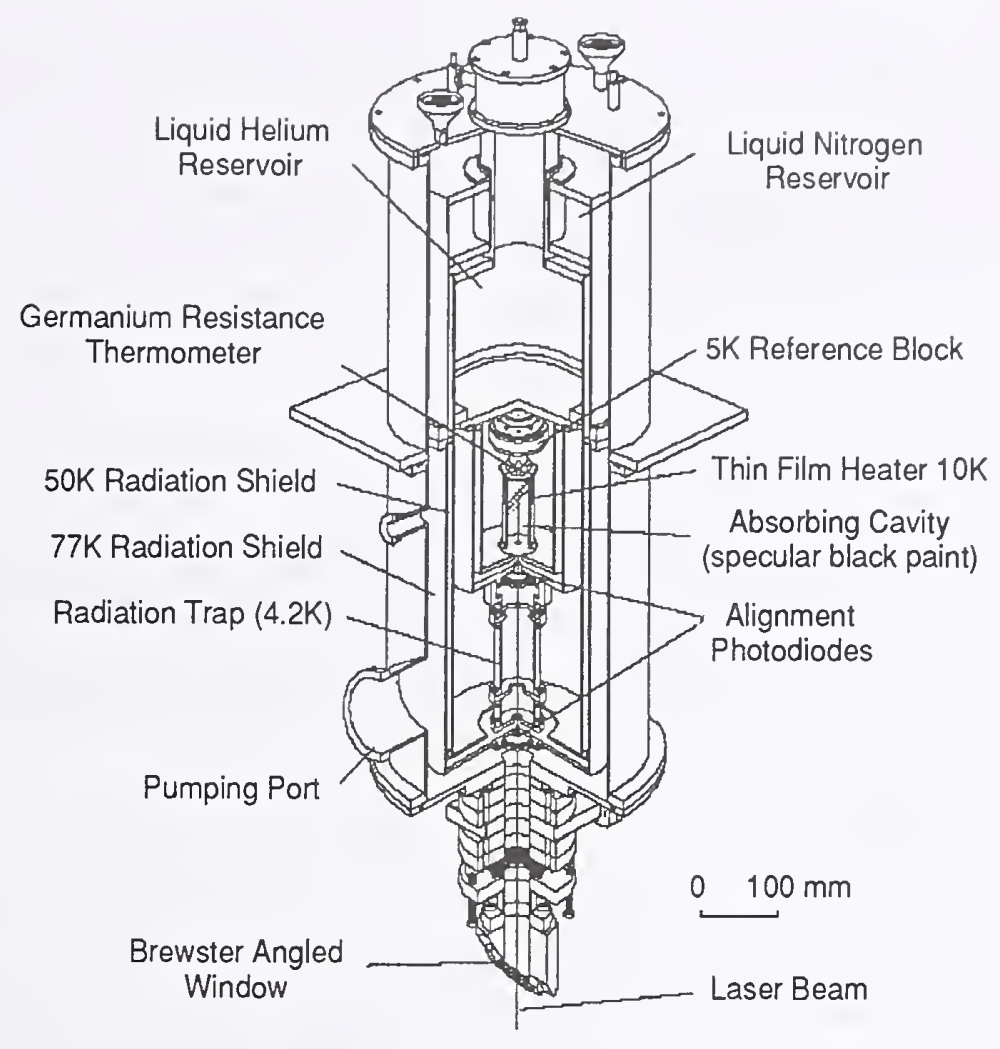

Figure 3 Construction of the High Accuracy Cryogenic Radiometer.

\subsubsection{NIST luminous flux unit}

Until 1994, the NIST luminous flux unit was derived from the previous luminous intensity unit which was based, in turn, on blackbody radiation. The previous luminous flux unit was last realized in 1985 by goniophotometric measurements [1], and was maintained on a group of six incandescent standard lamps. The unit was periodically transferred to groups of working standard lamps used for routine calibrations.

In 1995, a new NIST luminous flux unit was derived, based on the detector-based candela introduced in 1992, with a new method using an integrating sphere and an external source. The basic principle of the absolute integrating sphere method is to measure the total flux of a lamp inside the sphere compared to a known amount of fluxintroduced into the sphere from a source outside the sphere.

This method was first studied theoretically using a computer simulation technique [29], then experimentally verified [30] using a $0.5 \mathrm{~m}$ integrating sphere. Utilizing this method with a $2 \mathrm{~m}$ integrating sphere, the new NIST luminous flux unit was established in 1995 [31, 32]. Primary standard lamps and working standard lamps are calibrated periodically against the NIST illuminance unit in order to maintain the luminous flux unit and to provide routine calibrations. The details of the luminous flux unit realization are described in Section 5.1. 
The realization of the 1995 luminous flux unit has resulted in a change (increase) of the magnitude of NIST luminous flux unit by approximately $1.1 \%$. The measured lumen values reported by NIST are smaller by that percentage than those previously reported. At the time of the 1985 CCPR international intercomparison [26], the NIST lumen value was $1.0 \%$ smaller than the world mean. The new luminous flux unit has been disseminated in NIST calibrations since January 1, 1996.

\section{Outline of the calibration services}

This section provides a list of the photometric calibration services currently available at NIST. The complete description of these services is reported in the NIST Calibration Services Users Guide (SP250) [5]. Chapter 7 (Optical Radiation Measurements) of the SP250 is attached as Appendix B. The details of the artifacts and measurement procedures for calibration are described in Sections 3 through 7.

Table 4 lists the NIST photometric calibration services with typical measurement ranges and typical uncertainties. All the items listed here, including the Special Tests, are provided routinely. Fixed services (Test Numbers ending in the letter $\mathrm{C}$ ) are those in which NIST issues a calibrated artifact to customers. Special Tests (Test Number ending with the letter S), on the other hand, are those in which NIST calibrates artifacts submitted by customers.

The fees for the fixed services are listed in the Fee Schedule(SP250 Appendix). The fees for Special Tests depend on the type of artifacts, number of artifacts, measurement range requested, etc. A cost estimate will be given for each request for a Special Test.

Calibrations on special test items or under special conditions, other than listed below, may be available after consultation as Special Photometric Tests 37100S. 
Table 4. NIST Photometric Calibration Services

\begin{tabular}{|c|c|c|c|}
\hline Test no. & Item of test & $\begin{array}{l}\text { Rela } \\
\text { unce }\end{array}$ & $\begin{array}{l}\text { ve expanded } \\
\text { ainty }(k=2)\end{array}$ \\
\hline $37010 \mathrm{C}$ & $\begin{array}{l}\text { Luminous Intensity and Color Temperature } \\
\text { Standard Lamps }(\sim 1000 \mathrm{~cd}, 2856 \mathrm{~K})\end{array}$ & & $\begin{array}{l}0.5 \% \\
8 \mathrm{~K}\end{array}$ \\
\hline $37020 \mathrm{~S}$ & $\begin{array}{l}\text { Special Tests for Luminous Intensity and } \\
\text { Color Temperature of Submitted Lamps }\end{array}$ & $\begin{array}{l}10^{-1} \mathrm{~cd}-10^{4} \mathrm{~cd} \\
2856 \mathrm{~K}\end{array}$ & $\begin{array}{l}0.6 \% \\
8 \mathrm{~K}\end{array}$ \\
\hline $37030 \mathrm{C}$ & Color Temperature Standard Lamps & $2856 \mathrm{~K}$ & $8 \mathrm{~K}$ \\
\hline $37040 \mathrm{C}$ & $\begin{array}{l}\text { Each Additional Color Temperature } \\
\text { for } 37030 \mathrm{C}\end{array}$ & $2000 \mathrm{~K}-3200 \mathrm{~K}$ & $4 \mathrm{~K}-10 \mathrm{~K}$ \\
\hline $37050 \mathrm{~S}$ & $\begin{array}{l}\text { Special Tests for Color Temperature of } \\
\text { Submitted Lamps }\end{array}$ & $2000 \mathrm{~K}-3200 \mathrm{~K}$ & $4 \mathrm{~K}-10 \mathrm{~K}$ \\
\hline $37060 \mathrm{~S}$ & $\begin{array}{l}\text { Special Tests for Total Luminous Flux of } \\
\text { Submitted Lamps (Incandescent lamps } \\
\text { and fluorescent lamps) }\end{array}$ & $10^{-1} \operatorname{lm}-10^{5} \operatorname{lm}$ & $0.8 \%-2.0 \%$ \\
\hline $37070 \mathrm{C}$ & Opal Glass Luminance Coefficient Standards & $\sim 0.15 \mathrm{sr}^{-1}$ & $0.5 \%$ \\
\hline $37080 \mathrm{~S}$ & $\begin{array}{l}\text { Special Tests for Submitted Luminance } \\
\text { Sources and Transmitting Diffusers }\end{array}$ & $(1-4000) \mathrm{cd} / \mathrm{m}^{2}$ & $0.7 \%$ \\
\hline $37090 \mathrm{~S}$ & $\begin{array}{l}\text { Special Tests for Photometer heads, } \\
\text { Illuminance meters, and Luminance meters }\end{array}$ & $(0.1-3000) \mathrm{lx}$ & $0.5 \%-1 \%$ \\
\hline $37100 \mathrm{~S}$ & Special Photometric Tests & & \\
\hline
\end{tabular}




\section{Luminous intensity (candela) calibrations}

\subsection{NIST illuminance unit and the NIST candela}

\subsubsection{Principles of the detector-based candela realization}

As stated in Section 1.3, the NIST candela is realized and maintained on a group of eight NIST standard photometers. The illuminance responsivity (A/lx) of these photometers are calibrated annually utilizing the NIST spectral responsivity scale. The principles of the calibration of the photometers are described below.

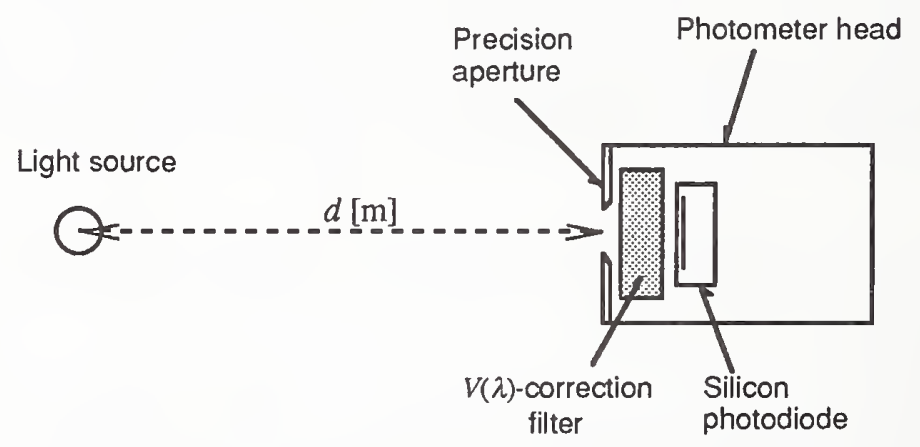

Figure 4 Geometry for the detector-based candela realization.

A standard photometer consists basically of a silicon photodiode, a $V(\lambda)$-correction filter, and a precision aperture, as shown in Figure 4. When the absolute spectral responsivity $s(\lambda)$ $(\mathrm{A} / \mathrm{W})$ of the photometer is measured, the photometric responsivity $R_{\mathrm{v}, \mathrm{f}}(\mathrm{A} / \mathrm{lm})$ of the photometer within the aperture is given by

$$
R_{\mathrm{v}, \mathrm{f}}=\frac{\int_{\lambda} P(\lambda) s(\lambda) \mathrm{d} \lambda}{K_{\mathrm{m}} \int_{\lambda} P(\lambda) V(\lambda) \mathrm{d} \lambda}
$$

where $P(\lambda)$ is the spectral power distribution of light to be measured, $V(\lambda)$ is the spectral luminous efficiency function, and $K_{\mathrm{m}}$ is the maximum spectral efficacy $(683 \mathrm{~lm} / \mathrm{W})$. Usually a Planckian radiator at $2856 \mathrm{~K}$ (CIE Illuminant $\mathrm{A}$ ) is used to provide the light flux $P(\lambda)$. If the area $A\left(\mathrm{~m}^{2}\right)$ of the aperture is known and the responsivity $R_{\mathrm{v}, \mathrm{f}}$ is uniform over the aperture, the responsivity $R_{\mathrm{v}, \mathrm{i}}(\mathrm{A} / \mathrm{lx})$ of the photometer for illuminance (lx) is given by

$$
R_{\mathrm{v}, \mathrm{i}}=A \cdot R_{\mathrm{v}, \mathrm{f}}
$$

When a photometer calibrated for $R_{\mathrm{v}, \mathrm{i}}$ is used to measure the illuminance from a point source, the luminous intensity $I_{\mathrm{v}}(\mathrm{cd})$ of the source is given by 


$$
I_{\mathrm{v}}=d^{2} \cdot y / R_{\mathrm{v}, \mathrm{i}},
$$

where $d$ is the distance $(\mathrm{m})$ from the light source to the aperture surface of the photometer and $y$ is the output current (A) of the photometer. In practice, $d$ must be larger than the minimum distance where the deviation from the inverse square law of the light source is negligibly small.

\subsubsection{Design of the NIST standard photometers}

Figure 5 shows the design of the NIST standard photometers. A silicon photodiode, a $V(\lambda)$-correction filter, and a precision aperture are mounted in a cylindrical housing. The photodiode is plugged into a socket with a teflon base of low electrical conductivity. The $V(\lambda)$-correction filter is made of several layers of glass filters, and affixed to the photodiode. On the front side of the filter, the precision aperture is glued to a holder which is carefully machined so that its front surface (the reference surface of the photometer) is $3.0 \mathrm{~mm}$ from the plane of the aperture knife edge.

An electronic assembly containing a current-to-voltage converter circuit having a high sensitivity and a wide dynamic range [33] is mounted directly behind the photodiode to minimize noise. The circuit has a switchable gain setting from $10^{4} \mathrm{~V} / \mathrm{A}$ to $10^{10} \mathrm{~V} / \mathrm{A}\left(10^{11} \mathrm{~V} / \mathrm{A}\right.$ for two of the photometers). An input equivalent noise of $\sim 1 \mathrm{fA}$ is achieved at the gain setting of $10^{11} \mathrm{~V} / \mathrm{A}$ with an integration time of $1.67 \mathrm{~s}$, and a bandwidth of $0.3 \mathrm{~Hz}$. This high sensitivity feature allows precise measurement of $s(\lambda)$ even in the wings of the $V(\lambda)$ curve.

Since the characteristics of the filter and photodiode can change with temperature, a temperature sensor is installed in the front piece of the housing to monitor the photometer temperature [34].

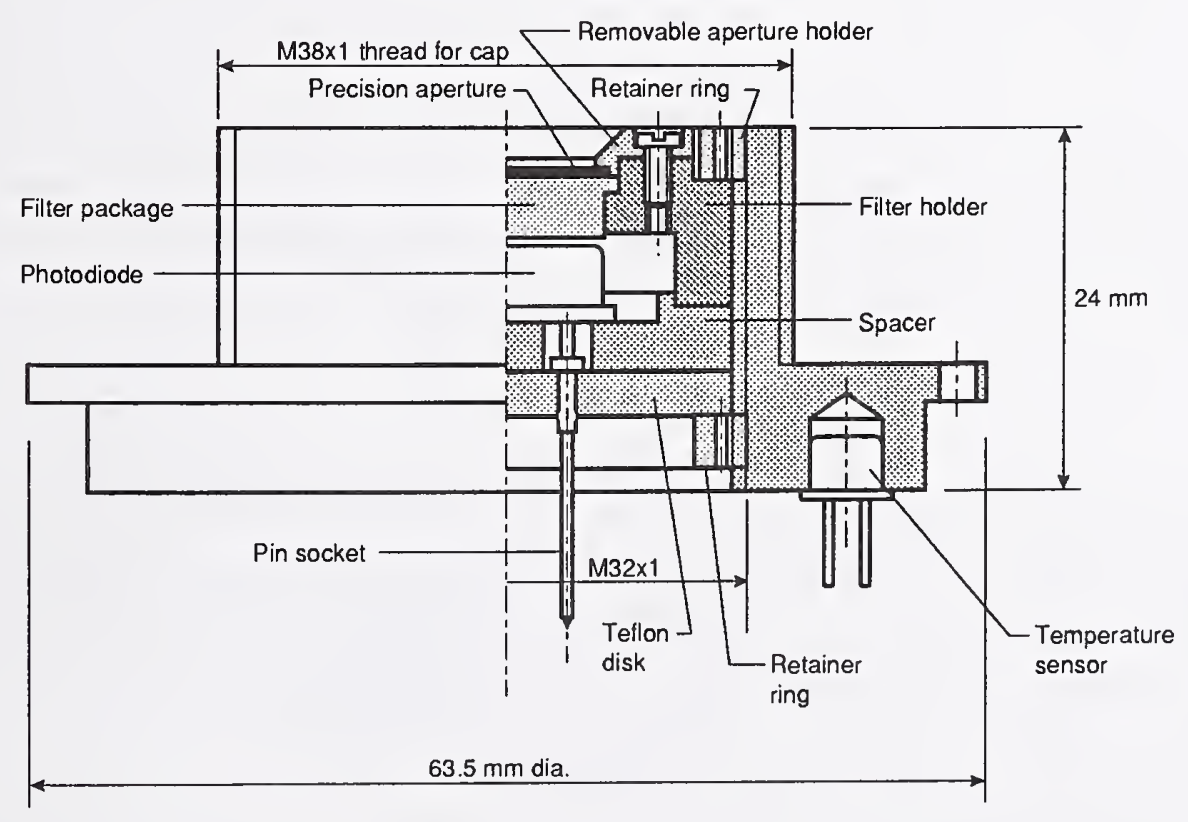

Figu re 5 Design of the NIST standard photometer. 


\subsubsection{Calibration of the NIST standard photometers}

The spectral responsivity $s(\lambda)$ of the photometers is measured with the NIST Spectral Comparator Facility (SCF) [25]. The photometer aperture is underfilled with a beam of $1 \mathrm{~mm}$ diameter from the monochromator, and the responsivity of the photometer is mapped over the entire area of the precision aperture at several wavelengths. From the mapping data, the ratio of the average responsivity over the aperture to the responsivity at the center of the aperture is calculated and applied in the responsivity calculation. The $\mathrm{f}_{1}{ }^{\prime}$ values of the eight photometers range from $1.4 \%$ to $6 \%$. The $\mathrm{f}_{1}{ }^{\prime}$ is a term recommended by CIE [35] to indicate the degree of spectral mismatch of a photometer to the $V(\lambda)$ function. The illuminance responsivity of NIST photometers $R_{\mathrm{v}, \mathrm{i}}$ [A/lx] are calculated for Planckian radiation at $2856 \mathrm{~K}$ (CIE Illuminant A) according to eqs (8) and (9).

\subsubsection{Spectral mismatch correction}

When the photometers measure light sources whose spectral distribution is different from the $2856 \mathrm{~K}$ Planckian source, an error occurs due to the spectral mismatch of the photometers. This error is corrected by a spectral mismatch correction factor, $c c f^{*}$, as given by

$$
c c f^{*}\left(S_{\mathrm{t}}(\lambda)\right)=\frac{\int_{\lambda} S_{\mathrm{A}}(\lambda) S_{\text {rel }}(\lambda) \mathrm{d} \lambda \int_{\lambda} S_{\mathrm{t}}(\lambda) V(\lambda) \mathrm{d} \lambda}{\int_{\lambda} S_{\mathrm{A}}(\lambda) V(\lambda) \mathrm{d} \lambda \int_{\lambda} S_{\mathrm{t}}(\lambda) S_{\text {rel }}(\lambda) \mathrm{d} \lambda},
$$

where $S_{\mathrm{t}}(\lambda)$ is the spectral power distribution of the test lamp, $S_{\mathrm{A}}(\lambda)$ is the spectral data of the $\mathrm{CIE}$ illuminant $\mathrm{A}$, and $s_{\mathrm{rel}}(\lambda)$ is the relative spectral responsivity of the photometer. Using this equation, the correction factor can be obtained for any light source with known spectral power distribution.

For convenience in measuring incandescent lamps, $c c f^{*}$ is expressed as a function of the distribution temperature $T_{\mathrm{d}}$ of the lamp to be measured. The $c c f^{*}\left(S_{\mathrm{t}}(\lambda)\right)$ is calculated for Planckian radiation of four temperatures, and then the correction factors are fitted into a polynomial function. The $c c f^{*}\left(T_{\mathrm{d}}\right)$ is then given by,

$$
c c f^{*}\left(T_{\mathrm{d}}\right)=\sum_{j=0}^{3} a_{j} T_{\mathrm{d}}^{j} .
$$

The polynomial constants are obtained for each of the NIST standard photometers. An example is shown in Figure 6. The spectral mismatch correction factors for incandescent lamps of known distribution temperature are automatically calculated using this polynomial. The output signal of the photometer is multiplied by this correction factor. 


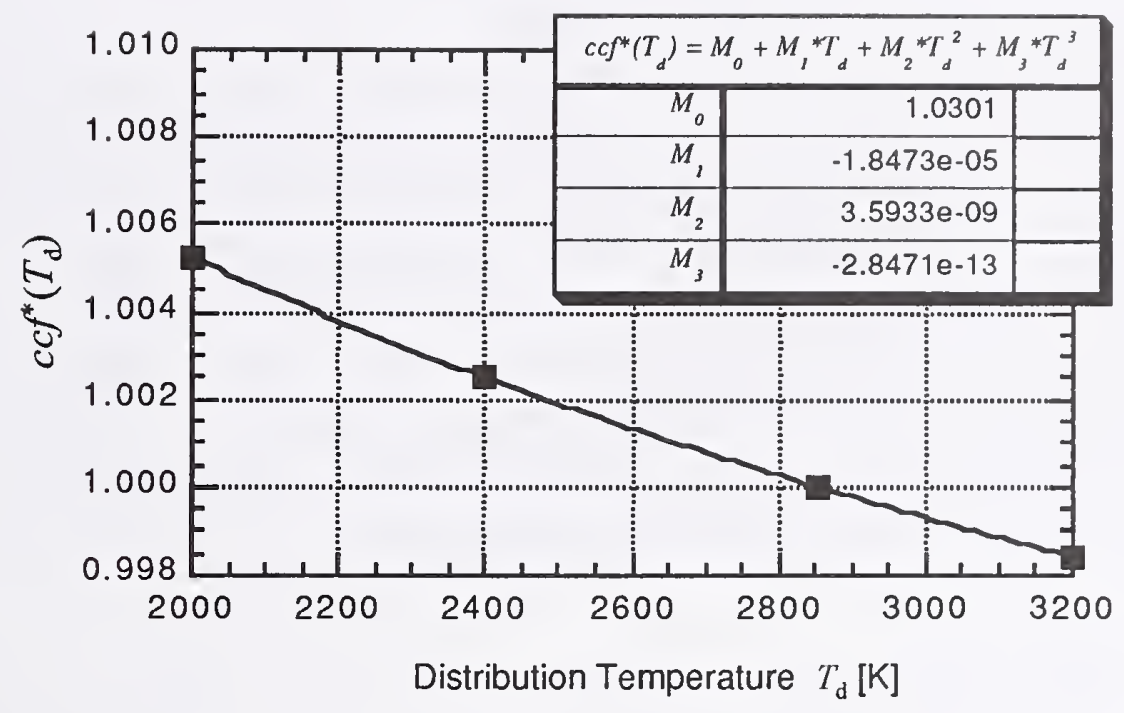

Figure 6 Polynomial fit for the spectral mismatch correction factors.

\subsubsection{Correction for the photometer temperature}

The temperature coefficients of the illuminance responsivity of the photometers, measured in a temperature-controlled chamber, are shown in Figure 7. The figure shows the data for three different photometers in the group. The temperature coefficients, $c_{\mathrm{p}}$, for the eight photometers range from $-0.049 \% /{ }^{\circ} \mathrm{C}$ to $-0.088 \% /{ }^{\circ} \mathrm{C}$. Whenever the photometers are used, the temperature correction factor, $k\left(T_{\mathrm{p}}\right)$, as given below, is calculated, and the output signal is multiplied by this correction factor.

$$
k\left(T_{\mathrm{p}}\right)=1-\left(T_{\mathrm{p}}-T_{0}\right) c_{\mathrm{p}}
$$

where $T_{0}$ is the temperature at which each photometer was calibrated.

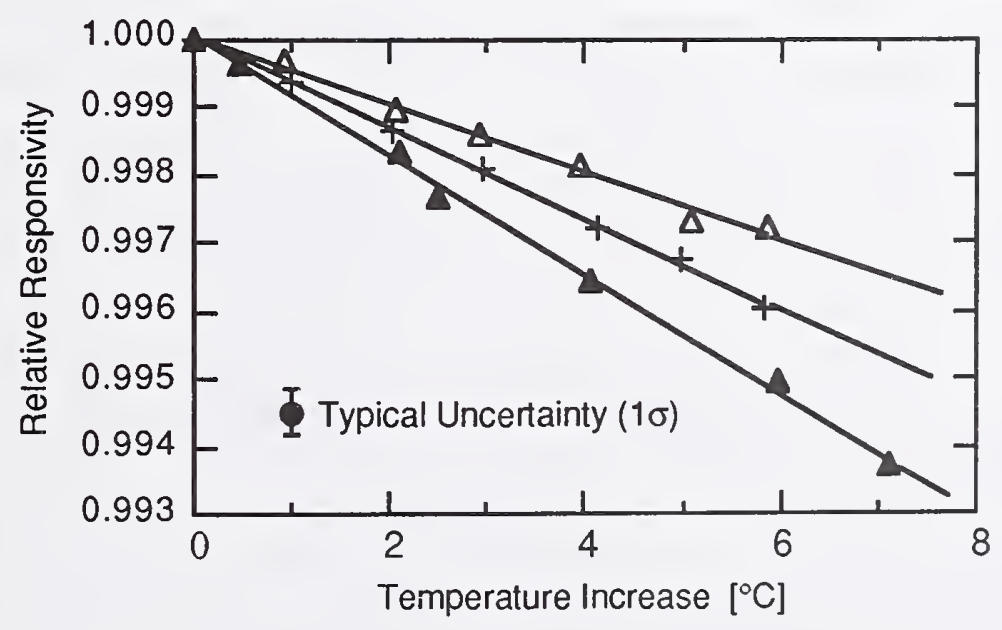

Figure 7 The temperature dependence of the photometers' illuminance responsivity. 


\subsubsection{Limearity of the NIST standard photometers}

The linearity of the photometers was measured using a beam conjoiner instrument [36], which is a ratio-and-additive beam device designed to test the linearity of photodetectors. Figure 8 shows the result from one of the NIST standard photometers for a $2856 \mathrm{~K}$ source. These data indicate that the photometer is linear over an output current range of $10^{-10} \mathrm{~A}$ to $10^{-4}$ A. This corresponds to an illuminance range of $10^{-2} \mathrm{~lx}$ to $10^{4} \mathrm{~lx}$, and means the photometers can be used to measure a luminous intensity as low as $10 \mathrm{mcd}$ at $1 \mathrm{~m}$, and as high as $10^{5} \mathrm{~cd}$ at $3 \mathrm{~m}$, without significantly increasing the uncertainty. If the integration time for the signal is longer, the photometer can be used for even lower levels [33]. The linearity data also assures negligible non-linearity error in the spectral responsivity measurements.

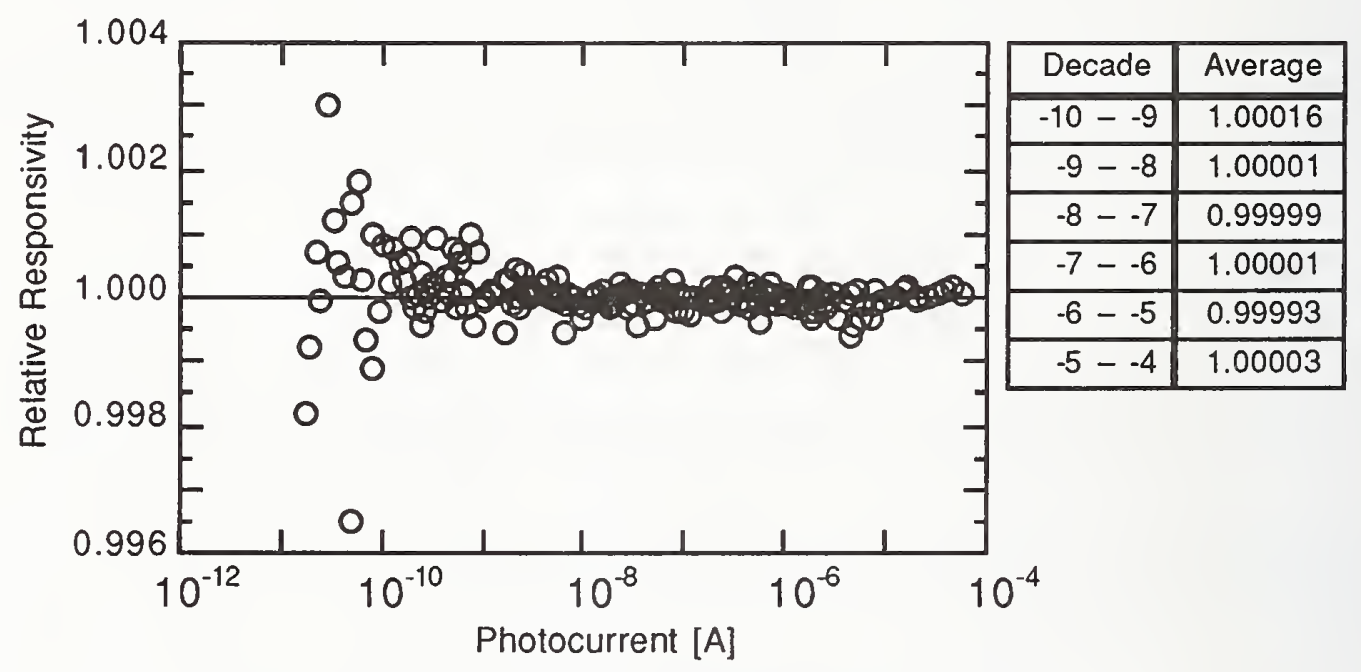

Figure 8 Linearity of one of the NIST standard photometers.

\subsubsection{Uncertainty of the NIST illuminance unit and the candela realization}

The uncertainty budgets for the NIST illuminance unit realization and the NIST candela realization are shown in Table 5 and Table 6, respectively. Long-term drift of the standard photometers are not included in these tables, but are taken into account in the uncertainty budgets for the calibrations. Type A uncertainty is of random nature and evaluated by statistical methods, and type B uncertainty is of systematic nature and evaluated by other means [4]. The overall uncertainty is calculated as the quadrature sum of all factors. Further details of the characterization, calibration, and uncertainty analysis for the NIST standard photometers are described in Reference [2]. 
Table 5. Uncertainty budget for the NIST illuminance unit realization

\begin{tabular}{lcc}
\hline \multicolumn{1}{c}{ Uncertainty factor } & $\begin{array}{c}\text { Relative expanded } \\
\text { uncertainty } \\
\text { Type A }\end{array}$ & $\begin{array}{c}\text { Type B } \\
\text { Ty }\end{array}$ \\
\hline $\begin{array}{l}\text { NIST absolute responsivity scale (visible region) } \\
\text { Comparison of photometer to the scale }\end{array}$ & 0.0822 \\
Wavelength calibration of monochromator & \multicolumn{2}{c}{0.08} \\
Numerical aperture of SCF output beam & 0.10 \\
Area of the photometer aperture & 0.10 \\
Temperature variation & 0.06 \\
Other factors & 0.24 \\
Overall uncertainty of the NIST illuminance unit realization & $\mathbf{0 . 3 8}$ \\
\hline
\end{tabular}

Table 6. Uncertainty budget for the NIST candela realization

\begin{tabular}{|c|c|c|}
\hline \multirow[t]{2}{*}{ Uncertainty factor } & \multicolumn{2}{|c|}{$\begin{array}{c}\text { Relative expanded } \\
\text { uncertainty }(k=2)[\%\end{array}$} \\
\hline & Type A & Type B \\
\hline The NIST illuminance unit (Table 5) & & 0.38 \\
\hline Distance measurement (uncertainty of the linear encc & er at $3 \mathrm{~m}$ ) & 0.02 \\
\hline Alignment of the lamp distance $(0.5 \mathrm{~mm}$ in $3 \mathrm{~m})$ & 0.03 & \\
\hline Determination of $c c f^{*}$ & & 0.04 \\
\hline Photometer temperature variation & 0.03 & \\
\hline Lamp current regulation & 0.02 & \\
\hline Stray light & & 0.05 \\
\hline Random noise & 0.10 & \\
\hline Overall uncertainty of the NIST candela realization & \multicolumn{2}{|c|}{0.40} \\
\hline
\end{tabular}

\subsubsection{Long-term stability of the NIST standard photometers}

The NIST standard photometers are usually calibrated on annual basis at the NIST Spectral Comparator Facility [25] utilizing the spectral responsivity scale. The drift of the illuminance responsivity of the NIST standard photometers over a 4 year period is shown in Figure 9. Note that these results include the uncertainty of the illuminance unit realization $(0.38 \%)$ shown in Table 5 . The filter surface of the photometers were not cleaned during this 
time period. Photometers 1, 2, and 3, which showed larger drift than the rest, employ $V(\lambda)$ correction filters from different manufacturers than the rest. On the filter surface of Photometers 1 and 2, which have a larger aperture $\left(0.5 \mathrm{~cm}^{2}\right)$ than the rest, a cloudy deposit of unknown composition and origin was observed. After cleaning the filter surface of these photometers, the responsivity increased to slightly higher than the 1991 values. In contrast to this, photometers 4 through 8 have been quite stable, with an average drift of $0.05 \%$ per year. The illuminance unit is now maintained on these five photometers. Photometers 1, 2, and 3 are used only for the annual unit realization.

The data shown in Table 5 are not yet sufficient to evaluate the long-term stability of the photometers due to the much larger uncertainty of the calibration of the photometers. However, in order to assign the uncertainty of the calibration, the maximum drift of Photometers 4 through 8 between calibrations $(0.26 \%)$ is tentatively used as the uncertainty value for the long-term drift of the photometers. This value may be reduced in the future as more data are accumulated for precise analysis.

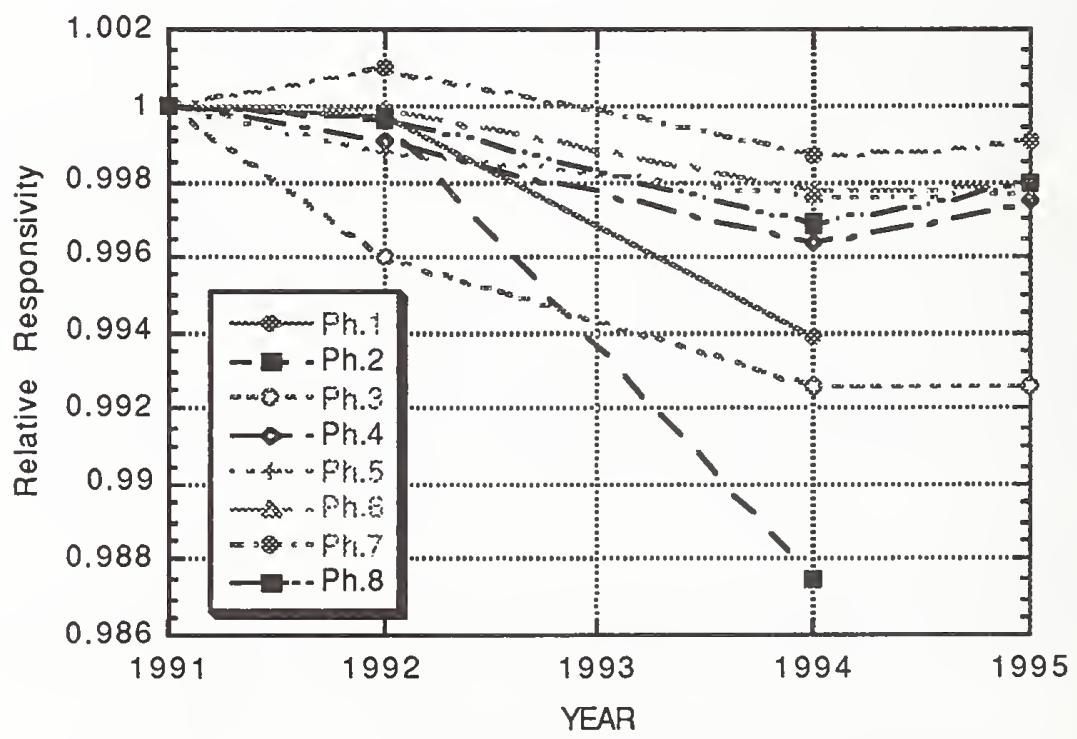

Figure 9 Drift of the illuminance responsivity of the NIST standard photometers over a 4 year period. 


\subsection{Artifacts for calibration}

\subsubsection{Type of test lamps and their characteristics}

For many years, NIST issued gas-filled, inside-frosted, $\mathrm{GE}^{\dagger}$ Airway Beacon type lamps $(100 \mathrm{~W}, 500 \mathrm{~W}$ and $1000 \mathrm{~W})$ as luminous intensity transfer standards of approximately $150 \mathrm{~cd}$, $700 \mathrm{~cd}$, and $1400 \mathrm{~cd}$, respectively. These lamps are still accepted for recalibration by NIST. The $100 \mathrm{~W}$ and $500 \mathrm{~W}$ lamps have T-20 bulbs, and the $1000 \mathrm{~W}$ lamps have T-24 bulbs. They all have medium bi-post bases and $\mathrm{C}-13 \mathrm{~B}$ filaments. The lamp designation number is etched on the bulb. Figure 10 (left) shows the appearance of this type of lamp and the electrical polarity applied during calibration by NIST. The designation number on the bulb always faces opposite to the direction of calibration.
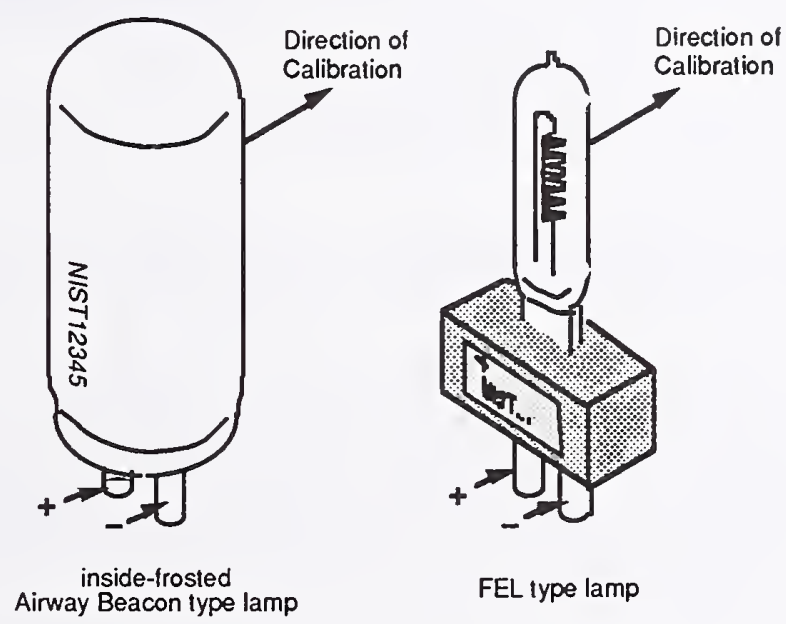

FEL type lamp

Figure 10 Appearance of the luminous intensity standard lamps and their electrical polarity.

Figure 11 shows the aging characteristics (drift as a function of operating time) of a typical Airway Beacon type lamp at $2856 \mathrm{~K}$. The lamp needs to be recalibrated after a certain operation time depending on the user's uncertainty requirements, and the aging characteristics of the individual lamp should be taken into account in the uncertainty budget. It is generally recommended that this type of lamp be recalibrated after $25 \mathrm{~h}$ of operating time.

$\uparrow$ Specific firms and trade names are identified in this paper to specify the experimental procedure adequately. Such identification does not imply recommendation or endorsement by the National Institute of Standards and Technology, nor does it imply that the materials or equipment identified are necessarily the best available for the purpose. 


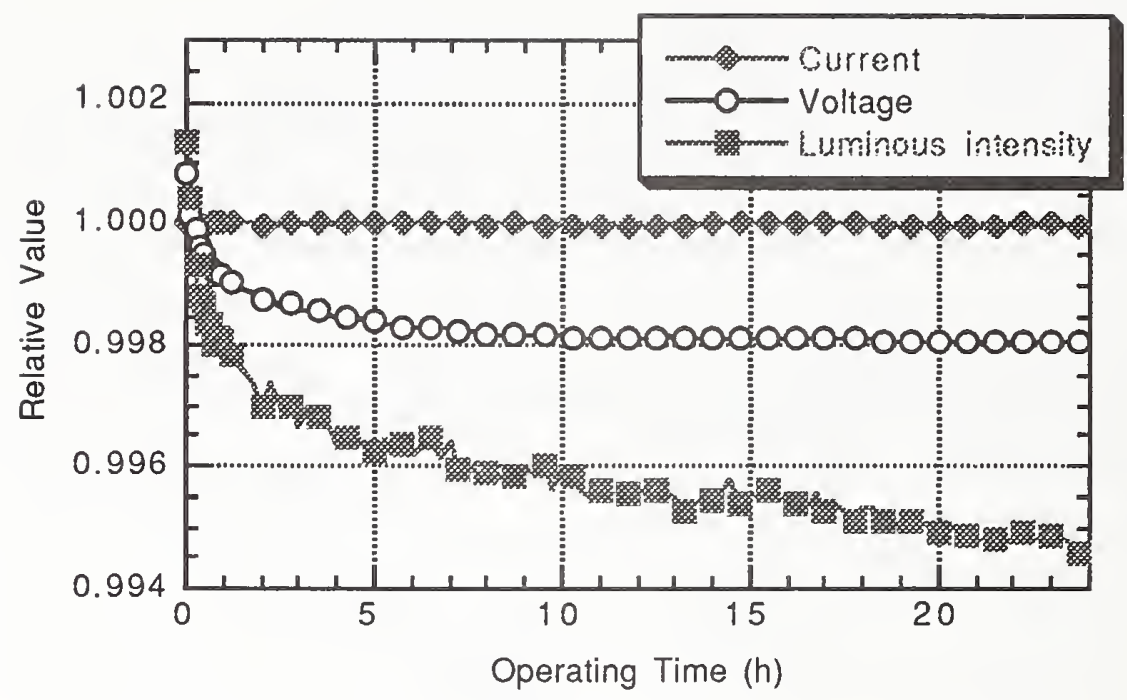

Figure 11 Aging characteristics of a typical Airway Beacon type lamp at $2856 \mathrm{~K}$.

NIST now issues standard lamps calibrated for luminous intensity and color temperature. The type of lamp issued by NIST is a $1000 \mathrm{~W}$, FEL type, quartz halogen lamp with a coiled-coil tungsten filament, as shown in Figure 10 (right). The lamps, manufactured by Osram-Sylvania Inc., are potted on a medium bi-post base, and seasoned with DC power for $48 \mathrm{~h}$ at $8.5 \mathrm{~A}$ and then for $72 \mathrm{~h}$ at $7.2 \mathrm{~A}$. Lamps are operated and calibrated at a color temperature of $2856 \mathrm{~K}$ with an operating current of $\sim 7.2 \mathrm{~A}$ and voltage of $\sim 85 \mathrm{~V}$. The lamp designation numbers and the electrical polarity are engraved on an identification plate affixed to the lamp base (See Fig. 10).

Figure 12 shows the aging characteristics of a typical selected FEL type lamp at $2856 \mathrm{~K}$. The luminous intensity lamps issued by NIST are screened to obtain a luminous intensity drift of smaller than $0.3 \%$ during a continuous $24 \mathrm{~h}$ period of operation. It can be assumed that the lamp changes at a similar rate in ensuing hours of operation. It is generally recommended that this type of lamp be recalibrated after no longer than $50 \mathrm{~h}$ of operating time. Further details of the characteristics of these FEL type lamps are described in Reference [37]. 


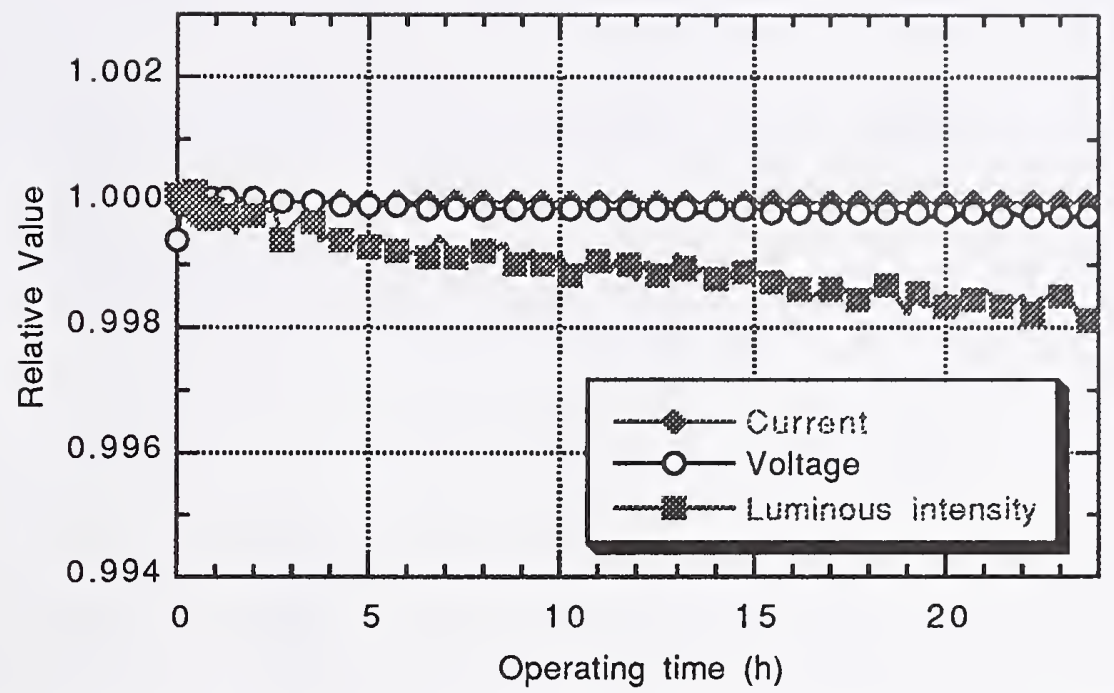

Figure 12 Aging characteristics of a selected FEL type lamp at $2856 \mathrm{~K}$.

The FEL type lamps issued by NIST are also screened for angular uniformity of luminous intensity. Figure 13 shows the data of a typical selected FEL type lamp. If the filament is tilted from the perpendicular of the optical axis, the angular uniformity is degraded. The lamps are selected for the variation of luminous intensity not to exceed $\pm 0.5 \%$ in a $\pm 1^{\circ}$ rectangular region around the optical axis. It should be noted that, even though the lamps are selected as mentioned above, the angular alignment of the FEL type lamps with a clear bulb is more critical than with the frosted lamps previously issued by NIST. NIST plans to issue FEL type lamps with frosted bulbs when they become available.

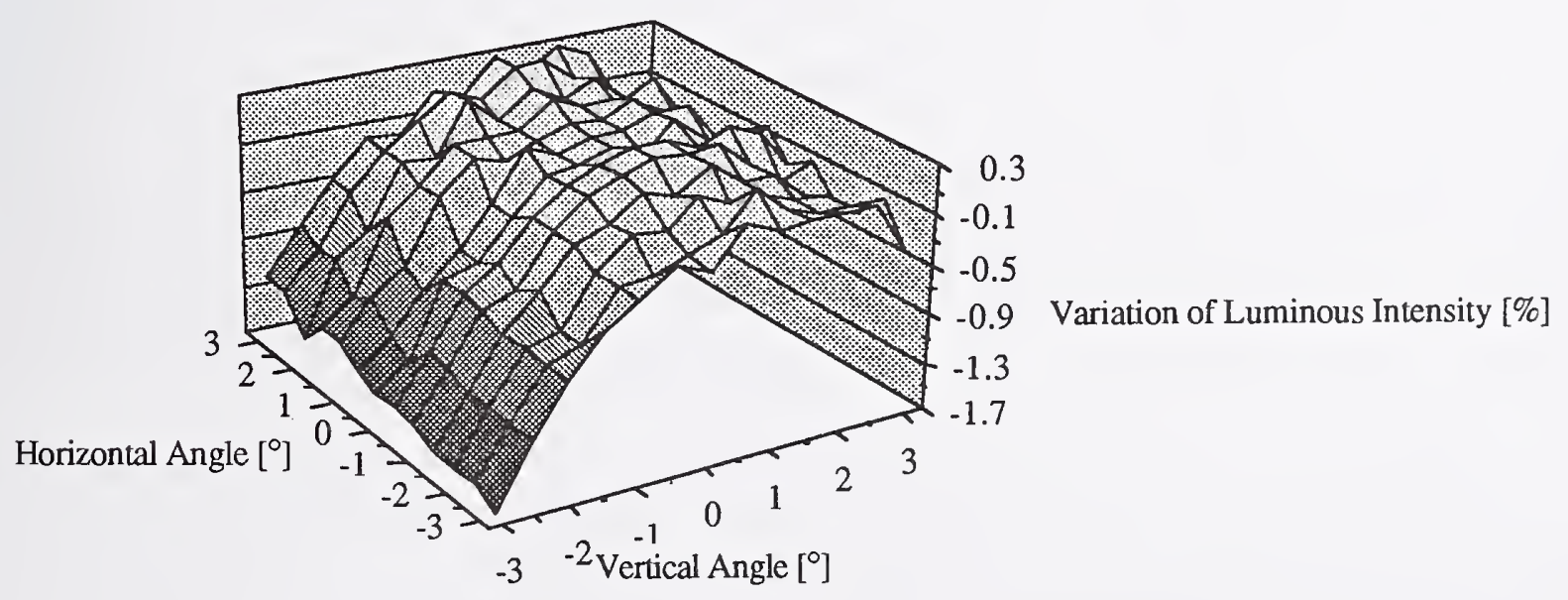

Figure 13 Spatial nonuniformity of a typical FEL type lamp. 


\subsubsection{Alignment of test lamps}

Each test lamp is mounted on a photometry bench in the base-down position, and with the identifying number facing the direction opposite to the photometer. Lamp orientation is accomplished, as shown in Figure 14, by aligning the lamp socket so the lamp posts are held vertically and the plane formed by the axes of the posts is perpendicular to the optical axis of the photometer. An alignmentjig (a mirror mounted on a bi-post base to be parallel to the plane formed by the axes of the posts) is used in combination with a laser. The laser is placed in the photometer's position and the beam is autocollimated.

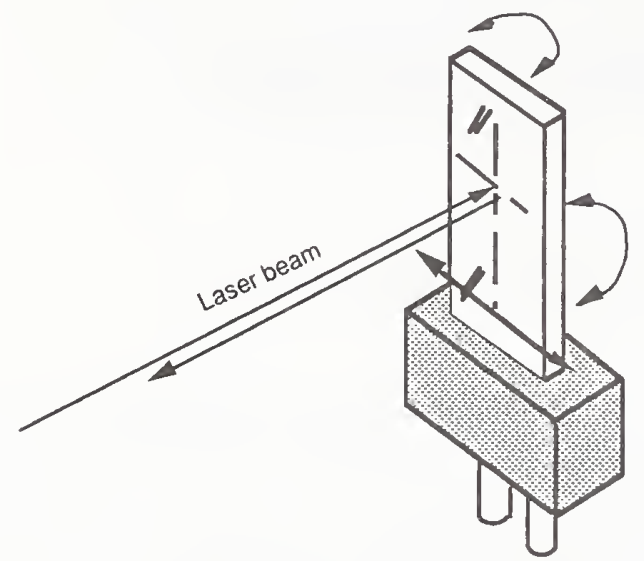

Figure 14 Alignment of the bi-post base socket using a jig and a laser beam.

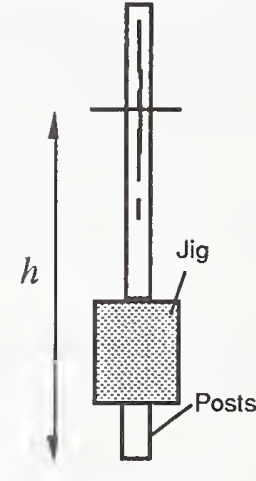

For Inside frosted lamp

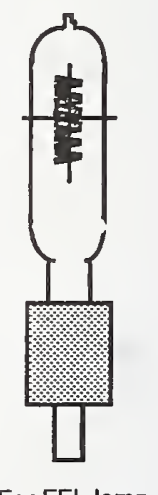

For FEL lamp
Figure 15 Alignment of the distance origin and height of the lamp.

The alignment of the distance origin and the height of the lamps are performed using a side viewing telescope as shown in Figure 15. For an FEL lamp with a clear bulb, the center of the lamp filament is adjusted to the distance origin of the photometric bench. For inside-frosted Airway Beacon type lamps, the center of the posts of the jig is adjusted to the distance origin, and the height of the lamp, $h$, is aligned so that the optical axis is $12.7 \mathrm{~cm}(5 \mathrm{in})$ for $100 \mathrm{~W}$ and $500 \mathrm{~W}$ lamps and $11.4 \mathrm{~cm}$ ( $4.5 \mathrm{in})$ for $1000 \mathrm{~W}$ lamps, from the bottom of the posts. It should be noted that, although the FEL type lamp is the same type as used for spectral irradiance calibrations [20], the distance origin of the lamp for luminous intensity is different from that for the spectral irradiance calibration. For spectral irradiance calibrations, the front surface of the jig plate is used, which is $3 \mathrm{~mm}$ off from the center of posts.

For lamps with a screw-base (E27 and E40) and with a clear bulb, alignment is performed by viewing the filament with the telescope. The distance origin of lamps with a screw base is aligned to the center of the lamp filament, and the height of the lamp is aligned so that the filament center is on the optical axis. 


\subsubsection{Operation and handling of test lamps}

The lamps should be carefully aligned in accordance with the procedures described above. The lamps should be operated on DC power with the polarity described above, and only at the current specified in the calibration report. The lamp current should be ramped up and down slowly (approximately $30 \mathrm{~s}$ ). Photometric measurements should be made after the lamp has stabilized ( 10 min after turning on).

The lamps should be handled very carefully to avoid mechanical shocks to the filament. The bulb of any lamp should not be touched with bare hands. Before operation, the bulb of the lamp should be cleaned with a soft, lint-free cloth to remove any dust accumulation from the packing material. Lamps are best kept in a container when not used.

Special attention should be paid to quartz halogen lamps (FEL lamps) to avoid moisture on the envelop. Water droplets on the bulb can cause a white spot on the quartz envelope after burning the lamp, and can result in a permanent damage to the lamp. If a quartz halogen lamp is accidentally touched with a bare hand, the bulb should be cleaned using ethyl alcohol.

\subsection{Equipment for calibration}

\subsubsection{Photometry bench}

The photometry bench shown in Figure 16 is used for luminous intensity and illuminance calibrations. The base of the bench consists of three $1.8 \mathrm{~m}$ long steel optical tables. A $5 \mathrm{~m}$ long rail system with movable carriages is mounted on the table. Two telescopes are rigidly mounted to the table for alignment of the lamps. The photometers are aligned against the front surface of a mount which is fixed on a carriage. The position of the carriage on the rails is monitored by a computer-readable, linear encoder that provides an absolute position with a resolution of $0.01 \mathrm{~mm}$. The encoder reading was verified by comparison with a $2.75 \mathrm{~m}$ NIST calibrated vernier caliper, and the uncertainty ${ }^{\dagger}$ of distance was determined to be within $0.36 \mathrm{~mm}$. The optical bench is covered by a light-tight box, the inside of which is covered with black velvet. The stray light, checked with various arrangements, is consistently less than $0.05 \%$, most of this is reflection from the edges of variable aperture diaphragms between the compartments of the photometric bench. Besides the shutter, a $V(\lambda)$-corrected monitor detector is mounted to monitor the stability of the lamp during calibration of photometers. This monitor detector gives a consistent signal regardless of the shutter position and the photometer mounted or not on the carriage.

$\dagger$ Throughout this paper, uncertainty is given in relative expanded uncertainty with coverage factor $k=2$, thus a two standard deviation estimate. 


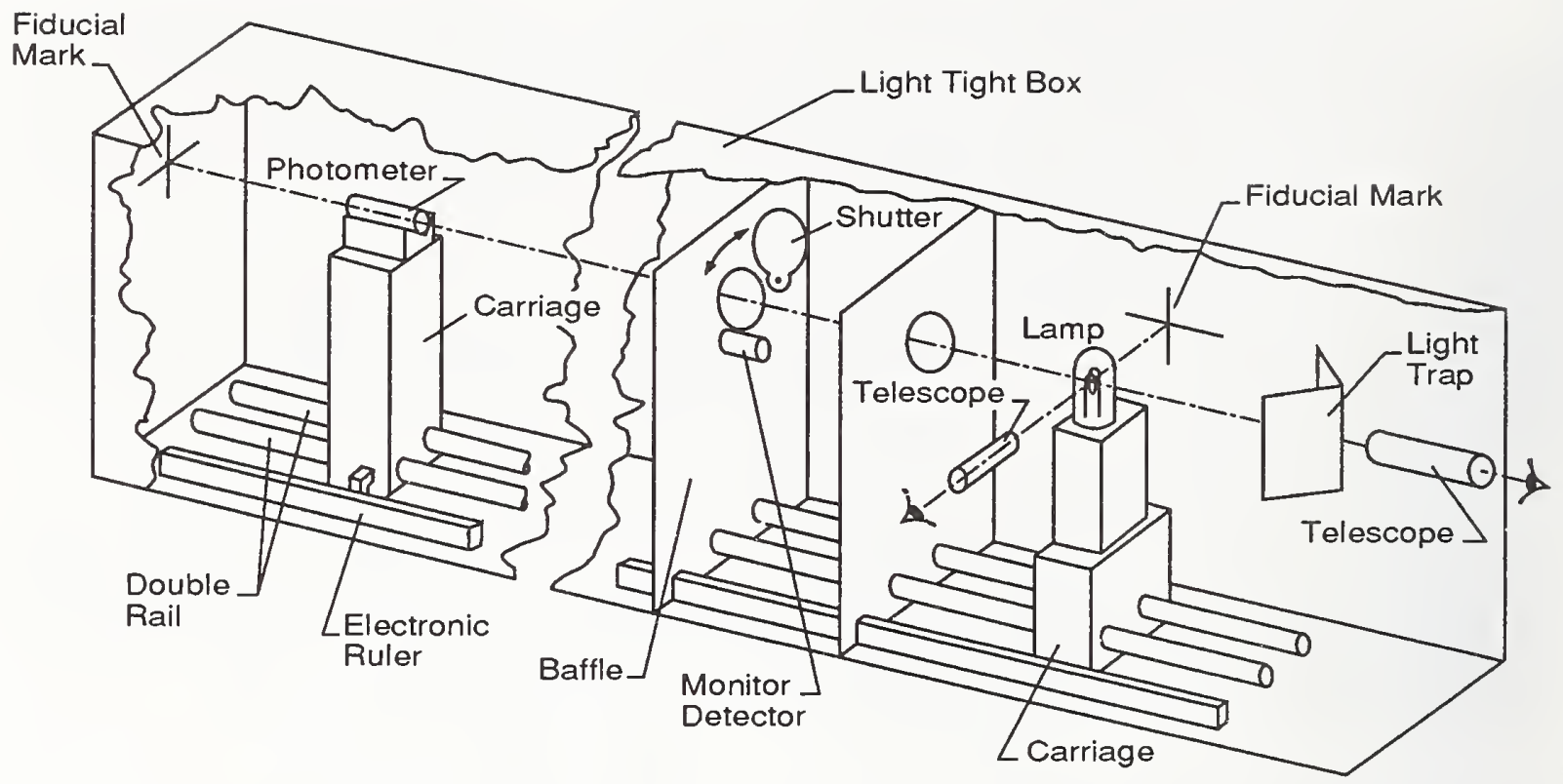

Figure 16 NIST Photometry Bench.

\subsubsection{Electrical power supply}

All the standard lamps and test lamps are operated at a specified current rather than a specified vol tage because lamp voltage, in general, does not reproduce well due to the variation of sockets used among customers. However, if the socket is designed well, the lamp voltage reproduces fairly well on the same socket, and the lamp voltage is useful to monitor for changes in the lamp.

The NIST photometric bench is equipped with a medium bipost-base socket which has four separate contacts, two for the current supply, and the other two for voltage measurements. For luminous intensity calibrations, the lamp voltage is reported, only for reference, without an uncertainty value. The bench is also equipped with a medium screw-base socket (E27) which has four contacts. Screw-based lamps submitted by a customer can be calibrated.

A DC constant-current power supply is used to operate standard lamps and test lamps. The lamp current is measured as the voltage across a reference current shunt $(0.1 \Omega)$, using a $6 \frac{1}{2}$ digit DVM, with an uncertainty better than $0.01 \%$. The DVM is on a one year calibration cycle. The current shunt is periodically calibrated at three different current levels with an uncertainty of $0.005 \%$.

The lamp current is automatically controlled by a computer feedback system to keep the current drift within $\pm 0.002 \%$. The power supply is operated in an external control mode, in which the output current is regulated by an external reference voltage. The external voltage is supplied by an 18 bit $\mathrm{D}$-to-A converter controlled by the computer. 


\subsection{Calibration procedures}

When a new lamp is calibrated for luminous intensity, the operating current of the lamp is first determined for a color temperature of $2856 \mathrm{~K}$. When a submitted lamp is calibrated with the lamp current specified by the customer, the color temperature of the lamp is measured and reported. The procedures for color temperature measurements are described in Section 7.

After the operating current of the lamp is assigned, the luminous intensity of the lamp is calibrated using the following procedures. The test lamp is mounted on the photometry bench, and its orientation and position are aligned precisely according to the procedures described in Section 3.2.2. The lamp is operated on DC power with the electrical polarity as shown in Figure 10. The lamp current is ramped up slowly $(\sim 30 \mathrm{~s})$ to the specified value, and allowed to stabilize (typically for $10 \mathrm{~min}$ ). Then the illuminance from the test lamp at a distance of approximately $3.5 \mathrm{~m}$ is measured using three of the NIST standard photometers. The average illuminance measured by the three photometers and the lamp-to-photometer distance are used to determine the luminous intensity of the test lamp.

The measured illuminance is usually the average of five readings taken between $10 \mathrm{~min}$ to 15 min after turning on the lamp. Each reading consists of twenty DVM samples with the shutter open, and ten DVM samples with the shutter closed. This process takes approximately $0.5 \mathrm{~min}$. The dark signal is subtracted from each reading. As soon as the measurement is finished, the lamp current is ramped down and turned off. The operating time of the test lamp is usually less than $15 \mathrm{~min}$. The test lamp is operated and measured three times, and the average value is reported.

When a luminous intensity measurement is made, the color temperature of the test lamp is also measured if it is not known, and the spectral mismatch correction factor, as described in Section 3.1.4, is calculated and applied to the results. The temperature of the photometer during calibration is monitored and the correction factor, as described in Section 3.1.5, is applied to the results. This correction is made automatically by the measurement program.

\subsection{Uncertainty of calibration}

Table 7 shows the uncertainty budget for luminous intensity calibrations for a typical luminous intensity standard lamp. The details of the uncertainty of the NIST illuminanceunit are given in 3.1.7. Lamp stability and reproducibility depend upon the individual lamps to be calibrated. If the test lamp is unstable, the overall uncertainty of the calibration will increase. 
Table 7. Uncertainty budget for the luminous intensity calibrations (typical)

\begin{tabular}{|c|c|c|}
\hline \multirow{2}{*}{ Uncertainty factor } & \multicolumn{2}{|c|}{$\begin{array}{c}\text { Relative expanded } \\
\text { uncertainty }(k=2)[\%]\end{array}$} \\
\hline & Type A & Type B \\
\hline The NIST illuminance unit realization & & 0.38 \\
\hline Long-term drift of the NIST standard photometers & & 0.28 \\
\hline Photometer temperature variation & 0.03 & \\
\hline Distance measurement (uncertainty of the linear encoder at $3 \mathrm{~m}$ ) & & 0.02 \\
\hline Alignment of the lamp distance $(1 \mathrm{~mm}$ in $3 \mathrm{~m})$ & 0.07 & \\
\hline Deviation from inverse square law $(3 \mathrm{~mm} \text { in } 2 \mathrm{~m}-10 \mathrm{~m})^{* *}$ & & 0.30 \\
\hline Determination of $c c f^{*}$ & & 0.04 \\
\hline Lamp current regulation and measurement uncertainty & 0.02 & \\
\hline Stray light & & 0.05 \\
\hline Random noise (scatter by dust, lamp drift, etc.) & 0.10 & \\
\hline Lamp reproducibility in 3 lightings (typical) $* *$ & 0.20 & \\
\hline Overall uncertainty of test lamp calibration with respect to SI & & .61 \\
\hline
\end{tabular}

** Uncertainty value depends on the test item 


\section{Illuminance calibrations}

Significant improvement in the quality of commercial photometers and illuminance meters has been made due to availability of high quality silicon photodiodes. As a result, many types of commercially available photometers can be used as photometric standards instead of traditional luminous intensity standard lamps. Standard lamps are sensitive to mechanical shocks, change with burning time, and drift during the stabilization period. Experience shows that well maintained photometers are less subject to such problems, and provide a dynamic range of several orders of magnitude. NIST experience indicates that the short-term stability of photometers is superior to lamps, and although the long-term stability has not been tested for many types of photometers, a few particular types tested have shown satisfactory stability ( $0.1 \%$ per year). It should be noted that some photometers have shown changes greater than $1 \%$ in a year, making their use as standards difficult. In general, for luminous intensity and illuminance measurements, the use of standard photometers is recommended, but the photometers should be calibrated frequently (at least once a year) until the long-term stability data are accumulated for the particular photometers a user laboratory may employ.

\subsection{Equipment for calibration}

The equipment used for the calibration of photometers and illuminance meters is the same equipment used in the luminous intensity calibrations described in 3.3 .

\subsection{Artifacts for calibration}

Photometer heads or photometers (photometer heads with a display unit) and illuminance meters are accepted for calibration by NIST. The requirements and recommendations for photometers used as transfer standards and reference standards are described below.

\subsubsection{Types of photometers and illuminance meters}

A reference photometer head should have either a limiting aperture (whose area is much smaller than the photodiode area) or a flat diffuser such as an opal glass in front of the $V(\lambda)$ correction filter so that the reference plane of the photometer is accurately and clearly defined. Some commercial photometer heads only have a $V(\lambda)$-correction filter attached in front of the silicon photodiode. If a photometer head does not have an aperture or a diffuser, the photodiode surface might be used as the reference plane of the photometer head. In this case, due to the refraction index of the $V(\lambda)$-correction filter which is usually several $\mathrm{mm}$ in thickness, the effective reference plane can be several $\mathrm{mm}$ from the photodiode surface. Sometimes, the front surface of the filter is simply defined as the reference plane of such photometer heads, in which case the true reference plane can be more than $1 \mathrm{~cm}$ from the filter surface. When the reference plane is not correctly defined, the departure from the inverse square law causes the responsivity 
of the photometer to vary depending on the distance to the source, and serious errors may occur when the photometer is used at close distances to the source. This is the same problem with a large-size lamp, for which the inverse square law does not hold well at close distances. To avoid these difficulties, reference photometers having a limiting aperture or a flat diffuser on the front are recommended.

Some illuminance meter heads employ a dome-shaped or mesa-shaped diffuser in the front. In this case, it is usually difficult to define the correct reference plane. Such illuminance meters are not recommended to be used as reference photometers unless the meters are always used at the same distance from the source. Also, illuminance meters with poor spectral match and (or) with only a 3 digit display are not adequate for use as reference photometers.

Illuminance meters may have various structure of the light-receiving surface for cosine correction. The reference plane of the illuminance meter heads should be provided by the customer. Upon request, the reference plane of photometer heads (without an aperture or a diffuser) and illuminance meter heads can be experimentally determined.

\subsubsection{Operation and handling of photometer heads and illuminance meters}

Illuminance meters are generally not designed to measure illuminance at very close distances to a source. It should be noted that the measurement error may increase greatly if an illuminance meter whose reference plane is not correctly defined is placed very close to a light source (e.g., less than $0.5 \mathrm{~m}$ ).

As described in 3.1.5, the responsivity of a photometer can be a function of temperature. If the photometer is neither a temperature-controlled type nor a temperature-monitored type, the photometer must be used close to the calibration temperature to avoid errors. If not, the temperature coefficient of the photometer should be measured, and correction factors should be applied as appropriate. The photometer should be placed in the laboratory several hours in advance of use so that the photometer's temperature equilibrates to the ambient temperature.

At NIST, photometers and illuminance meters are calibrated using incandescent lamps operated at $2856 \mathrm{~K}$ unless otherwise requested by the customer. In this case, when the photometers are used to measure light sources other than incandescent lamps of that color temperature, spectral mismatch errors occur, and in order to quantify or correct for this error, the relative spectral responsivity of the photometers or illuminance meters must be measured. The details of this calibration are described in 4.3.2.

\subsection{Calibration procedures}

\subsubsection{Illuminance responsivity of photometers}

Photometers and photometer heads are calibrated for illuminance responsivity in $\mathrm{A} / \mathrm{x}$, V/lx or readings $/ \mathrm{x}$. Calibration is performed on the NIST photometry bench using a $1000 \mathrm{~W}$ 
frosted FEL lamp operated at $2856 \mathrm{~K}$ (CIE Illuminant A). The calibration is performed by direct comparison with three of the NIST standard photometers. The responsivity is usually measured at two distances, $2.5 \mathrm{~m}$ and $3.5 \mathrm{~m}$ from the lamp, at illuminance levels of $85 \mathrm{~lx}$ and $150 \mathrm{~lx}$. Calibrations can also be made at other illuminance levels from $0.1 \mathrm{~lx}$ to $3000 \mathrm{~lx}$ for a linearity check, if requested by customers, using procedures described in 4.3.2. The procedure for regular calibration is described below.

After the lamp has been stabilized, the illuminance on a reference point $\sim 3 \mathrm{~m}$ from the lamp is first determined by three NIST standard photometers. This measurement is performed in the same manner as described in 3.4. Then the third NIST standard photometer is replaced by the photometer under test, and the readings are recorded. If the reference plane of the photometer head is located different from that of the NIST standard photometers, the distance offset is measured and recorded. The illuminance on the reference plane of the test illuminance meter is calculated from the corrected distance to the lamp and the luminous intensity of the lamp. Data are usually taken within $5 \mathrm{~min}$ at each illuminancelevel. During the comparison, the luminous intensity stability of the lamp is monitored by the monitor detector installed in the photometry bench (See 3.3.1). The ambient temperature during the calibration (usually $\sim 25^{\circ} \mathrm{C}$ ) is measured and reported.

\subsubsection{Illuminance meter calibration}

Calibrations for illuminance meters are performed basically the same way as described in 4.3.1, using a frosted FEL lamp at $2856 \mathrm{~K}$, with various illuminance levels from $100 \mathrm{~lx}$ to $3000 \mathrm{~lx}$ at distances from $0.6 \mathrm{~m}$ to $3 \mathrm{~m}$. Since the distance from the lamp to the photometer is small at higher illuminance levels, the definition of the reference plane of the illuminance meter head is important as discussed previously. For lower illuminance levels, a variable slit is used in front of the FEL lamp so that the illuminance levels can be lowered with negligible change of color temperature, and without changing the lamp.

At each illuminance level, the NIST standard photometer is replaced by the illuminance meter head under test with their reference planes positioned at the same location. During the comparison, the luminous intensity stability of the lamp is monitored by the monitor detector installed in the photometry bench. The ambient temperature of the photometer under test during the calibration (usually $\sim 25^{\circ} \mathrm{C}$ ) is measured and reported.

When an illuminance meter is calibrated, the errors of the reading at each illuminance level are reported. The meter reading is usually not adjusted. However, if the illuminance meter is so manufactured that the user can adjust the readings easily, the meter can be adjusted by NIST upon request by customers. In this case the instructions for the reading adjustment should be provided by the customer.

Illuminance meters can be calibrated for specific sources other than $2856 \mathrm{~K}$ source upon request by customers. In this case, the calibration is first performed using the $2856 \mathrm{~K}$ source as 
described in 4.3.1. Then, the spectral mismatch correction factors for the specific sources are obtained by the following procedure.

The relative spectral responsivity of the illuminance meter head is measured by the Spectral Comparator Facility [25] in the $350 \mathrm{~nm}$ to $1100 \mathrm{~nm}$ region at $5 \mathrm{~nm}$ increments. The monochromator output of the SCF is defocused on the photometer head to irradiate an area of several $\mathrm{mm}$ in diameter. The illuminance meter head is underfilled in this case. Measurements are made with the beam incident on several different spots of the receiving surface of the illuminance meter head, and the average is taken. This method can only be applied for illuminance meters whose relative spectral responsivity is fairly uniform over the receiving surface. From the relative spectral responsivity data and the spectral power distribution data (supplied by customer) of any particular light sources to be measured by the illuminance meter, the spectral mismatch correction factors for the particular sources are calculated using equation (11) as described in 3.1.4. The relative spectral responsivity data and the correction factors are reported to the customer.

\subsection{Uncertainty of calibration}

Table 8 shows the uncertainty budget for the calibration of illuminance responsivity of a typical photometer head in the illuminance range $50 \mathrm{~lx}$ to $200 \mathrm{~lx}$. The details of the uncertainty of the NIST illuminance unit are given in 3.1 and reference [2]. For much lower illuminance levels, the uncertainty of calibration will increase depending on the random noise of the photometers under test.

Table 9 shows an example of the uncertainty budget for the calibration of a typical illuminance meter in the illuminance range $300 \mathrm{~lx}$ to $3000 \mathrm{~lx}$. The overall uncertainty value depends on each individual illuminance meter and the illuminance levels. "Inconsistency of the calibration factors" is the range of the calibration factors obtained at the illuminance levels tested. For example, if the calibration factor is 0.999 at $300 \mathrm{~lx}$ and 1.005 at $3000 \mathrm{~lx}$, the inconsistency $(0.6 \%)$ will be added. This inconsistency is most often caused by the incorrect definition of the reference plane of the illuminance meter head since the calibration is conducted at different distances. 
Table 8. Uncertainty budget for the illuminance responsivity calibrations (typical)

Relative expanded
Uncertainty $(k=2)[\%]$
Type A Type B

The NIST illuminance unit realization

0.38

Long-term drift of the NIST standard photometers

Photometer temperature variation

0.28

Determination of $c c f^{*}$ of NIST standard photometers

Photometer head alignment $(0.5 \mathrm{~mm}$ in $2.5 \mathrm{~m}$ - for $150 \mathrm{~lx}) \quad 0.04$

Illuminance nonuniformity

Lamp current regulation

$\begin{array}{ll} & 0.38 \\ 0.03 & 0.28 \\ & 0.04 \\ 0.04 & \\ & 0.05 \\ 0.02 & \\ & 0.05 \\ 0.10 & \\ & 0.02 \\ & 0.12\end{array}$

Stray light in the photometry bench

Random noise (scatter by dust, lamp drift, etc.)

0.12

Transimpedance gain of the amplifier
Inconsistency at two illuminance levels (typical)**

0.51

Overall uncertainty of calibration with respect to SI

** Uncertainty value depends on the test item

Table 9. Uncertainty budget for the calibration of an illuminance meter (an example)

\begin{tabular}{|c|c|c|}
\hline \multirow[t]{2}{*}{ Uncertainty factor } & \multicolumn{2}{|c|}{$\begin{array}{c}\text { Relative expanded } \\
\text { uncertainty }(k=2)[\%]\end{array}$} \\
\hline & Type A & Type B \\
\hline \multicolumn{2}{|l|}{ The NIST illuminance unit realization (See 3.1.7) } & 0.38 \\
\hline \multicolumn{2}{|l|}{ Long-term drift of the NIST standard photometers (See 3.1.8) } & 0.28 \\
\hline \multicolumn{2}{|l|}{$\begin{array}{ll}\text { Photometer temperature variation } & 0.03\end{array}$} & \\
\hline \multicolumn{2}{|l|}{ Determination of $c c f^{*}$ of NIST standard photometers } & 0.04 \\
\hline \multicolumn{2}{|l|}{ Random noise in the photometer measurements } & \\
\hline \multicolumn{2}{|l|}{ Illuminance nonuniformity } & 0.05 \\
\hline \multicolumn{2}{|l|}{ Lamp current regulation } & \\
\hline \multicolumn{2}{|l|}{ Stray light in the bench } & 0.05 \\
\hline Illuminance meter head alignment (distance and angle)** & 0.08 & \\
\hline \multirow{2}{*}{\multicolumn{2}{|c|}{$\begin{array}{l}\text { Display resolution of the illuminance meter }(1 \text { in } 199)^{* *} \\
\text { Inconsistency of the calibration factors at different levels }\end{array}$}} & \\
\hline & & 0.30 \\
\hline \multicolumn{2}{|l|}{ Overall uncertainty of calibration with respect to SI } & .77 \\
\hline
\end{tabular}




\section{Total luminous flux calibrations}

\subsection{NIST luminous flux unit}

Traditionally, the luminous flux unit is realized using goniophotometers [38]. It is often difficult, however, to build and maintain high accuracy goniophotometers which require a large dark room and costly high precision positioning mechanisms. The measurements are also time consuming, resulting in longer burning times for the lamps.

To alleviate these difficulties, an alternative method (the integrating sphere method) has been developed at NIST using an integrating sphere with an external source. The total flux of a lamp inside the sphere is calibrated against the known amount of flux coming into the sphere from the external source through an aperture. This method has the advantage that a conventional integrating sphere can be used with minor modifications, and the sphere can still be used for ordinary substitution measurements. Measurements are accomplished faster, resulting in shorter burning times for the lamps. Corrections are needed for the spatial nonuniformity and the incident angle dependence of the sphere response and the spectral mismatch of the integrating sphere system. The NIST luminous flux unit has been maintained using the integrating sphere method since 1995, and is directly tied to the NIST detector-based candela established in 1992.

\subsubsection{Principles of the integrating sphere method [30-32]}

Figure 17 shows the original geometry of an integrating sphere designed for this purpose. An opening is placed at an angle of $135^{\circ}$ away from the detector, and the flux from the external source is introduced through a calibrated aperture placed in front of the opening. Two baffles are used to shield the detector and the opening from direct illumination by the internal source. The detector is exposed to the first reflection of the introduced flux from the external source in order to equalize the sphere responsivity for the internal source and that for the external source.

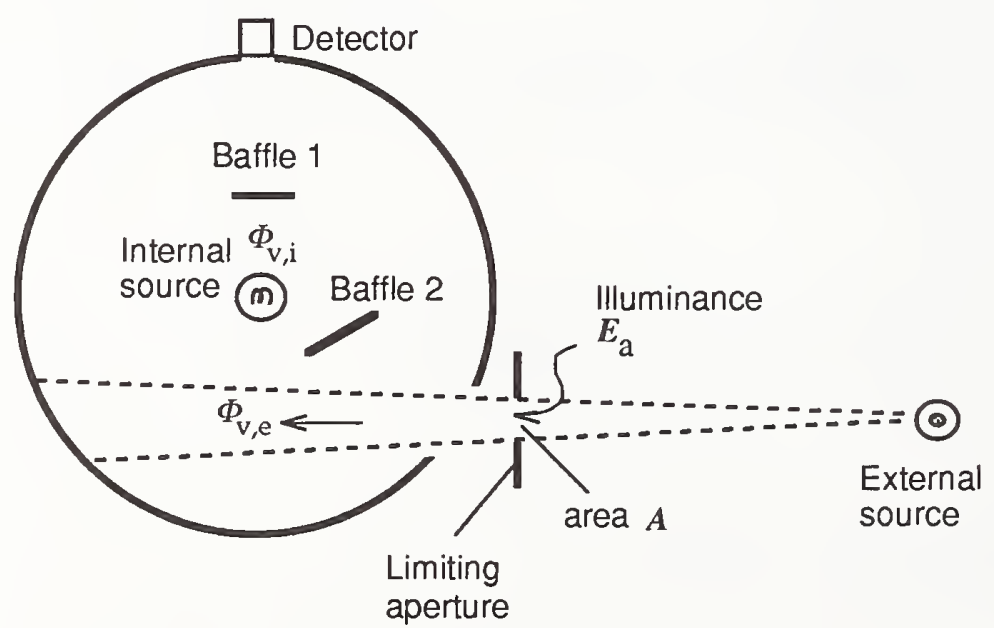

Figure 17 Geometry of the simulation model. 
The luminous flux $\Phi_{\mathrm{v}, \mathrm{e}}(\mathrm{lm})$ from the external source introduced into the sphere is given by

$$
\Phi_{\mathrm{v}, \mathrm{e}}=E_{\mathrm{a}} A,
$$

where $E_{\mathrm{a}}$ is the average illuminance (lx) over the limiting aperture of known area $A$. The internal source or the external source is turned on alternately. The introduced flux $\Phi_{\mathrm{v}, \mathrm{e}}$ is used as a reference, and the luminous flux of the internal source $\Phi_{\mathrm{v}, \mathrm{i}}$ is measured in comparison with the flux $\Phi_{\mathrm{v}, \mathrm{e}}$ as given by

$$
\Phi_{\mathrm{v}, \mathrm{i}}=c \Phi_{\mathrm{v}, \mathrm{e}} y_{\mathrm{i}} / y_{\mathrm{e}}
$$

where $y_{\mathrm{i}}$ is the detector current for the internal source, $y_{\mathrm{e}}$ is that for the external source, and $c$ is a correction factor.

The response of the integrating sphere is not uniform over the sphere wall due to baffles and other structures inside the sphere, and also due to nonuniform reflectance of the sphere wall. The light from the external source is incident at $45^{\circ}$ while the light from the internal source located at the sphere center is incident at the normal. When the incident angle is different, the diffuse reflectance of the sphere coating changes [39], which affects the sphere response. When the spectral power distribution of the internal source is different from that of the external source, a spectral mismatch error occurs. All these corrections are made to determine the correction factor $c$, as described in 5.1.3 through 5.1.5 in detail.

\subsubsection{Design of the NIST integrating sphere for the lumen realization}

Figure 18 shows the geometry of the modified NIST $2 \mathrm{~m}$ integrating sphere used in the realization work. The sphere is coated with barium sulfate paint with a reflectance of $96 \%$ to $97 \%$ in the visible region. An opening of $10 \mathrm{~cm}$ in diameter was cut at a position $45^{\circ}$ away from the detector. The geometry was modified from the original design (Fig. 17) for the convenience of installing the external source. The portion illuminated by the external source is located in the same geometry $\left(135^{\circ}\right.$ from the detector). Baffle 1 ( $20 \mathrm{~cm}$ in diameter) is located at $50 \mathrm{~cm}$ from the sphere center. Baffle $2(15 \mathrm{~cm}$ in diameter) is located at $60 \mathrm{~cm}$ from the sphere center.

The detector is a $V(\lambda)$-corrected and cosine-corrected photometer with an opal diffuser (20 $\mathrm{mm}$ diameter) attached in front. It has a built-in transimpedance amplifier with gain settings from $10^{4} \mathrm{~V} / \mathrm{A}$ to $10^{10} \mathrm{~V} / \mathrm{A}$ calibrated at each range (except $10^{10}$ range) with an uncertainty of $0.02 \%$. A built-in temperature sensor allows for corrections of the photometer temperature drift. The linearity of the photometer was measured, using a beam conjoiner instrument [36], to be constant over a luminous flux range of $10^{-1} \mathrm{~lm}$ to $10^{5} \mathrm{~lm}$ to within $0.05 \%$.

A $1000 \mathrm{~W}$ frosted FEL type quartz halogen lamp operated at $2856 \mathrm{~K}$ is used as the external source. The lamp is placed $70 \mathrm{~cm}$ from the limiting aperture, introducing a flux of $\sim 2.7 \mathrm{~lm}$ through the $40 \mathrm{~mm}$ aperture. Two stainless steel limiting apertures of $40 \mathrm{~mm}$ and $50 \mathrm{~mm}$ diameter and $3 \mathrm{~mm}$ thick, having sharp edges, are used. The area of the apertures was determined 
by the NIST Fabrication Technology Division with an uncertainty of $0.03 \%$. The apertures are placed as close to the opening as possible to minimize diffraction losses [40].

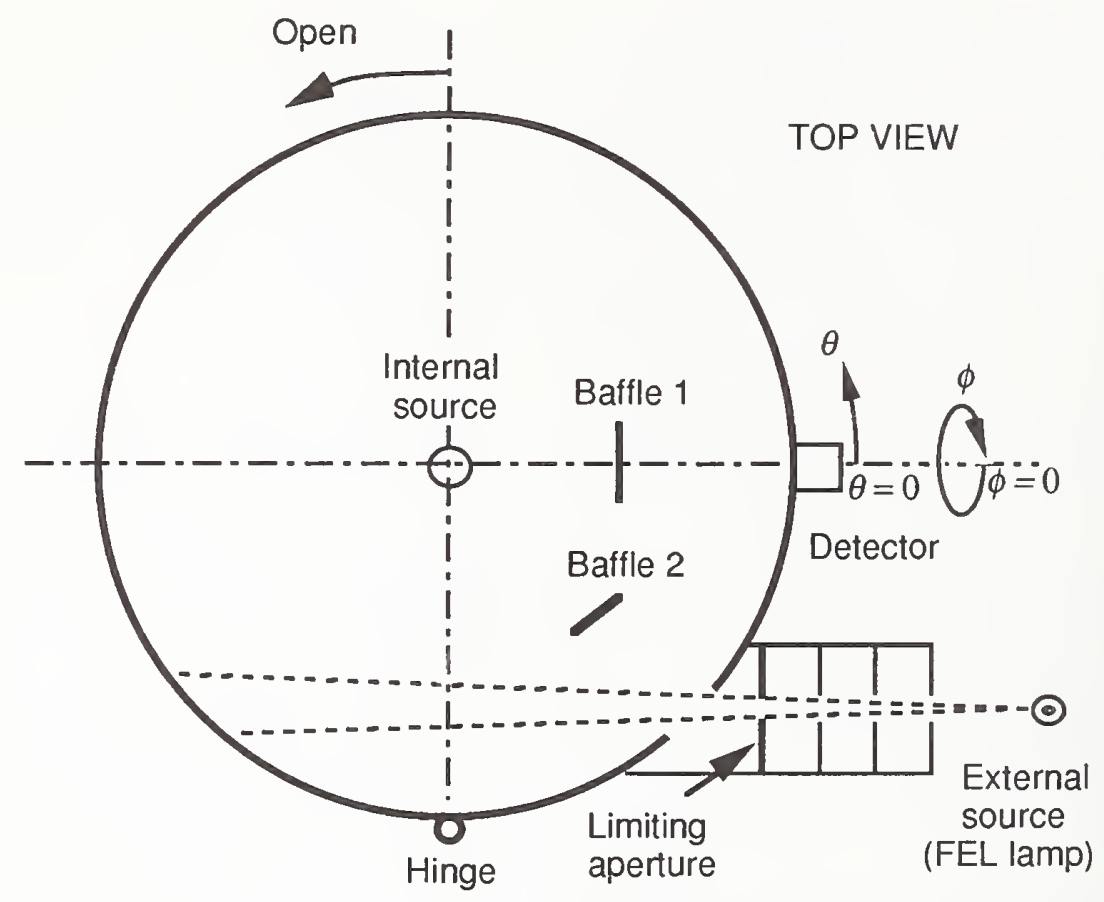

Figure 18 Geometry of the integrating sphere for the luminous flux unit realization.

\subsubsection{Correction for the spatial nonuniformity of the sphere responsivity}

The responsivity of the integrating sphere is not uniform over the sphere wall. The spatial response distribution function (SRDF), $K(\theta, \phi)$, of the sphere is defined as the sphere response at a point $(\theta, \phi)$ of the sphere wall (or on a baffle surface) divided by the sphere response at $(0,0) . K(\theta, \phi)$ can be obtained by measuring the detector signal while rotating a narrow beam inside the sphere. $K(\theta, \phi)$ is then normalized for the sphere response to an isotropic point source. The normalized $\operatorname{SRDF}, K^{*}(\theta, \phi)$, is defined as

$$
K^{*}(\theta, \phi)=4 \pi K(\theta, \phi) / \int_{\phi=0}^{2 \pi} \int_{\theta=0}^{\pi} K(\theta, \phi) \sin \theta \mathrm{d} \theta \mathrm{d} \phi .
$$

Using $K^{*}(\theta, \phi)$, the spatial correction factor $s c f_{\mathrm{e}}$ for the external source with respect to an isotropic point source is given by

$$
s c f_{\mathrm{e}}=1 / K^{*}\left(\theta_{\mathrm{e}}, \phi_{\mathrm{e}}\right),
$$

where $\left(\theta_{\mathrm{e}}, \phi_{\mathrm{e}}\right)$ is the point on which the center of the illuminated area by the external source is located. It is assumed that the area illuminated by the external source is small enough so that 
$K^{*}\left(\theta_{\mathrm{e}}, \phi_{\mathrm{e}}\right)$ represents the average SRDF over the area. The spatial correction factor, $s c f_{\mathrm{i}}$, for the internal source with respect to an isotropic point source is given by

$$
s c f_{i}=1 / \int_{\phi=0}^{2 \pi} \int_{\theta=0}^{\pi} I^{*}(\theta, \phi) K^{*}(\theta, \phi) \sin \theta d \theta d \phi,
$$

where $I^{*}(\theta, \phi)$ is the normalized luminous intensity distribution of the internal source given by

$$
I^{*}(\theta, \phi)=I_{\mathrm{rel}}(\theta, \phi) / \int_{\phi=0}^{2 \pi} \int_{\theta=0}^{\pi} I_{\mathrm{rel}}(\theta, \phi) \sin \theta d \theta d \phi,
$$

where $I_{\text {rel }}(\theta, \phi)$ is the relative luminous intensity distribution of the internal source. $I^{*}(\theta, \phi)$ is normalized so that its total luminous flux becomes $1 \mathrm{~lm}$. Goniophotometry is necessary to obtain $I_{\text {rel }}(\theta, \phi)$, but corrections for $s c f_{\mathrm{i}}$ (using goniophotometry data) may not be necessary if the internal sources have uniform spatial distribution [41].

The SRDF, $K(\theta, \phi)$, is measured by rotating a beam source which is burning position insensitive. A $6 \mathrm{~V}(1.2 \mathrm{~W})$ vacuum incandescent lamp equipped with a reflector $(40 \mathrm{~mm}$ diameter) and a cylindrical hood ( $100 \mathrm{~mm}$ long) is used. The inside of the hood is painted black, and the outside is painted white. The beam angle is $\sim 10^{\circ}$. The SRDF measurements are made at $5^{\circ}$ intervals for $\theta$ and $30^{\circ}$ intervals for $\phi$.

Figure 19 shows an example of the $\operatorname{SRDF}, K^{*}(\theta, \phi)$, of the NIST integrating sphere. The polar coordinate $(\theta, \phi)$ in the graph is originated in the position of the detector as illustrated in Figure 18. $\phi=0$ is the plane passing through the bottom of the sphere. The $s c f_{\mathrm{i}}$ for the group

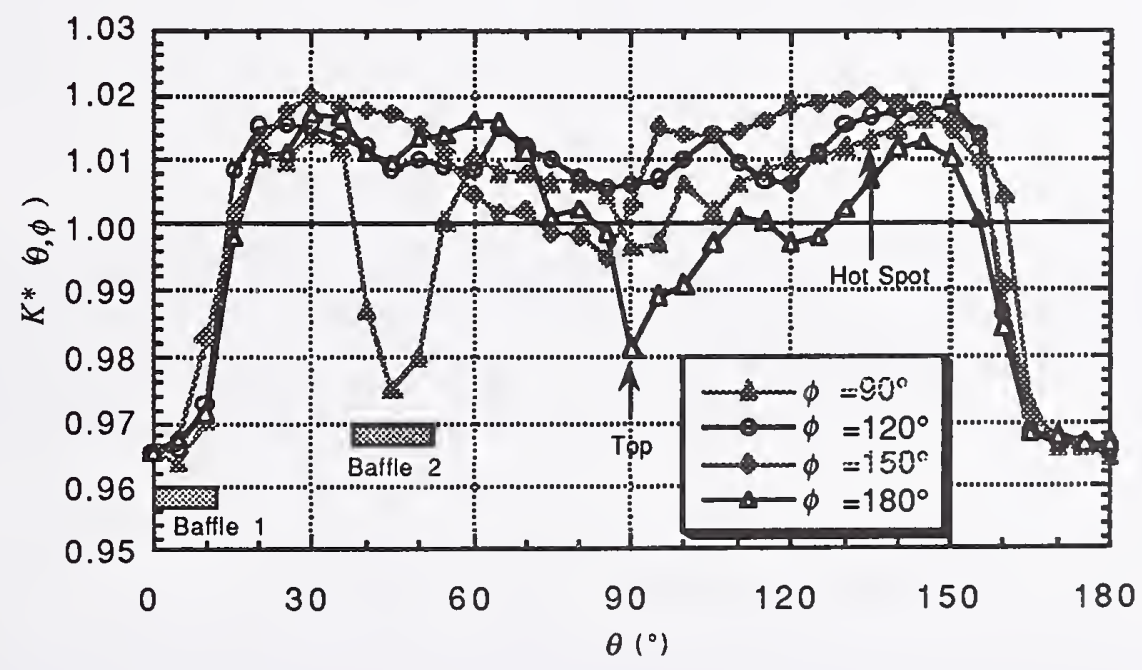

Figure $19 \mathrm{SRDF}$ of the NIST integrating sphere. $(\theta=0$ is at the detector. $\phi=0$ is the plane passing through the sphere bottom.) 
of $40 \mathrm{~W}$ opal lamps was calculated using equation (18) and determined to be 1.0003 , which turned out to be almost negligible. The $s c f_{\mathrm{e}}$ for the external source was calculated using eq (17) and determined to be 0.9870 .

\subsubsection{Incident angle dependence correction}

The SRDF is defined for normal incidence to the sphere wall. The light from the external source is incident at $45^{\circ}$. When the incident angle is different, the diffuse reflectance of the sphere coating changes, which affects the sphere response. The incident angle dependence correction factor $\beta$ is obtained by

$$
\beta=y_{0} / y_{45}
$$

where $y_{0}$ is the detector signal when a stable beam source is placed in the center of the sphere irradiating the sphere wall at $\left(\theta_{\mathrm{e}}, \phi_{\mathrm{e}}\right)$ at $0^{\circ}$ incidence, and $y_{45}$ is the detector signal when the source is placed on the optical axis of the external source irradiating nearly the same part of the sphere wall at $45^{\circ}$ incidence.

The correction factor $\beta$ was measured using the same beam source (used for the SRDF measurement). The correction factor $b$ was determined to be 0.9966 .

\subsubsection{Spectral mismatch correction}

The spectral power distribution of the internal source may be different from that of the external source, and a spectral mismatch correction is needed. The spectral mismatch correction factor, $c c f_{i}^{*}$, of the internal source against the Illuminant A ( $2856 \mathrm{~K}$ Planckian source) is given by

$$
c c f_{\mathrm{i}}^{*}=\frac{\int_{\lambda} S_{\mathrm{A}}(\lambda) R_{\mathrm{s}}(\lambda) \mathrm{d} \lambda \int_{\lambda} S_{\mathrm{i}}(\lambda) V(\lambda) \mathrm{d} \lambda}{\int_{\lambda} S_{\mathrm{A}}(\lambda) V(\lambda) \mathrm{d} \lambda \int_{\lambda} S_{\mathrm{i}}(\lambda) R_{\mathrm{s}}(\lambda) \mathrm{d} \lambda},
$$

where $S_{\mathrm{i}}(\lambda)$ is the relative spectral power distribution of the internal source, $S_{\mathrm{A}}(\lambda)$ is that of the Illuminant $\mathrm{A}, V(\lambda)$ is the spectral luminous efficiency function, and $R_{\mathrm{S}}(\lambda)$ is the relative spectral responsivity of the sphere system. $R_{\mathrm{s}}(\lambda)$ can be obtained by measuring the relative spectral responsivity of the detector $R_{\mathrm{d}}(\lambda)$, and the relative spectral throughput of the integrating sphere $T_{\mathrm{S}}(\lambda)$ as

$$
R_{\mathrm{s}}(\lambda)=R_{\mathrm{d}}(\lambda) T_{\mathrm{s}}(\lambda)
$$

The spectral mismatch correction factor, $c c f_{\mathrm{e}}^{*}$, of the external source against the Illuminant A is given by equation (21) with $S_{\mathrm{i}}(\lambda)$ replaced by the relative spectral power distribution $S_{\mathrm{e}}(\lambda)$ of the external source. 
Spectral mismatch correction factors were obtained for the external source $(2856 \mathrm{~K})$ and the internal sources $(2730 \mathrm{~K})$. The relative spectral throughput $T_{s}(\lambda)$ of the sphere was obtained using a spectroradiometer by taking the ratios of the spectral irradiance on the detector port of the sphere (in which a $500 \mathrm{~W}$ clear-bulb flux standard lamp was operated) and the spectral irradiance of the same lamp measured on the photometry bench. The relative spectral responsivity $R_{s}(\lambda)$ of the total integrating sphere system was then obtained using eq (22). Using eq (21), the spectral mismatch correction factors $c c f_{\mathrm{i}}^{*}$ and $c c f_{\mathrm{e}}^{*}$ were calculated to be 0.9982 and 1.0000 , respectively.

\subsubsection{Calibration of the primary standard lamps}

The illuminance from the external source at the aperture plane was measured using a transfer photometer which was calibrated against the NIST standard photometers under illumination by the same frosted FEL lamp (used as the external source, operated at $2856 \mathrm{~K}$ ), at a distance of $\sim 3.5 \mathrm{~m}$. The transfer photometer, with an opal diffuser ( $10 \mathrm{~mm}$ in diameter) in front, is equipped with a built-in temperature sensor which allow for compensation of the photometer temperature drift.

The illuminance distribution over the aperture area was measured by spatially scanning the transfer photometer to determine the average illuminance factor, $k_{\mathrm{a}}$, which is a ratio of the average illuminance $E_{\mathrm{a}}$ to the illuminance on the aperture center, $E_{\mathrm{c}}$. Once $k_{\mathrm{a}}$ is determined, only $E_{\mathrm{c}}$ needs to be measured to obtain $E_{\mathrm{a}}$.

The transfer photometer is attached to a holding plate which can be mounted interchangeably with the aperture. The position of the photometer on the holding plate is aligned, using an alignment telescope, so that the reference plane of the photometer and that of the limiting aperture coincide when they are mounted. After measuring the illuminance $E_{\mathrm{c}}$, the aperture is mounted, and the signal of the integrating sphere photometer, $y_{\mathrm{e}}$, is taken. The integrating sphere responsivity, $R_{\mathrm{s}}{ }^{\prime}$, is then determined by

$$
R_{\mathrm{s}}^{\prime}=y_{\mathrm{e}} c c f_{\mathrm{e}}^{*} \operatorname{scf} \beta /\left(E_{\mathrm{c}} k_{\mathrm{a}} S\right) .
$$

$R_{\mathrm{s}}{ }^{\prime}$ is determined with a particular internal source (a representative lamp) inside the sphere. If a different test lamp is measured, a self-absorption correction must be applied. The selfabsorption correction factor $\alpha$ is obtained by

$$
\alpha=y_{\mathrm{r}, \mathrm{e}} / y_{\mathrm{t}, \mathrm{e}},
$$

where $y_{\mathrm{r}, \mathrm{e}}$ is the detector signal with the representative lamp inside the sphere, and $y_{\mathrm{t}, \mathrm{e}}$ is the detector signal with the test lamp inside the sphere, when only the external source is operated. Then the total luminous flux $\Phi_{\mathrm{i}}(\mathrm{lm})$ of an internal source (test lamp) is obtained by

$$
\Phi_{\mathrm{i}}=y_{\mathrm{i}} c c f_{\mathrm{i}}^{*} s c f_{\mathrm{i}} \alpha / R_{\mathrm{s}}{ }^{\prime} .
$$


According to this procedure, a group of twelve $40 \mathrm{~W}$ opal-bulb incandescent lamps are calibrated to serve as the total luminous flux primary standards. At the same time, eight $60 \mathrm{~W}$ inside frosted incandescent lamps are also calibrated to serve as working standards. Routine calibrations for luminous flux are performed using these working standard lamps. The working standard lamps are recalibrated at every $10 \mathrm{~h}$ of total operating time. The uncertainty budget for the luminous flux realization is shown in Table $\mathbf{1 0 .}$

Table 10. Uncertainty budget for the NIST 1995 luminous flux unit

\begin{tabular}{|c|c|c|}
\hline \multirow[t]{2}{*}{ Uncertainty factor } & \multicolumn{2}{|c|}{$\begin{array}{c}\text { Relative expanded } \\
\text { uncertainty }(k=2)[\%]\end{array}$} \\
\hline & Type A & Type B \\
\hline \multicolumn{3}{|l|}{ Uncertainty of the determination of $\Phi_{\mathrm{e}}$ composed of: } \\
\hline The NIST Illuminance unit realization & & 0.39 \\
\hline Ave. long-term drift of the standard photometers $(2 \mathrm{~m}$ & onths) & 0.03 \\
\hline Transfer to the transfer photometer & 0.07 & \\
\hline Transfer photometer position alignment $( \pm 0.2 \mathrm{~mm})$ & 0.06 & \\
\hline Aperture alignment (difference of the two apertures) & & 0.05 \\
\hline Aperture area & & 0.03 \\
\hline Average illuminance factor $k_{\mathrm{a}}$ & & 0.03 \\
\hline Stray light & & 0.05 \\
\hline Drift of the external source during calibration & 0.02 & \\
\hline \multicolumn{3}{|c|}{ Uncertainty of the lamp luminous flux with respect to $\Phi_{\mathrm{e}}$ composed of: } \\
\hline Spatial nonuniformity correction factor $s c f_{\mathrm{i}} / s c f_{\mathrm{e}}$ & & 0.30 \\
\hline Incident angle dependence correction factor $\beta$ & 0.06 & \\
\hline Spectral mismatch correction factor $c c f_{\mathrm{i}}^{*} / c c f_{\mathrm{e}}^{*}$ & & 0.03 \\
\hline Self-absorption correction factor $\alpha$ & 0.03 & \\
\hline Random variation in the $R_{\mathrm{S}}$ determination & 0.04 & \\
\hline Detector linearity & & 0.05 \\
\hline Reproducibility of the standard lamps & 0.06 & \\
\hline Overall uncertainty of the NIST 1995 luminous flux unit & \multicolumn{2}{|c|}{0.53} \\
\hline
\end{tabular}

\subsection{Artifacts for calibration}

\subsubsection{Types of test lamps}

For many years NIST has issued gas-filled, incandescent lamps $(100 \mathrm{~W}, 200 \mathrm{~W}, 500 \mathrm{~W}$, and $1000 \mathrm{~W}$ ) with medium screw base or mogul screw base and miniature lamps ranging from $1.2 \mathrm{~W}$ to $30 \mathrm{~W}$ as luminous flux transfer standards. These lamps and other standard quality 
incandescent lamps, including miniature lamps, ranging from $0.1 \mathrm{~lm}$ to $10^{5} \mathrm{~lm}$ are accepted for calibration at NIST.

Four foot linear fluorescent lamps of any color submitted by customers are also accepted for calibration at NIST, and while other types of fluorescent lamps are currently not accepted, there are plans to expand the types of fluorescent lamps approved for calibration.

At the moment, NIST does not provide luminous flux standard lamps due to unavailability of standard quality lamps, although a search for commercially available lamps for this purpose is underway.

When lamps are submitted to NIST for calibration, the lamps must be seasoned and tested for stability by the customer. In case of new lamps, the lamps usually have to be seasoned for $5 \%$ of the rated life time, at the current to be used for calibration. The operating current, or operating color temperature, and burning position must be specified by the customer.

For miniature lamps, the size of the sockets tend to be much larger relative to the size of the lamps. When a miniature lamps is mounted in a socket, the total flux may decrease significantly due to the absorption by the socket surfaces. Sometimes miniature lamps are calibrated in combination with a particular socket, and in such cases, a combination of lamp and socket is required as a calibration artifact.

\subsubsection{Operation and handling of test lamps}

As with other standard lamps, care must be shown in the handling of luminous flux lamps. Lamps should be handled very carefully to avoid mechanical shocks to the filament, and the bulb of the lamps should not be touched with bare hands. Before calibration, the bulb of the lamps should be cleaned with a soft, lint-free cloth to remove any dust from the packing material. Lamps should be kept in a container when not used.

Incandescent standard lamps should be operated on DC power with the specified polarity, and only at the current specified in the calibration report. The lamp current should be ramped up and down slowly (approximately $30 \mathrm{~s}$ ). Photometric measurements should be made after the lamp has stabilized (approximately $10 \mathrm{~min}$ after turning on).

Most of the lamps, including gas-filled tungsten lamps, are sensitive to burning position. The calibrated lamps must be operated in the same burning position as described in the calibration report. Linear fluorescent lamps are always operated in the horizontal position. Linear fluorescent lamps should be operated on AC power at a specified current, using a reference ballast as described in the calibration report. Calibration can be performed with the cathode power either on or off by request from the customer. The luminous flux of fluorescent lamps changes significantly with ambient temperature. The ambient temperature (usually measured at the back side of the baffle) must be controlled within $25^{\circ} \mathrm{C} \pm 1{ }^{\circ} \mathrm{C}$. Before starting the measurements, the lamps should be stabilized for $15 \mathrm{~min}$ with the integrating sphere open. When the measurement starts, the sphere should be closed very slowly to avoid drafts. 


\subsection{Equipment for calibration}

\subsection{1 $2 \mathrm{~m}$ integrating sphere}

Figure 20 shows the geometry of the NIST $2 \mathrm{~m}$ integrating sphere in the routine calibration setting. The integrating sphere is equipped with a $V(\lambda)$-corrected, cosine-corrected detector, a baffle screen, an auxiliary lamp, a temperature sensor, and a spectroradiometer.

A baffle of $20 \mathrm{~cm}$ or $30 \mathrm{~cm}$ diameter is used for incandescent lamps. A rectangular baffle $(8.5 \mathrm{~cm} \times 75 \mathrm{~cm})$ is used for fluorescent lamps. The rectangular baffle has a circular part of $15 \mathrm{~cm}$ in diameter in the center so that either standard lamps or fluorescent lamps can be baffled. The baffles are placed at $1 / 2$ the sphere radius from the lamp.

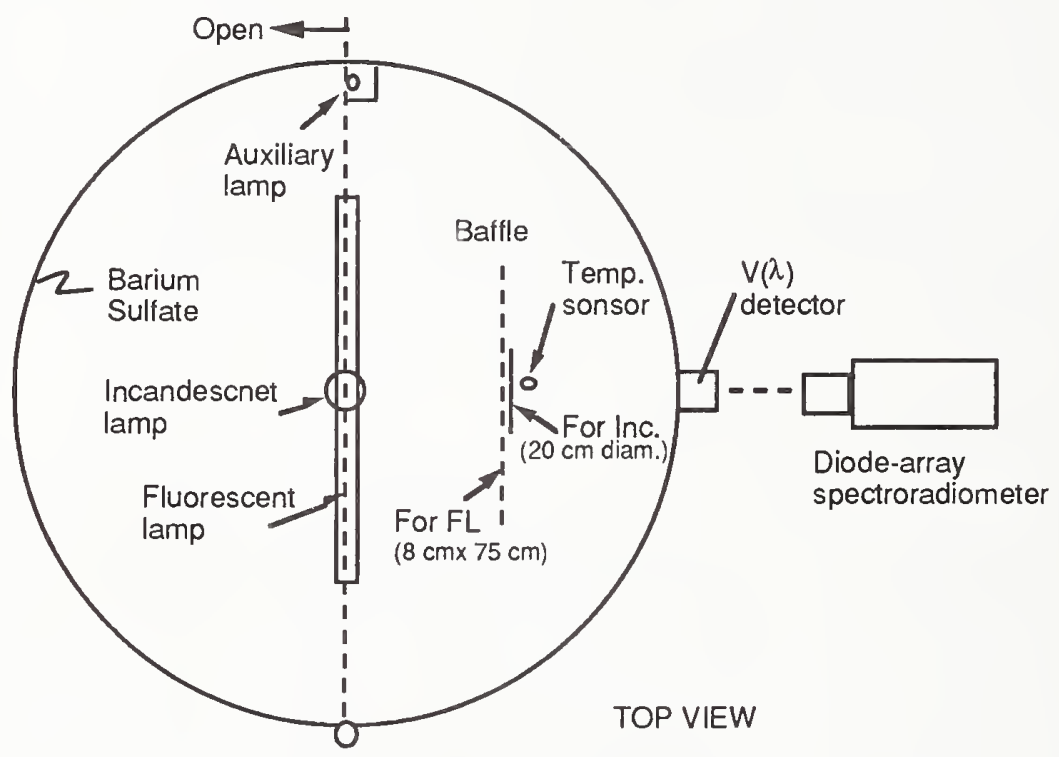

Figure 20 NIST $2 \mathrm{~m}$ integrating sphere set up for routine calibrations.

The $V(\lambda)$-corrected detector is of the same design as the NIST standard photometers for the illuminance unit, but equipped with an opal glass diffuser. The detector has a linearity response in the range $10^{-10} \mathrm{~A}$ to $10^{-4} \mathrm{~A}$. Based on these characteristics, total luminous flux from $10^{-1} \mathrm{~lm}$ to $10^{5} \mathrm{~lm}$ can be measured in direct substitution with total luminous flux standard lamps of any wattage.

The sphere wall is coated with barium sulfate paint with diffuse reflectance approximately 0.97 in the visible region. However, the reflectance of the coating drops slightly in the shorter wavelength region, resulting in a significant drop of sphere throughput in that region, which affects the total spectral response of the sphere system. The spectral throughput of the sphere is obtained by measuring the relative spectral irradiance of a tungsten lamp operated inside and outside the sphere with a spectroradiometer. The distribution temperature 
of this lamp, as a function of emitting angle, is fairly uniform (within $\pm 10 \mathrm{~K}$ ) over the entire solid angle. The measured spectral throughput of the sphere is shown in Figure 21 (solid line).

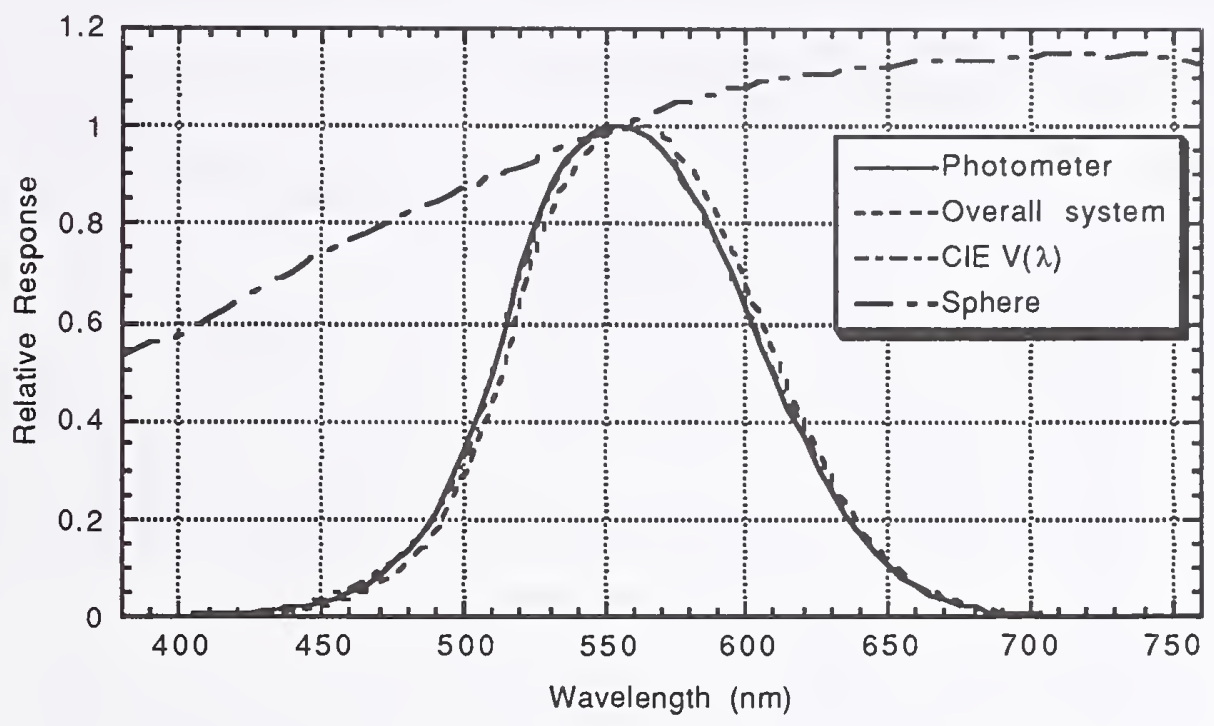

Figure 21 Spectral characteristics of the NIST integrating sphere.

The spectral throughput data are multiplied by the spectral responsivity of the detector (broken line) to obtain the spectral responsivity of the total system as shown in the dotted line. This data is used to obtain the spectral mismatch correction factors for the test lamps as given by eq (21). For incandescent lamps, the spectral mismatch correction factors, $c c f^{*}\left(T_{\mathrm{d}}\right)$, are fitted to a polynomial function of the distribution temperature $T_{\mathrm{d}}$ as

$$
c c f^{*}\left(T_{\mathrm{d}}\right)=\sum_{j=0}^{2} M_{j} T_{\mathrm{d}}{ }^{j}
$$

This function obtained for the NIST 2 m integrating sphere is shown in Figure 22.

The integrating sphere is also equipped with an auxiliary lamp (30 W tungsten) on the sphere wall. The auxiliary lamp is used to measure the self-absorption effects of a lamp in the sphere.

The room temperature of the Photometry Laboratory at NIST is controlled to be approximately $24^{\circ} \mathrm{C}$. A temperature sensor is mounted at the back side of the baffle, and the air temperature inside the sphere during measurement is monitored. The temperature inside the sphere tends to increase when a lamp is operated in the sphere. This provides for an ambient temperature in the sphere of approximately $25^{\circ} \mathrm{C}$. 


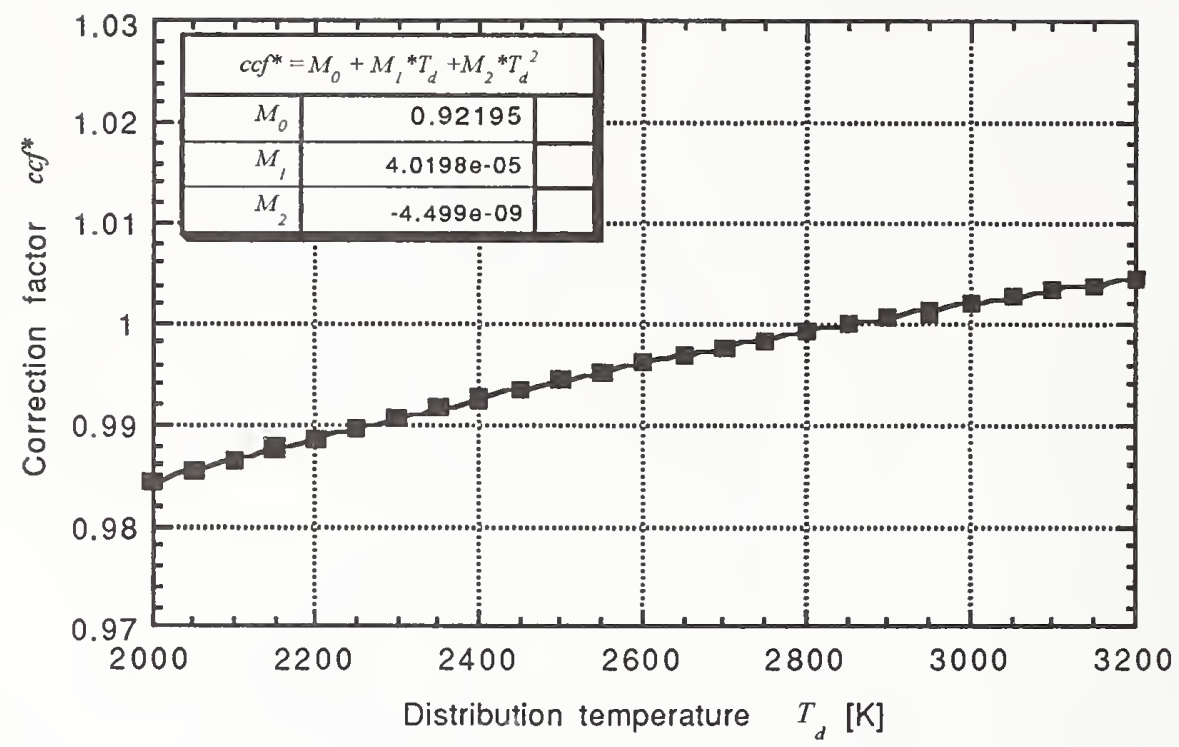

Figure 22 Spectral mismatch correction factor of the NIST $2 \mathrm{~m}$ integrating sphere as a function of the distribution temperature of a Planckian source.

\subsubsection{Electrical facility for incandescent lamps}

All the standard lamps and test lamps are operated at a specified current rather than a specified voltage because the lamp voltage, in general, does not reproduce well due to the construction of the sockets used among customers. However, lamp voltages reproduce fairly well on the same socket, and the lamp voltage is a useful indicator of changes in the lamps.

The NIST 2 m integrating sphere can be equipped with a medium screw base socket, mogul screw base socket, medium bi-post base socket, or a special small socket (top surface is $3 \mathrm{~mm}$ in diameter) for miniature lamps with leads. These are two-contact sockets, but four separate wires, two for the current supply and the other two for voltage measurements, are soldered to separate parts of the socket. For luminous flux calibration, the lamp voltage is reported, only for reference purposes, without an uncertainty value.

A DC constant-current power supply is used to operate standard lamps and test lamps. The lamp current is measured as the voltage across a reference current shunt $(0.1 \Omega)$, using a $61 / 2$ digit DVM with a stated uncertainty better than $0.01 \%$. The DVM is calibrated every 12 months. The current shunt is periodically calibrated with an uncertainty of $0.005 \%$.

The lamp current is automatically controlled by a computer feedback system to keep the current drift within $\pm 0.002 \%$. The power supply is operated in an external control mode, in which the output current is regulated by an external reference voltage. The external voltage is supplied by an 18 bit D-to-A converter which is controlled by the computer. 


\subsubsection{Electrical facility for fluorescent lamp}

The electrical circuits for fluorescent lamp measurements are constructed according to the IES Guide LM-9-1988 [42] and ANSI standards [43, 44]. A regulated AC power supply $(1 \mathrm{kVA}, 60 \mathrm{~Hz})$ is used as the main power supply. The output voltage is transformed into higher voltage ( $400 \mathrm{~V}$ maximum) by using a variac and a step-up transformer. The high voltage is fed to a measurement circuit with a reference ballast. Figure 23 shows the measurement circuit for rapid start type linear fluorescent lamps.

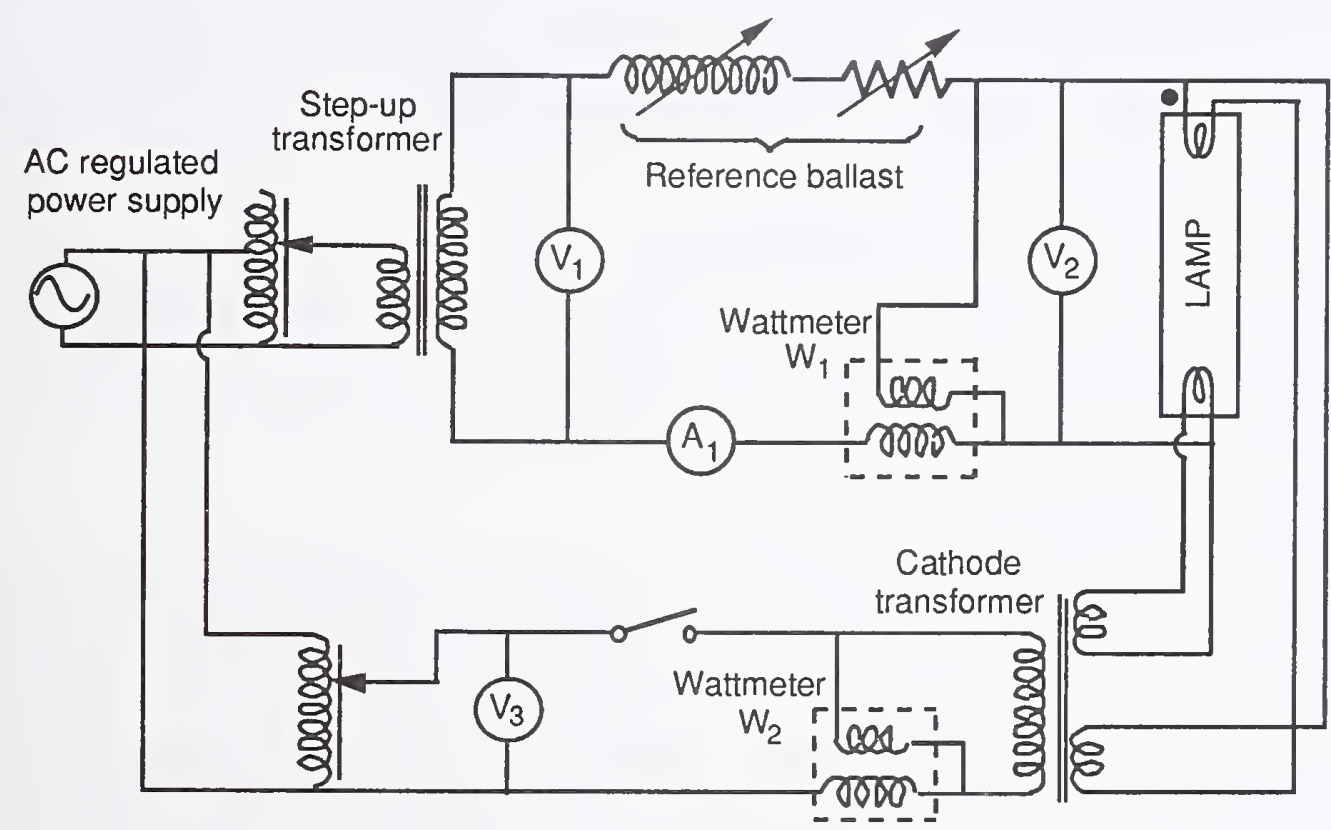

Figure 23 Measurement circuit for a rapid start fluorescent lamp.

Prior to photometric measurements, the electrical parameters of the measurement circuit are set up according to the specification of the lamp to be tested. The cathode transformer is calibrated, in advance, in terms of the primary voltage needed to provide the desired secondary voltage under normal load conditions, and the power loss in the transformer under this normal load condition. The input voltage on $V_{3}$ is adjusted to the calibrated value. Input power for the cathode transformer is read on $\mathrm{W}_{2}$. The impedance (reactance and resistance) of the reference ballast is set in accordance with the specification of the lamp. The lamp is mounted on the socket, and turned on, and the supply voltage $V_{1}$ is adjusted so that the lamp current $A_{1}$ equals the specified value. When the lamp current is adjusted, the cathode power is usually kept on. Measurements can be made with the cathode power off if requested by customer. During photometric measurements, the supply voltage, $V_{1}$, the lamp current, $A_{1}$, the lamp voltage, $V_{2}$, and the lamp power, $W_{1}$, and the cathode power, $W_{2}$ are measured and recorded. If the cathode power is kept on during the measurements, the sum of $W_{1}$ and $W_{2}$ (corrected by the power loss of the cathode transformer) is reported as the total lamp power. 


\subsection{Calibration procedures}

\subsubsection{Correction for the sphere detector temperature}

When a lamp is turned on in the integrating sphere, the sphere detector is heated due to heat from the lamp. For a $1000 \mathrm{~W}$ incandescent lamp that is turned on for $10 \mathrm{~min}$ in the NIST $2 \mathrm{~m}$ integrating sphere, the detector temperature increases by $\sim 3{ }^{\circ} \mathrm{C}$. The responsivity of the sphere detector slightly changes with its temperature and is monitored with a temperature sensor installed in the detector package. The temperature coefficient $c_{\mathrm{p}}$, of the photometric responsivity of the detector was measured in a temperature chamber, and found to be $-0.088 \% /{ }^{\circ} \mathrm{C}$, and the detector signal is corrected (multiplied) by the temperature correction factor, $k\left(T_{\mathrm{p}}\right)$, as given by

$$
k\left(T_{\mathrm{p}}\right)=1-\left(T_{\mathrm{p}}-T_{\mathrm{r}}\right) c_{\mathrm{p}},
$$

where $T_{\mathrm{p}}$ is the detector temperature at the measurement, $T_{\mathrm{r}}$ is a reference temperature that can be chosen arbitrary. At NIST, $T_{\mathrm{r}}=298 \mathrm{~K}$ is used. In other words, the detector signal is always corrected to the value at $298 \mathrm{~K}$.

\subsubsection{Self-absorption correction}

As the first step of the luminous flux calibration, the self-absorption of the lamps is measured. The auxiliary lamp ( $30 \mathrm{~W}$ miniature lamp) in the $2 \mathrm{~m}$ integrating sphere is turned on and allowed to stabilize for $15 \mathrm{~min}$. The detector signal $y_{01}$ is first taken with the test lamps and lamp holders removed from the sphere (null condition). Then the detector signal, $y_{i}$, is taken with each standard lamp and test lamp $(1, \ldots, i, . ., n)$ plus appropriate holders installed in the sphere. These lamps are not turned on during self-absorption measurements. Then the detector signal, $y_{02}$, is taken for the null condition again, and the self-absorption factor, $\alpha_{i}$, of lamp $i$ is obtained by,

$$
\alpha_{i}=y_{i} /\left\{\left(y_{01}+y_{02}\right) / 2\right\}
$$

The measured detector signal for lamp $i$ is divided by $\alpha_{i}$ for the self-absorption correction.

\subsubsection{Spectral mismatch correction}

The spectral power distributions of all the standard lamps and test lamps are measured using the spectroradiometer described in Section 7.4. The spectroradiometer is first calibrated by measuring a relative spectral radiant flux standard lamp operated in the sphere, and subsequently the test lamps are measured. For incandescent lamps, only the color temperature of the lamp is recorded.

The spectral mismatch correction factor $\operatorname{ccf}\left(S_{\mathrm{t}}, S_{\mathrm{s}}\right)$ of the integrating sphere system, for a test lamp with spectral distribution $S_{\mathrm{t}}(\lambda)$ against a standard lamp with spectral distribution $S_{\mathrm{s}}(\lambda)$ is given by 


$$
c c f\left(S_{\mathrm{t}}, S_{\mathrm{s}}\right)=\frac{\int_{\lambda} S_{\mathrm{s}}(\lambda) R_{\mathrm{s}}(\lambda) \mathrm{d} \lambda \int_{\lambda} S_{\mathrm{t}}(\lambda) V(\lambda) \mathrm{d} \lambda}{\int_{\lambda} S_{\mathrm{s}}(\lambda) V(\lambda) \mathrm{d} \lambda \int_{\lambda} S_{\mathrm{t}}(\lambda) R_{\mathrm{s}}(\lambda) \mathrm{d} \lambda},
$$

where $R_{s}(\lambda)$ is the relative spectral responsivity of the sphere system, and $V(\lambda)$ is the spectral luminous efficiency function.

However, luminous flux working standard lamps often have different color temperatures, depending on wattage, and these standard lamps are often used in combination. Calculation by eq (29) will be confusing when more than two different types of standard lamps are used. Therefore, at NIST, a normalized spectral mismatch correction factor, $c c f^{*}$, is introduced. The theory is given below.

The relationship between $c c f$ 's for three arbitrary sources with spectral distributions $S_{1}(\lambda), S_{2}(\lambda)$, and $S_{3}(\lambda)$ is given by

$$
\operatorname{ccf}\left(S_{3}, S_{1}\right)=\frac{c c f\left(S_{3}, S_{2}\right)}{c c f\left(S_{1}, S_{2}\right)} .
$$

The total flux of test lamp $\Phi_{\mathrm{t}}$ is given by

$$
\Phi_{\mathrm{t}}=\Phi_{\mathrm{s}} \cdot y_{\mathrm{t}} / y_{\mathrm{s}}
$$

where $\Phi_{\mathrm{s}}$ is the total flux of the standard lamp, $y_{\mathrm{t}}$ is the signal for the test lamp, $y_{\mathrm{s}}$ is the signal for the standard lamp. The correction factor, $\operatorname{ccf}\left(S_{\mathrm{t}}, S_{\mathrm{s}}\right)$, can be applied as

$$
\begin{aligned}
\Phi_{\mathrm{t}} & =\Phi_{\mathrm{s}} \cdot \frac{y_{\mathrm{t}}}{y_{\mathrm{s}}} c c f\left(S_{\mathrm{t}}, S_{\mathrm{s}}\right) \\
& =\Phi_{\mathrm{s}} \cdot \frac{y_{\mathrm{t}} \cdot \operatorname{ccf}\left(S_{\mathrm{t}}, S_{\mathrm{A}}\right)}{y_{\mathrm{s}} \cdot \operatorname{ccf}\left(S_{\mathrm{s}}, S_{\mathrm{A}}\right)},
\end{aligned}
$$

where $S_{\mathrm{A}}(\lambda)$ is the spectral distribution of CIE Illuminant A (2856 K blackbody). With $\operatorname{ccf}\left(S_{\mathrm{t}}, S_{\mathrm{A}}\right)$ defined as $c c f^{*}\left(S_{\mathrm{t}}\right)$, eq (32) is expressed as

$$
\Phi_{\mathrm{t}}=\Phi_{\mathrm{s}} \cdot \frac{y_{\mathrm{t}} \cdot c c f^{*}\left(S_{\mathrm{t}}\right)}{y_{\mathrm{s}} \cdot c c f^{*}\left(S_{\mathrm{s}}\right)}
$$

This means that the spectral mismatch correction factors for all the standard lamps and test lamps can be calculated against CIE Illuminant A as given by $c c f^{*}\left(S_{\mathrm{t}}\right)$. All the detector readings are simply multiplied by this factor. 


\subsubsection{Correction for the spatial nonuniformity of the sphere response}

The response of the sphere is not spatially uniform because of various objects in the sphere, contamination of the sphere wall, gaps between the hemispheres, etc. Therefore, when measuring a test lamp whose luminous intensity distribution is different from the standard lamp, an error can occur and can be corrected using the following theory.

Total luminous flux, $\Phi_{v}$, of a lamp is obtained from the luminous intensity distribution of the lamp, $I(\theta, \phi)$, by the following equation:

$$
\Phi_{\mathrm{v}}=\int_{\mathrm{A}} E \mathrm{~d} A=\int_{\varphi=0}^{2 \pi} \int_{\theta=0}^{\pi} I(\theta, \phi) \sin \theta \mathrm{d} \theta \mathrm{d} \phi .
$$

A normalized luminous intensity distribution, $I^{*}(\theta, \phi)$, is defined as

$$
I^{*}(\theta, \phi)=\left(4 \pi / \Phi_{\mathrm{v}}\right) \cdot I(\theta, \phi)
$$

Then, the spatial nonuniformity correction factor, $s c f^{*}$, of the lamp against an isotropic point source is calculated by

$$
s c f^{*}=\frac{\int_{\phi=0}^{2 \pi} \int_{\theta=0}^{\pi} K(\theta, \phi) \sin \theta \mathrm{d} \theta \mathrm{d} \phi}{\int_{\phi=0}^{2 \pi} \int_{\theta=0}^{\pi} I^{*}(\theta, \phi) K(\theta, \phi) \sin \theta \mathrm{d} \theta \mathrm{d} \phi},
$$

where $K(\theta, \phi)$ is the spatial response distribution function. $K(\theta, \phi)$ can be measured by rotating a beam lamp (which is burning-position insensitive) at the center of the sphere. $I^{*}(\theta, \phi)$ does not need to be highly accurate. Manufacturer's typical data is usually sufficient to calculate $s c f^{*}$ accurately enough for this correction.

\subsubsection{Determination of luminous flux}

Incandescent lamps are operated in the sphere center with the base up position unless otherwise stated. The lamps are operated at the lamp current or at the color temperature specified by the customer. When the color temperature is specified, the lamp current is first determined by color temperature measurements as described in Section 7.5. When the lamp current is specified, the color temperature of the lamp is measured and reported together with the luminous flux value. The lamps are allowed to stabilize, usually for $10 \mathrm{~min}$. The color temperature values are used for the spectral mismatch corrections.

Linear fluorescent lamps are operated horizontally in the center of the integrating sphere. The lamp is operated at a specified current using the electric circuit described in 5.3.3. The lamp is stabilized for at least $15 \mathrm{~min}$ with the sphere open, and the sphere is closed very slowly immediately before the measurements. The ambient temperature inside the sphere is kept at $25^{\circ} \mathrm{C} \pm 1{ }^{\circ} \mathrm{C}$. 
The photometer output voltage is measured with a DVM. The average of 20 DVM readings is recorded. The measurement program records the electrical parameters and the burning time of the lamp, the signal and temperature of the detector, the ambient temperature of the lamp inside the sphere, and the correction factors. After the data are taken, the lamp is turned off (ramped down slowly for incandescent lamps), and the dark readings are taken. Finally, the detector signal, $y$, for a standard lamp or a test lamp is corrected by

$$
y^{\prime}=y \cdot k\left(T_{\mathrm{p}}\right) \cdot c c f^{*} \cdot s c f^{*} / \alpha_{i}
$$

where $k\left(T_{\mathrm{p}}\right)$ is the temperature correction factor, $c f^{*}$ is the spectral mismatch correction factor, $s c f^{*}$ is the spatial nonuniformity correction factor, and $\alpha_{i}$ is the self-absorption factor. The spatial nonuniformity correction factor, $s c f^{*}$, is usually not applied in the routine calibrations for regular incandescent lamps. The $s c f^{*}$ is applied for special types of lamps such as reflector type lamps.

The luminous flux of test lamps is determined by substitution with the standard lamps. First, two standard lamps are measured, then the test lamps are measured three times (remounted and relighted), and at the end, the same two standard lamps are measured. Let the corrected signals of the standard lamp 1 be $y_{1,1^{\prime}}$ and $y_{1,2^{\prime}}$ and the corrected signals of standard lamp 2 be $y_{2,1}{ }^{\prime}$ and $y_{2,2}{ }^{\prime}$, the total luminous flux of the standard lamps 1 and 2 be $\Phi_{1}$ and $\Phi_{2}$, respectively, and the corrected signals for test lamp $i$ be $y_{i, 1}{ }^{\prime}, y_{i, 2}{ }^{\prime}$, and $y_{i, 3}{ }^{\prime}$. The total luminous flux $\Phi_{i}$ of test lamp $i$ is obtained by,

$$
\Phi_{i}=\frac{1}{3} \sum_{j=1}^{3} y_{i, j}^{\prime} / \frac{1}{4} \sum_{j=1}^{2} \sum_{k=1}^{2} \frac{y_{j, k}^{\prime}}{\Phi_{j}} .
$$

A two standard deviation of the luminous flux values of each test lamp in the three lightings is calculated and included in the uncertainty for the calibration. The voltage across the lamp socket is reported only for reference information because the measured voltage usually does not reproduce well on other sockets used by customers.

\subsection{Uncertainty of calibration}

The uncertainty budgets for the luminous flux calibration of incandescent lamps and of $4 \mathrm{ft}$ linear fluorescent lamps are shown in Table 11 and Table 12, respectively. 
Table 11. Uncertainty budget for total luminous flux calibrations of standard incandescent lamps (typical)

\begin{tabular}{|c|c|c|}
\hline \multirow[t]{2}{*}{ Uncertainty factor } & \multicolumn{2}{|c|}{$\begin{array}{c}\text { Relative expanded } \\
\text { ncertainty }(k=2)[\%]\end{array}$} \\
\hline & Type A & Type B \\
\hline NIST luminous flux unit (primary/working standard lamps) & & 0.53 \\
\hline Aging of the working standard lamps between calibrations & & 0.30 \\
\hline \multicolumn{3}{|l|}{ Transfer from working standards to test lamps: } \\
\hline Geometric differences & & 0.30 \\
\hline Self-absorption correction & 0.10 & \\
\hline Spectral mismatch correction & & 0.20 \\
\hline Reproducibility of test lamps (typical)** & 0.20 & \\
\hline Overall uncertainty of test lamp calibration with respect to $S$ & \multicolumn{2}{|c|}{0.74} \\
\hline
\end{tabular}

Table 12. Uncertainty budget for total luminous flux calibrations of $4 \mathrm{ft}$ linear fluorescent lamps (typical)

\begin{tabular}{|c|c|c|}
\hline \multirow[t]{2}{*}{ Uncertainty factor } & \multicolumn{2}{|c|}{$\begin{array}{l}\text { Relative expanded } \\
\text { uncertainty }(k=2) \quad[\%]\end{array}$} \\
\hline & Type A & Type B \\
\hline NIST luminous flux unit (primary/working star & mps) & 0.53 \\
\hline Aging of the working standard lamps between & ons & 0.30 \\
\hline \multicolumn{3}{|c|}{ Transfer from working standards to test lamps consists of: } \\
\hline Geometric differences & & 0.30 \\
\hline Self-absorption correction & 0.10 & \\
\hline Spectral mismatch correction & & 0.20 \\
\hline Current variation $( \pm 0.2 \%)$ & 0.20 & \\
\hline Temperature variation $\left( \pm 1^{\circ} \mathrm{C}\right)$ & 0.50 & \\
\hline Reproducibility of test lamps (typical)** & 1.50 & \\
\hline \multicolumn{3}{|c|}{$\begin{array}{ll}\text { Overall uncertainty of test lamp calibration with respect to SI } & \mathbf{1 . 7 5}\end{array}$} \\
\hline
\end{tabular}




\section{Luminance calibrations}

\subsection{NIST luminance unit}

Luminance units are commonly established using a white reflectance standard or a transmitting diffuser illuminated by a luminous intensity standard lamp [35]. The determination of the luminance factor of the material includes comparison of the incident and outgoing illuminances, which differ by three to four orders of magnitude, and which makes precise calibration difficult. The uncertainty is also limited by that of the standard lamp used.

Using the NIST standard photometers, a detector-based luminance unit is realized on a reference integrating-sphere source operated at $2856 \mathrm{~K}$. Figure 24 shows the arrangement. The sphere source is $15 \mathrm{~cm}$ in diameter and has a $V(\lambda)$-corrected monitor detector on the sphere wall. The source has a double sphere structure, the large sphere being irradiated by an intermediate $5 \mathrm{~cm}$ sphere which is irradiated by a quartz halogen lamp. The sphere source is operated by a constant-current power supply. Precision apertures of $6 \mathrm{~mm}$ and $21 \mathrm{~mm}$ diameter were attached, alternately, to the exit port (50 mm diameter) of the sphere source. The sphere source and the photometers are placed on the photometry bench (see 3.3.1) in a light tight box to reduce stray light. The illuminances at $2 \mathrm{~m}$ from the sphere source are measured by the eight NIST standard photometers that hold the illuminance unit. The distance is measured from the front surface of the aperture by using a length gage. The sphere source is allowed to stabilize for $60 \mathrm{~min}$ before calibration since the responsivity of the monitor detector drifts as the sphere warms up.

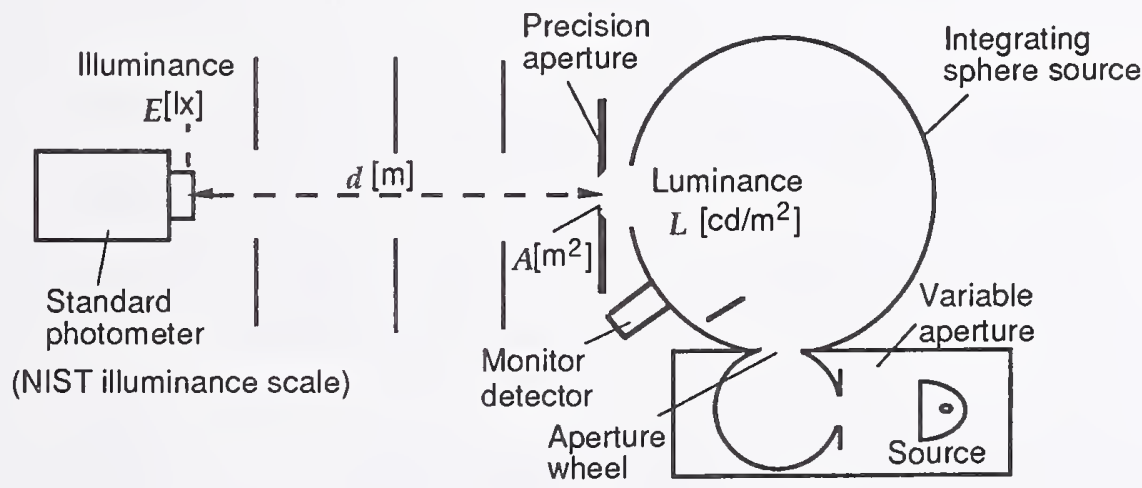

Figure 24 Arrangement for NIST luminance unit realization.

The average luminance $L \quad\left(\mathrm{~cd} / \mathrm{m}^{2}\right)$ over the aperture plane is determined from the illuminance $E(\mathrm{~lx})$, the distance, $d(\mathrm{~m})$, and the aperture area, $A\left(\mathrm{~m}^{2}\right)$, as given by

$$
L=k E d^{2} / A,
$$


where $k$ is a geometrical correction factor determined by the radius, $r_{\mathrm{a}}$, of the aperture, the radius, $r_{\mathrm{d}}$, of the detector sensitive area, and the distance, $d$, as given by

$$
k=1+\left(\frac{r_{\mathrm{a}}}{d}\right)^{2}+\left(\frac{r_{\mathrm{d}}}{d}\right)^{2} \quad ; r_{\mathrm{a}}, r_{\mathrm{d}}<\frac{d}{10}
$$

The error, $1-k$, is negligible with distance $d=2 \mathrm{~m}$. The data with the $21 \mathrm{~mm}$ aperture are corrected for the interreflections (between the sphere and the aperture) and the spatial nonuniformity of the luminance, and converted into values equivalent to the $6 \mathrm{~mm}$ aperture condition. Therefore, the luminance is determined for a circular area of $6 \mathrm{~mm}$ diameter on the center of the exit port. The diffraction loss with the aperture [40] is calculated to be negligible $(<0.01 \%)$ in the geometry used in this measurement. When the luminance, $L$, is determined, the monitor detector signal, $y$, is recorded, and the monitor detector responsivity, $R_{\mathrm{LUM}} \mathrm{A} /\left(\mathrm{cd} / \mathrm{m}^{2}\right)$, is determined.

For routine calibrations of luminance when a luminance surface with larger area is needed, the precision aperture is removed from the sphere source, and the sphere port can be full open (50 $\mathrm{mm}$ diameter) or equipped with another aperture ( $25 \mathrm{~mm}$ diameter). In these cases, the luminance changes due to the interreflections between the aperture surface, and the sphere wall. This change of luminance is determined by the signal from the monitor detector installed on the sphere wall. The correction factors are obtained for each condition. The average luminance over the exit port or $25 \mathrm{~mm}$ aperture is calculated from the spatial distributions of the luminance. The ratio of the center luminance versus the average luminance is obtained and used as a correction factor.

Table 13. Uncertainty budget for the NIST luminance unit realization

\begin{tabular}{lcc}
\multicolumn{1}{c}{ Uncertainty factor } & \multicolumn{2}{c}{$\begin{array}{c}\text { Relative expanded } \\
\text { uncertainty } \\
\text { Type A }\end{array}$} \\
$\begin{array}{lcc}\text { Type B } \\
\text { Ty }\end{array}$ \\
\hline NIST illuminance unit realization & 0.38 \\
Long-term drift of the average of 5 standard photometers & 0.10 \\
Determination of the spectral mismatch correction factor & 0.04 \\
Distance measurement (0.5 mm in 2 m) & 0.05 \\
Aperture area & \multicolumn{2}{c}{0.20} \\
Stray light in luminous intensity measurement & 0.10 \\
Drift of the sphere source during calibration & 0.10 \\
Reproducibility of the sphere source & 0.16 \\
Total uncertainty of the luminance unit realization & \multicolumn{2}{c}{$\mathbf{0 . 4 9}$} \\
\hline
\end{tabular}


The luminance unit is realized annually using the same procedures, and maintained by the responsivity, $R_{\mathrm{LUM}}$, of the monitor detector. The color temperature of the sphere source is also calibrated annually. The unit is transferred to a reference luminance meter used as a working standard for routine calibrations. The uncertainty budget for the NIST luminance unit realization is shown in Table 13.

\subsection{Artifacts of calibration}

Commercially available luminance sources and luminance meters of various types, submitted by the customers, are accepted for calibration at NIST. For sphere sources, operating current or voltage, or a set point for the monitor detector, and the stabilization time must be specified by customer. The customers are responsible for ensuring stability of the sources. For luminance meters, luminance levels and measurement angles must be specified for calibration. The luminance range for calibration is $1 \mathrm{~cd} / \mathrm{m}^{2}$ to $4000 \mathrm{~cd} / \mathrm{m}^{2}$.

NIST issues opal glasses calibrated for luminance coefficient (ratio of luminance to illuminance), and recalibrates submitted opal glasses. The opal glass issued by NIST is $50 \mathrm{~mm} \mathrm{x}$ $50 \mathrm{~mm}$ in size and $3 \mathrm{~mm}$ in thickness. It has a diaphragm of $25 \mathrm{~mm}$ diameter attached on the flashed side of the opal glass.

In general, use of opal glass requires a luminous intensity standard lamp and a photometric bench (distance measurement capability) in a dark room. Sphere sources usually do not need such facilities (of course, ambient light must be reduced) and are more convenient in terms of instrumentation. Use of sphere sources with a monitor detector is highly recommended because the monitor detector can maintain the scale more stably than the lamp of the source (almost regardless of the operating time of the source). If there is no monitor detector, it is recommended that the source be recalibrated after every $50 \mathrm{~h}$ of use. The luminance of typical commercial sphere sources can change (decrease) by $1 \%$ to $2 \%$ and color temperature by $10 \mathrm{~K}$ to $20 \mathrm{~K}$ per $100 \mathrm{~h}$ of operation at $2856 \mathrm{~K}$. It should be noted, however, that a sphere monitor detector, without temperature control, can drift by $\sim 0.5 \%$ during the first hour while the sphere warms up. It should also be noted that the sphere coating or the monitor detector will be contaminated or degraded after use or storage of a long period of time. Even when the scale is maintained on the monitor detector or when the source is not used, it is recommended that the sphere source be calibrated yearly. The exit port of the sphere source should always be capped when not used, and care exercised to monitor dust-free optical surfaces.

\subsection{Equipment for calibration}

The integrating sphere source shown in Figure 24 and a referenceluminance meter are used in the luminance calibration. The integrating sphere source is described in 6.1. The reference luminance meter has measurement angles of $6^{\prime}, 20^{\prime}, 1^{\circ}$, and $3^{\circ}$. The luminance meter is equipped with a $3 \frac{1}{2}$ digit display and an analog output, the voltage of which is measured with a 
$61 / 2$ digit DVM. The stray light error (due to the surrounding field outside the measured area) of this luminance meter was checked according to the CIE Pub. 69 [35] and found to be less than $0.1 \%$. Figure 25 shows the relative spectral responsivity of the luminance meter measured at the Spectral Comparator Facility [25]. The $\mathrm{f}_{1}{ }^{\prime}$ value [35] derived from the data is $2.1 \%$.

A spectroradiometer described in 7.4 is used to measure the color temperature of the sphere sources or spectral distribution of sources with phosphor simulation filters.

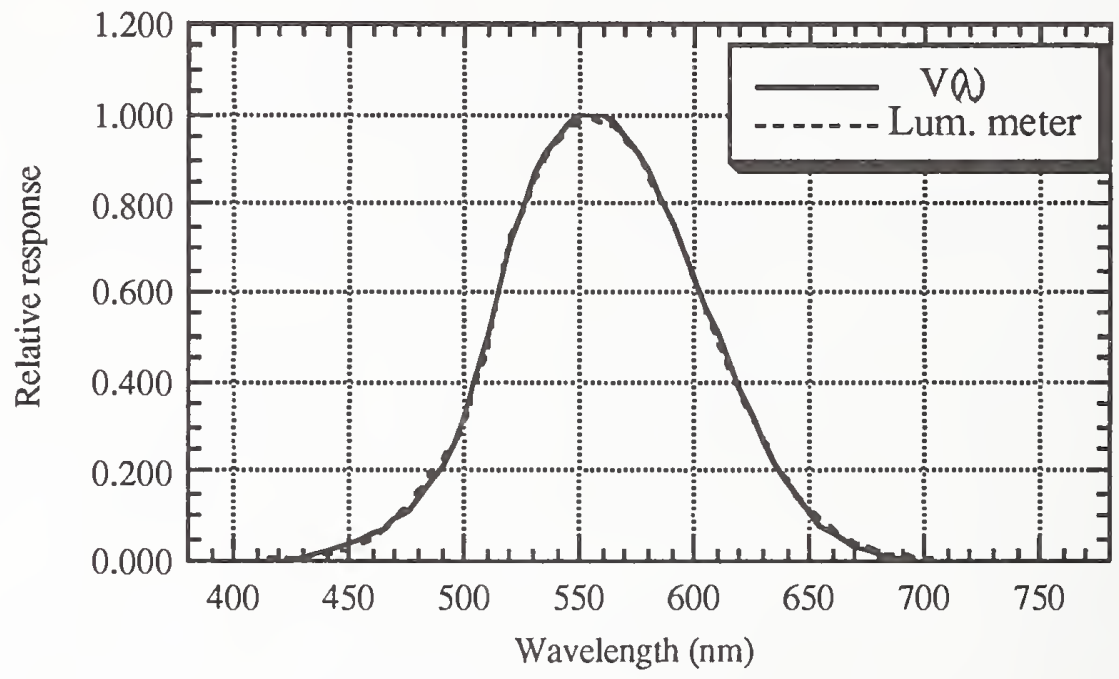

Figure 25 Relative spectral responsivity of the reference luminance meter.

\subsection{Calibration of luminance sources}

Luminance sources under test are calibrated against the reference sphere source described in 6.1 using the following procedures. Prior to calibration, the reference sphere source is turned on and stabilized for $1 \mathrm{~h}$, and the reference luminance meter described in 6.3 is calibrated against the luminance value indicated by the monitor detector signal of the sphere source. At this time, the value from the monitor detector is cross-checked by the value of the reference luminance meter.

The sphere source under test is aligned using a laser beam, so that the center of the exit port of the source is on the optical axis, and so that the front surface around the exit port is normal to the optical axis. The reference luminance meter is placed on the optical axis at $1 \mathrm{~m}$ to $3 \mathrm{~m}$ from the source depending on the measurement area. The measurement area is usually a circular area of $8 \mathrm{~mm}$ in diameter (distance is $1.5 \mathrm{~m}$ ) unless requested otherwise. The measurement angle of the reference luminance meter is usually $20^{\prime}\left(1 / 3^{\circ}\right)$. The luminance meter is focused on the plane of the exit port.

The test source is turned on and allowed to stabilize for the time period specified by the customer. The room temperature during the calibration is usually $\sim 24^{\circ} \mathrm{C}$. The mean value of 
several readings is reported.

The color temperature of the source is also measured using the facilities and procedures described in Section 7 to obtain a spectral mismatch correction factor (See 3.1.4). Equation (12) is used for ordinary sphere sources, and eq (11) is used for sphere sources with phosphor simulation filters.

The relative expanded uncertainty $(k=2)$ of the luminance source calibration is typically $0.7 \%$, and depends on the test item and measurement conditions. The uncertainty budget is shown in Table 14.

Table 14. Uncertainty budget for luminance source calibrations (typical)

\begin{tabular}{|c|c|c|}
\hline \multirow[t]{2}{*}{ Uncertainty factor } & \multicolumn{2}{|c|}{$\begin{array}{c}\text { Relative expanded } \\
\text { uncertainty }(k=2) \quad[\%]\end{array}$} \\
\hline & & Type B \\
\hline The NIST luminance unit realization & & 0.49 \\
\hline Long-term drift of the reference luminance source & & 0.30 \\
\hline \multicolumn{3}{|l|}{ Uncertainty in transfer to the test instrument composed of: } \\
\hline Range calibration of the reference luminance meter & & 0.15 \\
\hline Out-of-field sensitivity of the reference luminance meter & 0.10 & \\
\hline Spatial nonuniformity of the reference sphere source & & 0.15 \\
\hline Alignment of the measured spot $(1 \mathrm{~mm})$ to the center & 0.10 & \\
\hline Spectral mismatch correction for the test source & & 0.10 \\
\hline Stability of the test source during calibration (typical) & 0.20 & \\
\hline Overall uncertainty of the calibration with respect to SI & & 67 \\
\hline
\end{tabular}

\subsection{Calibration of luminance meters}

A luminance meter under test is calibrated against the reference luminance source (described in 6.3) operated at $2856 \mathrm{~K}$ using the following procedures. Prior to calibration, the reference sphere source is turned on and allowed to stabilize for $1 \mathrm{~h}$, and the luminance value determined from the monitor detector signal is cross-checked by the value of the reference luminance meter.

The reference sphere source is aligned so that the center of the exit port of the source is on the optical axis, and that the front surface around the exit port is normal to the optical axis. The luminance meter under test is placed and aligned on the optical axis, using a laser beam, at $1 \mathrm{~m}$ to $3 \mathrm{~m}$ from the source depending on the measurement angle of the luminance meter. If the measurement area is more than $10 \mathrm{~mm}$ in diameter on the exit port of the reference sphere source, the luminance value is corrected for the spatial nonuniformity. The luminance meter is focused on the plane of the exit port, aiming at the center of the exit port of the reference sphere source. 
The luminance values indicated by the luminance meter under test are compared with the luminance values determined from the monitor detector signal of the reference sphere source. The room temperature at calibration is usually $\sim 24^{\circ} \mathrm{C}$.

Luminance meters used for particular sources other than incandescent sources can be calibrated for those specific sources (e.g., color displays) upon request by customers. In this case, the calibration is first performed using the $2856 \mathrm{~K}$ source as described above. Then, the spectral mismatch correction factors for the sources are obtained using the following procedures.

The relative spectral responsivity of the NIST luminance meter is measured by the Spectral Comparator Facility [25] in the $350 \mathrm{~nm}$ to $1100 \mathrm{~nm}$ region. The monochromator output of the SCF is defocused on an PTFE (polytetrafluoroethylene) plaque to irradiate an area of several $\mathrm{mm}$ in diameter. The luminance meter under test is placed so that it will measure the luminance of the spot on the PTFE plaque at 0/45 geometry, and that the irradiated spot underfills the measurement area of the luminance meter. This method can only be applied for luminance meters whose relative spectral responsivity is fairly spatially uniform within the measurement angle. From the relative spectral responsivity data and the spectral power distribution data (supplied by customer) of the light sources to be measured by the luminance meter, the spectral mismatch correction factors are calculated using equation (11) as described in 3.1.4. The relative spectral responsivity data and the correction factors are reported to the customer.

The uncertainty budget for the calibration of a typical luminance meter is shown in Table 15. This budget does not include the uncertainty factor for the out-of-field sensitivity of

Table 15. Uncertainty budget for luminance meter calibrations (typical)

\begin{tabular}{|c|c|c|}
\hline \multirow[t]{2}{*}{ Uncertainty factor } & \multicolumn{2}{|c|}{$\begin{array}{l}\text { Relative expanded } \\
\text { ncertainty }(k=2)[\%]\end{array}$} \\
\hline & Type A & Type B \\
\hline The NIST luminance unit realization & & 0.49 \\
\hline Long-term drift of the reference luminance source & & 0.30 \\
\hline \multicolumn{3}{|l|}{ Transfer to the luminance meter under test: } \\
\hline Spatial nonuniformity of the reference luminance source ${ }^{* 1}$ & & 0.10 \\
\hline Alignment of the measured spot $(1 \mathrm{~mm})$ to the center & 0.10 & \\
\hline Inconsistency of the calibration factors at different levels ${ }^{* 2}$ & & 0.20 \\
\hline Display resolution of the test luminance meter ${ }^{* 2}$ & 0.20 & \\
\hline Overall uncertainty of the calibration with respect to $\mathrm{SI}^{* 3}$ & \multicolumn{2}{|c|}{0.66} \\
\hline
\end{tabular}

*1 Depends on the measurement angle of the test instrument

*2 Depends on the test instrument

*3 Out-of-field responsivity of the test instrument is not included in this budget. 
the test instrument. If the luminance meter's out-of-field blocking is poor, the responsivity of the instrument is affected by the illuminance of the area outside the measurement angle. Therefore, the calibration value is reported with the measurement geometry used at the calibration, and may not be valid with other geometry.

\subsection{Calibration for luminance coefficient opal glass}

\subsubsection{Calibration procedures}

An opal glass under test is calibrated for luminance coefficient (ratio of luminance to illuminance, unit $\left[\mathrm{sr}^{-1}\right]$ ) of diffuse transmission, by comparison with three reference opal glass standards. The reference opal glasses are calibrated by directly measuring the incident illuminance by using the NIST standard photometers (See 3.1), and the transmitted luminance on the opal glass surface by using a reference luminance meter which is calibrated against the NIST luminance unit. When the illuminance, $E[\mathrm{~lx}]$, and the luminance, $L[\mathrm{~cd} / \mathrm{m} 2]$, are measured, the luminance coefficient, $q\left[\mathrm{sr}^{-1}\right]$, of the opal glass is given by,

$$
q=L / E
$$

Figure 26 shows the arrangement for opal glass calibration. All the instruments are placed on the photometry bench (See 3.3.1) in a light tight box. The reference opal glasses and the opal glass under test are placed alternately and irradiated by a $1000 \mathrm{~W}$ frosted quartz halogen lamp operated at a color temperature of $2856 \mathrm{~K}$ (unless otherwise stated in the report) at a distance of approximately $2 \mathrm{~m}$ from the opal glass. A reference luminance meter is placed at $\sim 1.5 \mathrm{~m}$ from the opal glass. The centers of the lamp filament, the opal glass, and the luminance meter lens are aligned on the optical axis. The opal glasses are placed with the aperture side facing the luminance meter. The glass surface is aligned to be perpendicular to the optical axis.

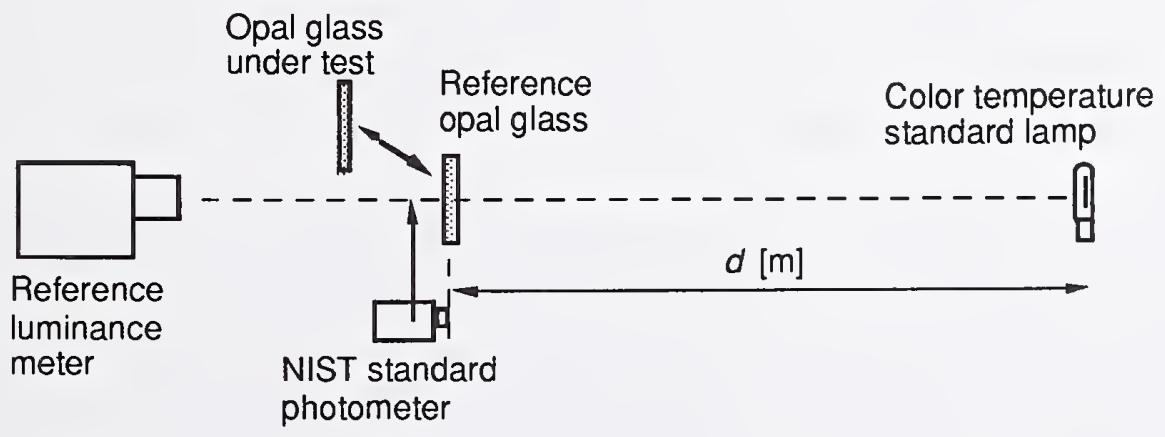

Figure 26 Configuration for opal glass calibration. 
The luminance meter is aimed at the center of the circular apertured area and set to a measurement angle of $20^{\prime}(1 / 3)^{\circ}$. With these dimensions, the luminance of the center area of $9 \mathrm{~mm}$ in diameter is measured. The luminance coefficient of the opal glass under test is calculated by comparison to the reference opal glasses.

It should be noted that the color temperature of the transmitted light is shifted due to the spectral transmittance of the opal glass and decreases typically by $100 \mathrm{~K}$ to $200 \mathrm{~K}$. As an option, if a set of a luminous intensity standard lamp and an opal glass are submitted for calibration, the operating current of the lamp can be set so that the transmitted light from the opal glass produces color temperature of $2856 \mathrm{~K}$ (See Section 7 for color temperature calibration), and the luminance coefficient of the opal glass can be calibrated under that condition.

\subsubsection{Use of opal glass standards for luminance coefficient}

NIST issues opal glasses of $50 \mathrm{~mm}$ square, $3 \mathrm{~mm}$ thick, having an aperture of $25 \mathrm{~mm}$ in diameter, as calibrated standards for luminance coefficient. A luminance standard can be obtained by combining these standards and an incandescent lamp operated at approximately $2856 \mathrm{~K}$. The opal glass should be placed so that the transparent glass side (with no aperture) faces the lamp. The luminance standard will be on the opal side with the aperture. The luminance, $L\left[\mathrm{~cd} / \mathrm{m}^{2}\right]$, of the illuminated opal glass is obtained by

$$
L=q \cdot E,
$$

where $q$ is the luminance coefficient $\left[\mathrm{sr}^{-1}\right]$ and $E$ is the illuminance $[\mathrm{lx}]$ on the reference plane of the opal glass. The reference plane is $2 \mathrm{~mm}$ inside from the surface of the transparent glass side. Illuminance $E$ can be measured by placing a standard photometer on the reference plane of the opal glass. Illuminance $E$ can also be determined by using a luminous intensity standard lamp applying the inverse square law. In this case the distance should be measured from the reference plane of the opal glass.

It is recommended that distance, $d$, be greater than $1 \mathrm{~m}$ because a small distance error creates a large luminance error at shorter distances. It should be noted that the luminance coefficient, $q$, is calibrated for the central $9 \mathrm{~mm}$ diameter area of the opal glass (unless otherwise stated in the calibration report) and in the direction normal to the opal surface. Luminance may vary up to $\pm 1 \%$ typically, outside that central area. Luminance may also vary if viewed at different angles.

An opal glass is sensitive to stray light on both sides of the glass. Extreme care should be taken to minimize ambient reflection from both the front side and the back side. It is important that an opal glass is illuminated uniformly over its entire surface area, since light incident on one part of the glass affects to luminance on other parts by volume diffusion. For example, a holder for the glass should not block the light falling on the edges of the glass. No labels should be affixed on the glass surface after calibration. The calibration will not be valid if the aperture is removed from the opal glass or if the black coating around the edges of the glass is removed. 


\subsubsection{Uncertainty of calibration}

The uncertainty budget for calibration of NIST-issued opal glasses is shown in Table 16. For calibration of customer-submitted opal glasses of sizes different from the reference opal glasses, additional uncertainty factors such as (1) difference in stray light around the opal glass, (2) Calibration to different angle $\left(3^{\circ}\right.$ or $\left.0.1^{\circ}\right)$ of the reference luminance meter, (3) nonuniformity of illuminance field, are taken into account.

Table 16. Uncertainty budget for opal glass calibrations

\begin{tabular}{|c|c|c|}
\hline \multirow[t]{2}{*}{ Uncertainty factor } & \multicolumn{2}{|c|}{$\begin{array}{c}\text { Relative expanded } \\
\text { uncertainty }(k=2)[\%]\end{array}$} \\
\hline & Type A & Type B \\
\hline \multicolumn{3}{|c|}{ Uncertainty of the reference opal glass standards composed of: } \\
\hline \multicolumn{2}{|c|}{ Luminance unit with respect to NIST illuminance unit (See 6.1) } & 0.30 \\
\hline \multicolumn{2}{|c|}{ Luminance measurement with respect to NIST luminance scale } & 0.20 \\
\hline \multicolumn{2}{|c|}{ Illuminance measurement with respect to NIST illuminance scale } & 0.13 \\
\hline Opal glass position relative to the reference plane & 0.04 & \\
\hline Stray light around the opal glass & & 0.10 \\
\hline \multicolumn{3}{|l|}{ Uncertainty in transfer to test opal glass composed of: } \\
\hline Drift of the standard lamp during calibration & 0.10 & \\
\hline Orientation alignment of the opal glass & 0.20 & \\
\hline Position alignment of the opal glass $(0.5 \mathrm{~mm}$ in $2 \mathrm{~m})$ & 0.05 & \\
\hline Overall uncertainty of the luminance coefficient calibration & & 0.46 \\
\hline
\end{tabular}




\section{Color temperature calibrations}

\subsection{General descriptions}

Color temperature is a concept used to express the color of a light source in a simple manner using just one number. According to CIE [15], color temperature is defined as "the temperature of a Planckian radiator whose radiation has the same chromaticity as that of a given stimulus." The spectral power distribution of the test source is not necessarily identical or even similar to that of a blackbody. Strictly speaking, however, the chromaticity coordinate of most of the light sources including incandescent lamps do not fall on the blackbody locus. The CIE definition does not say how close the chromaticity should be to be considered as "the same." Therefore, the definition of color temperature is somewhat vague, and this term is considered to be a general term to introduce the concept.

For practical calibration of sources used in photometry, either "distribution temperature" or "correlated color temperature" is used. Another similar concept is a radiance temperature, which is defined as "Temperature of the Planckian radiator for which the radiance at the specified wavel ength has the same spectral concentration as for the thermal radiator considered" [15]. Radiance temperature is used only for blackbodies and transfer lamps to blackbodies.

Distribution temperature is defined as "Temperature of the Planckian radiator whose relative spectral distribution $S_{t}(\lambda)$ is the same or nearly the same as that of the radiation considered in the spectral range of interest" by CIE [15]. Practically speaking, distribution temperature is a concept to represent the relative spectral power distribution of a near Planckian source, such as an incandescent lamp, by one number. CIE [45] gives more precise definition of distribution temperature $\left(T_{\mathrm{d}}\right)$ given by the equation;

$$
\begin{aligned}
& \text { minimum } \int_{\lambda_{1}}^{\lambda_{2}}\left[1-S_{\mathrm{t}}(\lambda) / a S_{\mathrm{b}}\left(\lambda, T_{\mathrm{d}}\right)\right]^{2} \mathrm{~d} \lambda \\
& \text { where } S_{\mathrm{b}}\left(\lambda, T_{\mathrm{d}}\right)=\lambda^{-5}\left[\exp \left(c_{2} / \lambda T_{\mathrm{d}}\right)-1\right]^{-1}
\end{aligned}
$$

The distribution temperature of the source $S_{\mathrm{t}}(\lambda)$ is the temperature $T$ of the Planckian radiation $S_{\mathrm{b}}(\lambda, T)$ when the value of equation (43) is minimized. CIE also specifies that the wavelength region shall be $380 \mathrm{~nm}$ to $780 \mathrm{~nm}$, and the wavelength interval for calculation shall be less than $10 \mathrm{~nm}$. It is also specified that the difference of the relative spectral power distribution of the radiation considered and that of a Planckian radiation should be less than $10 \%$ in order to use distribution temperature.

Correlated color temperature $\left(T_{\mathrm{cp}}\right)$ is used for sources whose spectral power distribution is significantly different from that of Planckian radiation; such as discharge lamps. Correlated color temperature is defined as "Temperature of the Planckian radiator whose perceived color most closely resembles that of a given stimulus at the same brightness and under specified 
viewing conditions" [15]. Practically, correlated color temperature is obtained from the chromaticity coordinate (on the CIE $1960 \mathrm{u}, \mathrm{v}$ diagram) of the point on the Planckian locus which is at the closest distance from that of the light source in question [46].

If the relative spectral power distribution of the given radiation is identical to that of the Planckian radiator, the values of color temperature, distribution temperature, and correlated color temperature will be all the same. The differences between distribution temperature and correlated color temperature for typical incandescent lamps are only $2 \mathrm{~K}$ or $3 \mathrm{~K}$, but can be much larger depending on lamp type.

\subsection{NIST color temperature scale}

NIST has traditionally used the term "color temperature" for incandescent lamps even though their chromaticity coordinates are not exactly the same as the Planckian radiator. The NIST color temperature scale is based on the computation of correlated color temperature from the relative spectral power distributions of sources.

The NIST color temperature scale is derived from the NIST spectral irradiance scale [20] which is based on the International Temperature Scale of 1990 [21]. The scale realization chain for the spectral irradiance scale and the color temperature scale is shown in Figure 27.

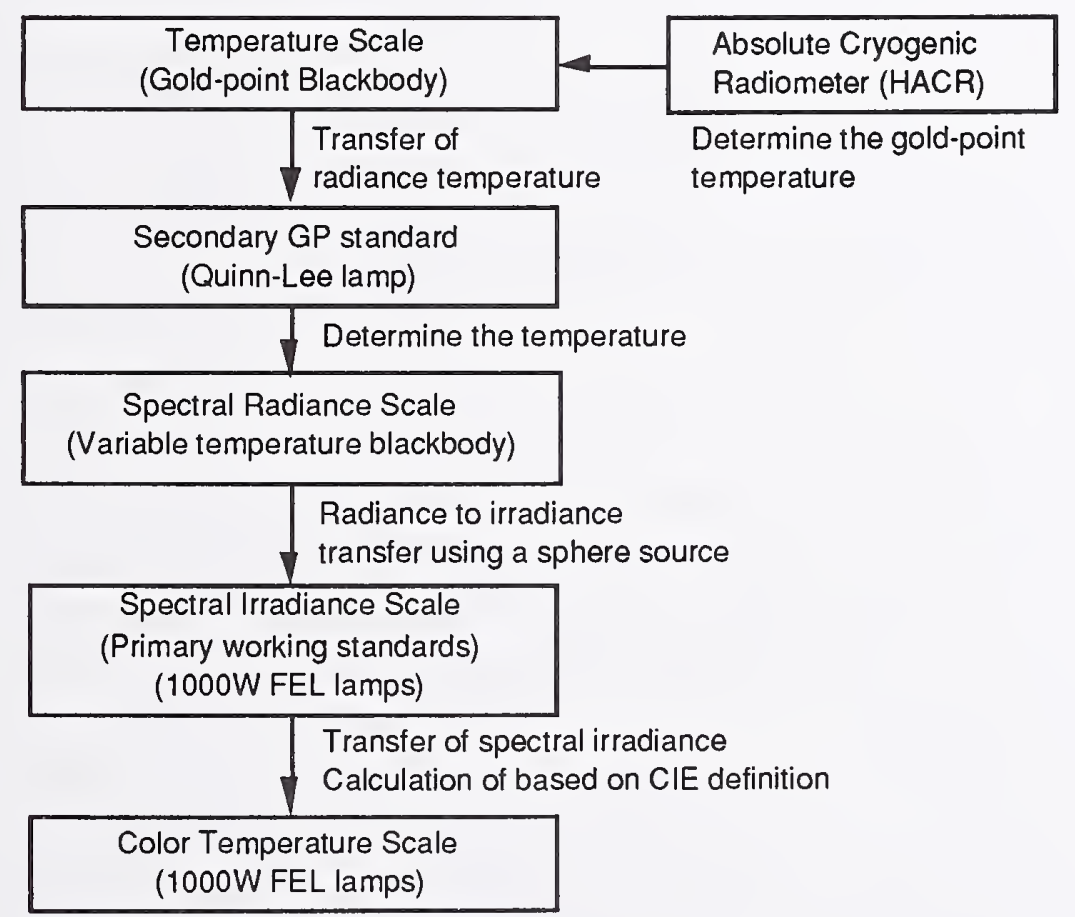

Figure 27 Realization of the NIST spectral irradiance scale and the color temperature scale. 
Three $1000 \mathrm{~W}$ FEL type quartz halogen lamps are maintained as the NIST color temperature primary standard lamps in the range of $2000 \mathrm{~K}$ to $3200 \mathrm{~K}$. These lamps have demonstrated stability of operation in this color temperature range [37]. The spectral irradiance of these lamps is calibrated periodically against the NIST spectral irradiance scale [20] at $2000 \mathrm{~K}, 2300 \mathrm{~K}$, $2600 \mathrm{~K}, 2856 \mathrm{~K}$, and $3200 \mathrm{~K}$. The correlated color temperatures of these lamps are computed from the spectral irradiance values according to the procedures recommended by reference [46]. The color temperature scale on these lamps are transferred to several other FEL type lamps and $200 \mathrm{~W}$ quartz halogen lamps for routine calibration work. A spectroradiometer described in Section 7.4 is used for the transfer measurements.

\subsection{Artifacts for calibration}

For many years in the past, NIST issued $500 \mathrm{~W}$ Airway Beacon lamps as color temperature standards. These lamps are still accepted for recalibration at NIST. These lamps have medium bi-post bases, clear bulbs, and $\mathrm{C}$-13B filaments. The lamp designation number is etched on the bulb. The appearance and the electrical polarity of this type of lamp is shown in Figure 10.

NIST now issues FEL type $1000 \mathrm{~W}$ quartz halogen lamps calibrated for color temperature. This is the same type of lamp used for luminous intensity standards as described in 3.2. The lamps are manufactured by Osram-Sylvania Inc., and potted on a medium bi-post base, and seasoned on DC power for at least $72 \mathrm{~h}$ at 7.2 A. Lamps are usually calibrated at a color temperature of $2856 \mathrm{~K}$, but can be used for color temperature standards in the range of $2000 \mathrm{~K}$ to $3200 \mathrm{~K}$. The operating current and voltage of the lamp are approximately $7.2 \mathrm{~A}$ and $85 \mathrm{~V}$ at $2856 \mathrm{~K}$. The lamp designation numbers and the electrical polarity are engraved on an identification plate affixed on the lamp base as shown in Figure $\mathbf{1 0 .}$

\subsection{Equipment for calibration}

Figure 28 shows the arrangement used for color temperature calibration. A PTFE plaque is placed in the photometry bench (described in 3.3.1). The plaque is placed approximately $1 \mathrm{~m}$ from the lamp, and irradiated at normal incidence. The diffuse reflection at $45^{\circ}$ is directed to a spectroradiometer. The plaque is mounted on a kinematic base, and can be removed when the luminous intensity is measured.

The spectroradiometer is a diode-array system, consisting of imaging optics in front, a single diffraction grating, and a cooled 256 element photodiode array, and is calibrated against the NIST spectral irradiance standards. This spectroradiometer has measurement angles of $0.125^{\circ}$ circular and $0.5^{\circ} \times 1.5^{\circ}$ rectangular. The rectangular aperture is used for color temperature calibrations. The short measurement time (normally less than $10 \mathrm{~s}$ ) of the spectroradiometer allows for the determination of the operating current of a lamp for a specified color temperature 
precisely within a few min, minimizing the labor time and the lamp burning time. The spectroradiometer is connected to a computer which calculates chromaticity coordinates and the correlated color temperature of the source almost instantly.

The red-blue ratio substitution method is commonly used for color temperature transfer measurements, but is not used at NIST. This method is liable to errors caused by even a slight difference in spectral emissivity of the test lamp and the standard lamp; for example when a gasfilled incandescent lamp is measured against a quartz-halogen standard lamp. A diode-array ty pe spectroradiometer gives better results in this respect.

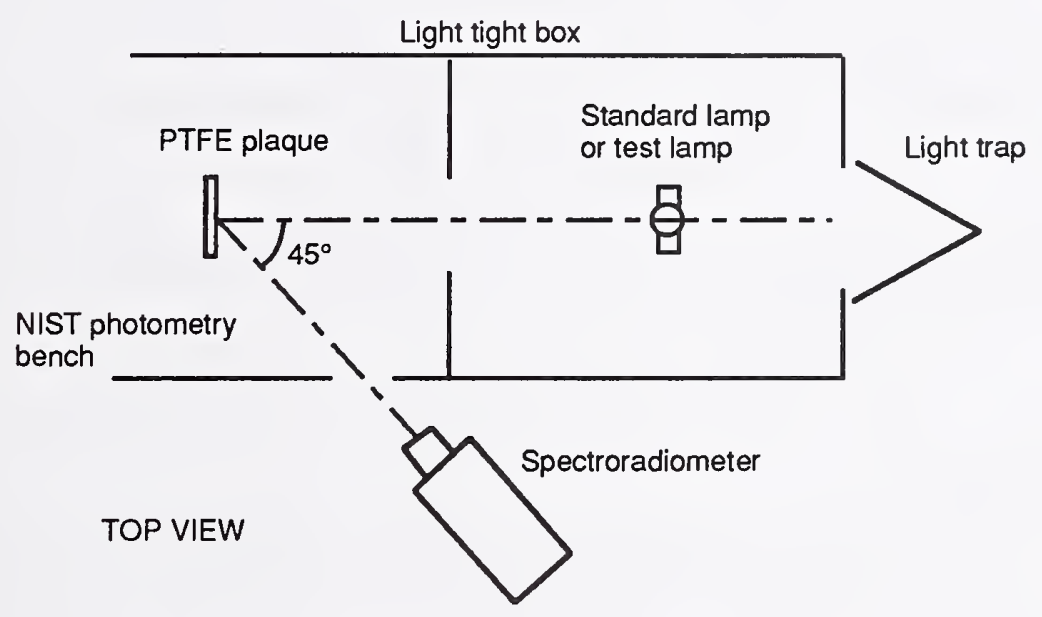

Figu re 28 Configuration for color temperature calibration.

This type of spectroradiometer, however, is subject to fairly large stray light errors due to a single diffraction grating installed in a compact unit. When the radiometer is calibrated using a $2856 \mathrm{~K}$ Planckian source, there will be errors when sources of different color temperatures are measured. For calibrations at NIST, therefore, this spectroradiometer is used basically to transfer the same color temperature from the standard lamp to the test lamp. For this reason, the color temperature standards for several different color temperatures are maintained.

Since the procedures for the spectral calibration of the instrument are not simple, and since the responsivity of the spectroradiometer is fairly stable over a long period of time, its internal calibration factors are calibrated only every 6 months. Instead, prior to each calibration of test lamps, the spectroradiometer's color temperature reading is calibrated by measuring two color temperature working standard lamps, and correction values as shown in Figure 29 is determined and applied to the measured values. If the measurement point lies between the calibration points of the standard lamps, the correction value is determined by interpolation based on the second order polynomial function. 


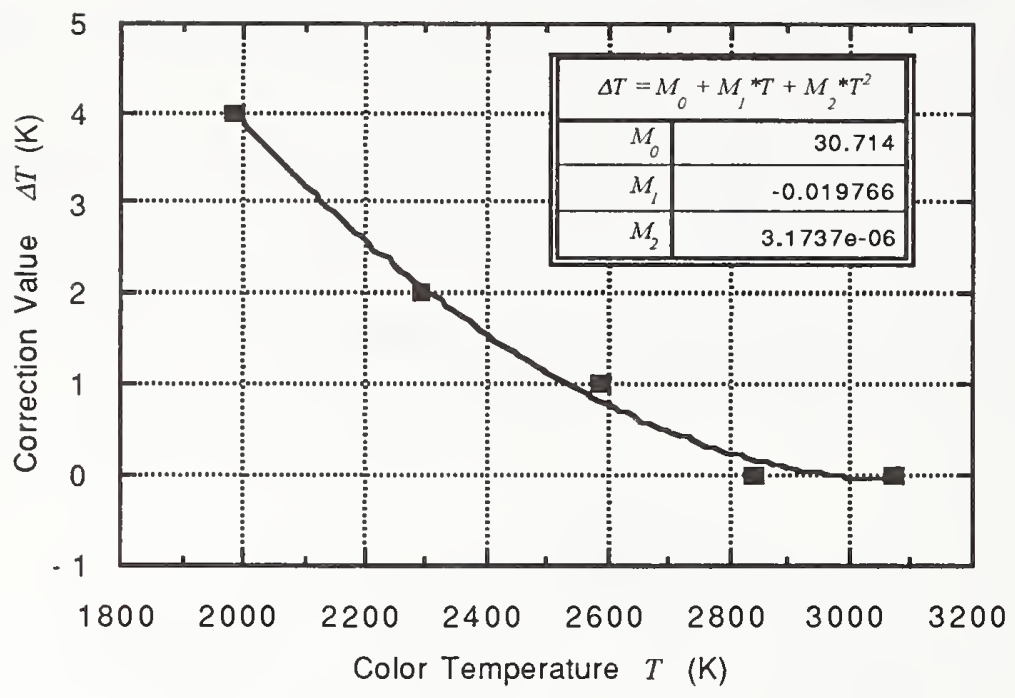

Figure 29 Color temperature correction values for the NIST diode-array spectroradiometer.

\subsection{Calibration procedures}

Prior to the measurement of test lamps, the spectroradiometer's color temperature reading is calibrated against two color temperature working standard lamps at the color temperature points required for the calibration. The test lamp is mounted on the photometry bench and aligned with the same procedure as the luminous intensity measurements. The lamp is operated in the base-down position, with the identifying number on the opposite side from the spectroradiometer. Lamp orientation is accomplished by aligning the lamp socket so that the lamp posts are held vertically, and the plane formed by the axes of the posts is perpendicular to the optical axis of the spectroradiometer. An alignmentjig (a mirror mounted on a bi-post base to be parallel to the plane formed by the axes of the posts) is used in combination with a laser and an end-viewing telescope. The distance from the lamp to the input optics (a PTFE plaque) of the spectroradiometer is approximately $1 \mathrm{~m}$.

The lamp is operated on DC power. The electrical polarity is marked on the identification plate of the lamp. The test lamp is slowly $(\sim 30 \mathrm{sec})$ ramped up to the specified current, and allowed to stabilize for at least ten minutes before calibration. When a lamp current is to be determined for a specified color temperature, the lamp current is adjusted repeatedly until the spectroradiometer indicates the specified color temperature. The lamp current and voltage are recorded when the lamp reaches that color temperature. When the same lamp is calibrated for different color temperatures, at least $3 \mathrm{~min}$ are allowed before any measurements after the lamp current is changed from one color temperature to another.

Color temperature calibrations at NIST are most often done at $2856 \mathrm{~K}$. Requests for calibration at any other color temperatures between $2000 \mathrm{~K}$ to $3200 \mathrm{~K}$ are accepted. 


\subsection{Uncertainty of calibration}

The NIST color temperature scale is derived from the NIST spectral irradiance scale [20]. The uncertainty of the color temperature scale, however, depends on the uncertainty of the relative spectral irradiance. According to Reference [20], the uncertainty of the spectral irradiance calibration on $1000 \mathrm{~W}$ FEL lamps with respect to the NIST spectral radiance scale is analyzed in Table 17.

Table 17. The uncertainty of the spectral irradiance calibration with respect to the NIST spectral radiance scale

\begin{tabular}{lccc}
\hline \multicolumn{4}{c}{ Relative expanded uncertainty $(\mathrm{k}=2)[\%]$} \\
\multicolumn{1}{c}{ Uncertainty factor } & \multicolumn{1}{c}{$350 \mathrm{~nm}$} & $655 \mathrm{~nm}$ & $900 \mathrm{~nm}$ \\
\hline Spectral radiance on the integrating sphere source & 0.28 & 0.17 & 0.23 \\
Radiance to irradiance transfer to FEL lamp* & 0.22 & 0.19 & 0.59 \\
Test lamp irradiance transfer & 0.15 & 0.11 & 0.28 \\
$\begin{array}{l}\text { Overall uncertainty of the spectral irradiance calibration } \\
\text { with respect to the NIST spectral radiance scale }\end{array}$ & 0.39 & 0.28 & 0.69 \\
\hline
\end{tabular}

* The time drift model uncertainty is not included.

The values shown in the table are regarded as the uncertainty of the relative spectral irradiance calibrations less the uncertainty of the spectral radiance scale on the variable temperature blackbody. The time drift model uncertainty included in Table V of Reference [20] is not included because this factor contributes mostly to the absolute irradiance and not to the relative spectral irradiance. To convert these uncertainty values of irradiance into an uncertainty value of color temperature, a worst case is assumed where the errors are at the high (low) end of the uncertainty at wavelengths shorter than $555 \mathrm{~nm}$ and at the low (high) end of the uncertainty at wavelengths longer than $555 \mathrm{~nm}$. This computation has the nature of a limit-of-error calculation and thus is approximately an estimate in an expanded uncertainty with coverage factor $k=3$. Therefore, the results are restated in an expanded uncertainty with coverage factor $k=2$, and are shown in Table 18. The overall uncertainty of the color temperature calibration is calculated as the quadrature sum of the uncertainty factors listed in this table. The NIST radiance temperature scale (on the variable temperature blackbody) is given in Reference [47]. 
Table 18. The uncertainty budget for the NIST color temperature calibration

\begin{tabular}{lccccc}
\hline \multicolumn{1}{c}{ Factor } & \multicolumn{5}{c}{ Expanded uncertainty $(k=2)$} \\
& $2000 \mathrm{~K}$ & $2300 \mathrm{~K}$ & $2600 \mathrm{~K}$ & $2856 \mathrm{~K}$ & $3200 \mathrm{~K}$ \\
\hline NIST radiance temperature scale & 0.8 & 1.0 & 1.3 & 1.5 & 1.9 \\
Relative spectral irradiance calibration & 3.0 & 4.1 & 5.3 & 6.4 & 7.9 \\
Transfer to working standard lamps & 1.0 & 1.0 & 1.0 & 1.0 & 1.0 \\
Aging of the working standard lamps & 1.4 & 1.9 & 2.5 & 3.0 & 3.6 \\
Reproducibility of working standards & 1.0 & 1.0 & 1.0 & 1.0 & 1.0 \\
Transfer to the test lamp & 1.0 & 1.0 & 1.0 & 1.0 & 1.0 \\
Reproducibility of test lamp & 1.0 & 1.0 & 1.0 & 1.0 & 1.0 \\
Overall uncertainty of calibration & 3.9 & 5.0 & 6.3 & 7.5 & 9.1 \\
\hline
\end{tabular}




\section{Future work}

\subsection{Total spectral radiant flux scale realization}

Total spectral radiant flux is the geometrically total radiant flux of a given bandwidth at a given wavelength. The unit is $\mathrm{W} / \mathrm{nm}$. This quantity is often used to evaluate the total power of light sources at given wavelengths, especially in UV and IR, or to determine the color of light sources. Total spectral radiant flux standards are most often used in an integrating sphere to calibrate a spectroradiometer which is connected to the integrating sphere. For color measurement, only the relative values of total spectral radiant flux are required.

At NIST, work is underway to establish a total spectral radiant flux scale based on the integrating sphere method described in Section 5.1. A double monochromator is installed at the NIST $2 \mathrm{~m}$ integrating sphere. A $1000 \mathrm{~W}$ FEL type lamp calibrated for spectral irradiance against the NIST spectral irradiance scale [20] is used as an external source. The distance from the lamp to the aperture is set to be exactly the same as that at the spectral irradiance calibration. The total spectral radiant flux $\Phi_{\mathrm{i}}(\lambda)$ of the internal source is then obtained by

$$
\Phi_{\mathrm{i}}(\lambda)=c(\lambda) S E(\lambda) y_{\mathrm{i}}(\lambda) / y_{\mathrm{e}}(\lambda)
$$

where $E(\lambda)$ is the average spectral irradiance ( $\mathrm{W} \mathrm{m}^{-2} \mathrm{~nm}^{-1}$ ) over the limiting aperture of known area $S\left(\mathrm{~m}^{2}\right), y_{\mathrm{e}}(\lambda)$ is the detector current for the external source, and $y_{\mathrm{i}}(\lambda)$ is the detector current for the internal source. $c(\lambda)$ is a correction factor which consists of the spatial nonuniformity correction and the incident angle dependence correction factor which are determined spectrally using the method described in subsections 5.1.3 and 5.1.4.

When the total spectral radiant flux is established in the nearfuture, NIST plans to start providing calibration services for this quantity from the near UV to near the IR region.

\subsection{Total luminous flux calibration of other discharge lamps}

At the time of publication, for total luminous flux, NIST routinely provides calibration services only for incandescent lamps and $4 \mathrm{ft}$ linear fluorescent lamps. Basically, NIST entrusts industrial laboratories to transfer the luminous flux unit of incandescent lamps (provided by NIST) to other discharge lamps by themselves. NIST develops calibration procedures for industrial laboratories to do such transfer measurement as accurately as possible by applying correction techniques. However, luminous flux standards of various types of discharge lamps are still needed in order to allow direct substitution measurements. Even though most of the discharge lamps are not satisfactory in terms of reproducibility of light output, NIST plans to expand the calibration services for several more types of discharge lamps, such as linear fluorescent lamps of other sizes, compact fluorescent lamps, and limited types of HID (High Intensity Discharge) lamps if they have acceptable reproducibility. 


\subsection{Issuing calibrated standard lamps}

As of September 1995, standard quality incandescent lamps for total luminous flux are not commercially available with reasonable cost. The luminous intensity standards issued by NIST are limited to $1000 \mathrm{~W}$ FEL type lamps. The unavailability of standard lamps is a worldwide concern. However, there is some hope that a few lamp companies are preparing to produce standard quality lamps again. When high quality lamps are available, NIST will investigate the stability and reproducibility of these newly available lamps, and if satisfactory, will plan to issue luminous flux standard lamps and more types of luminous intensity standard lamps.

\subsection{Flashing light standards}

All the photometric standards now available at NIST are in the form of steady light. NIST has entrusted flashing light industries to transfer from steady light standards (such as candela) to flashing light standards (such as candela'second). However, there are rather large uncertainties in the transfer measurements in industrial laboratories. Needs for much higher accuracies are addressed as the flashing light sources are used for safety purposes such as the anti-collision lights of aircraft. Driven by such circumstances, work on developing flashing light standards has started at NIST. A group of standard photometers to measure flashing light (in lux.second) will be developed, and NIST plans to start providing calibration services for submitted flashing light meters in the near future. 


\section{Acknowledgments}

There have been tremendous efforts by many staff members of Optical Technology Division in establishing the new photometric units and reconstructing the NIST photometry laboratory. Albert Parr and Chris Cromer developed the concept of the NIST detector-based candela, and established the project. George Eppeldauer played a key role in designing and constructing the NIST standard photometers and characterizing them. Jonathan Hardis contributed with theoretical studies and detailed analyses on the candela realization. Tom Larason contributed with the absolute spectral responsivity measurements, computer automation, and other calibration work. Jack Hsia, Robert Saunders and other staff members took time to review this document and gave precious discussions and comments. The author is very grateful to these and other staff members in the Division who have contributed to the recent photometry work. 


\section{References}

[1] Booker, R. L. and McSparron, D. A., Photometric Calibrations, NBS Special Publication 250-15 (1987).

[2] Cromer, C. L., Eppeldauer, G., Hardis, J. E., Larason, T. C. and Parr, A. C., National Institute of Standards and Technology detector-based photometric scale, Applied Optics 3216, 2936-2948 (1993).

[3] Ohno, Y., Cromer, C.L., Hardis, J.E., and Eppeldauer, G., The Detector-based Candela Scale and Related Photometric Calibration Procedures at NIST, J. IES, 23-1, 88-98 (1994).

[4] Taylor, B. N. and Kuyatt, C. E., Guidelines for Evaluating and Expressing the Uncertainty of NIST Measurement Results, NIST Techrical Note 1297 (1994).

[5] NIST Special Publication 250, NIST Calibration Services Users Guide (1996), to be published.

[6] CIE Compte Rendu, p.67, (1924).

[7] CIE Compte Rendu, Table II, pp.25-26 (1931).

[8] CIE Publication No.18.2, The Basis of Physical Photometry (1983).

[9] CIPM, Comité Consultatif de Photométrie et Radiométrie 10e Session-1982, Bureau International Des Poids et Mesures, Pavillon de Breteuil, F-92310, Sèvres, France (1982).

The same content is published in BIPM Monographie - Principles Governing Photometry (1983), Bureau International Des Poids et Mesures, Pavillon de Breteuil, F-92310, Sèvres, France.

[10] CIE Disk D001 Photometric and Colorimetric Tables (1988).

[11] CGPM, Comptes Rendus des Séances de la 16e Conférence Générale des Poids et Mesures, Paris 1979, p.100, Bureau International des Poids et Mesures, F-92310 Sèvres, France.

[12] CIE Compte Rendu, Vol. 3, Table II, pp.37-39 (1951).

[13] CIPM Procés-Verbaux 44, 4 (1976).

[14] CIE Publication No. 81, Mesopic photometry: History, special problems and practical solutions (1989).

[15] CIE Publication No.17.4, CIE International Lighting Vocaburary (1987).

[16] ISO, Quantities and units, ISO Standards Handbook, Third edition (1993).

[17] Taylor, B.N., Editor, NIST Special Publication 814, Interpretation of the SI for the United States and Metric Conversion Policy for Federal Agencies (1991).

[18] Taylor, B.N., NIST Special Publication 811, Guide for the use of the International System of Units (SI) (1995). 
[19] Lighting Handbook 8th Edition, Illuminating Engineering Society of North America, Apendix, pp. 946-949 (1993).

[20] Walker, J.H., Saunders, R.D., Jackson, J.K., and McSparron, D.A., Spectral Irradiance Calibrations, NBS Special Publication 250-20 (1987).

[21] Mielenz, K.D., Saunders, R. D., Parr, A. C., and Hsia, J. J., The new international temperature scale of 1990 and its effect on radiometric, photometric, and colorimetric measurements and standards, CIE Proceedings 22nd Session 1-1, Melbourne 1991, Div.2, 65-68 (1991).

[22] Gentile, T. R., Houston, J. M., Hardis, J. E., Cromer, C. L., and Parr, A. C., The NIST High-Accuracy Cryogenic Radiometr, Applied Optics 35-7, 1056-1068 (1996).

[23] Gentile, T. R., Houston, J. M., and Cromer, C. L., Realization of a scale of absolute spectral response uning the NIST High Accuracy Cryogenic Radiometer,Applied Optics 35-22, 4392-4403 (1996).

[24] Houston, J. M., Cromer, C. L., Hardis, J. E., and Larason, T. C., Comparison of the NIST High-Accuracy Cryogenic Radiometer and the NIST Scale of Detector Spectral Response, Metrologia 30-4, 285-290 (1993).

[25] Larason, T, et al, The NBS Photodetector Measurement Service, NIST Special Publication 250-17 (1996) to be published.

[26] CCPR Rapport de la 1le session 1986, BIPM, Pavillon de Breteuil, F-92312, Sèvres Cedex, France.

[27] Bonhoure, J., Photometric Standards of the National Laboratories, Metrologia 25, 125 (1988).

[28] Ohno, Y. and Sauter, G., 1993 Intercomparison of Photometric Units Maintained at NIST (USA) and PTB (Germany), J. Res. Natl. Inst. Stand. Technol. Vol.100, No.3, 227-239 (1995).

[29] Ohno, Y., Integrating Sphere Simulation - Application to Total Flux Scale Realization, Applied Optics, 33-13, 2637-2647 (1994).

[30] Ohno, Y., New Method for Realizing a Total Luminous Flux Scale using an Integrating Sphere with an External Source, J. IES, 24-1, 106-115 (1995).

[31] Ohno, Y., Realization of NIST 1995 Luminous Flux Scale using Integrating Sphere Method, J. IES, 25-1, 13-22 (1996).

[32] Ohno, Y., Realization of NIST Luminous Flux Scale Using an Integrating Sphere with an External Source, the CIE Proceedings, 23rd Session, New Delhi 1995.

[33] Eppeldauer, G. and Hardis, J.E., Fourteen-decade photocurrent measurements with largearea silicon photodiodes at room temperature, Applied Optics, 30-22, 3091-3099 (1991). 
[34] Eppeldauer, G., Temperature Monitored/Controlled Silicon Photodiodes for Standardization, in Surveillance Technologies, SPIE Proceedings 1479: $71-77$ (1991).

[35] CIE Publication No. 69, Methods of characterizing illuminance meters and luminance meters (1987).

[36] Thompson, A. and Chen, H., Beamcon III, a Linearity Measurement Instrument for Optical Detectors, J. Res. NIST, 99-6: 751-755 (1994).

[37] Ohno, Y. and Jackson, J. K., Characterization of modified FEL quartz-halogen lamps for photometric standards, Metrologia, 32-6, 693-696 (1996)

[38] CIE Publication No.84, Measuremetns of Luminous Flux (1987).

[39] Venable, W. H., Hsia, J. J., and Weidner, V. R., Establishing a Scale of DirectionalHemispherical Reflectance Factor I: The Van den Akker Method, J.R.NBS, 82-1:29-55 (1977)

[40] Blevin, W. R., Diffraction Losses in Radiometry and Photometry, Metrologia 7, 39-44 (1970)

[41] Ohno, Y., Lindemann, M., and Sauter, G., "Analysis of integrating sphere errors for lamps having different angular intensity distributions", 1996 IESNA Conference Proceedings: 895906 (1996)

[42] IES LM-9-1988, IES Approved Method for the Electrical and Photometric Measurements of Fluorescent Lamps.

[43] ANSI C78.1-1991, Rapid Start Types Dimensional and Electrical Characteristics.

[44] ANSI C82.2-1984, Fluorescent Lamp Ballasts - Methods of Mmeasurement.

[45] CIE Publication No.114, CIE Collection in Photometry and Radiometry (1994).

[46] CIE Publication No.15.2, Colorimetry- Second Edition (1986)

[47] Mielenz, K.D., Saunders, R. D., Parr, A. C., and Hsia, J. J., The 1990 NIST Scale of Thermal Radiometry, J. Res. NIST, 95-6, 621 (1990). 
Attached below is a reprint published by BIPM in 1988. Note that NIST (NBS then) and some other national laboratories revised their photometric units after this publication.

\title{
Letter to the Editor
}

Metrologia 25, 125 (1988)

\section{Photometric Standards of the National Laboratories}

\author{
J. Bonhoure \\ Bureau International des Poids et Mesures (BIPM), Pavillon de Breteuil, F-92312 Sèvres Cedex, France \\ Received: January 13, 1988
}

A new definition of the candela was adopted in 1979 by the 16th Conférence Générale des Poids et Mesures. After allowing time for the national laboratories to establish their own new realizations of the candela and the lumen, the Comite International des Poids et Mesures (CIPM) in 1985 organized international comparisons at the Bureau International des Poids et Mesures (BIPM) to check the uniformity of the results of photometric measurements obtained with the new definition of the candela. But, at the time of the comparisons, several national laboratories and the BIPM were continuing to base their calibration services on photometric standards that were not in agreement with the new definition of the candela.

The aim of Table 1 is to give a clear account of the present status of photometric standards used as the basis for calibration services.
In the left part of the table, we indicate whether the laboratory has, since the comparisons, adjusted the values attributed to its standards used for representing and disseminating the candela and the lumen, giving the date (column 2) and the magnitudes in \% of the adjustments (columns 3 and 4).

In the right part of the table, we indicate for each laboratory the differences between its adjusted values and the mean values of the 1985 comparisons. In fact, we give the values of the luminous intensity (column 5), or of the luminous Aux (column 6), attributed to a same fictitious standard of nominal value $1 \mathrm{~cd}$, or $1 \mathrm{~lm}$, which would be calibrated in all the laboratories. $1.000 \mathrm{~cd}$ and $1.000 \mathrm{~lm}$ correspond to the mean values of the 1985 comparisons.

Table 1.

\begin{tabular}{|c|c|c|c|c|c|}
\hline \multirow{2}{*}{ Laboratory } & \multicolumn{3}{|c|}{ Adjustments } & \multicolumn{2}{|c|}{ Present values of calibration } \\
\hline & $\begin{array}{l}\text { Date } \\
\text { (2) }\end{array}$ & $\begin{array}{l}\text { Luminous } \\
\text { intensity } \\
\text { (3) }\end{array}$ & $\begin{array}{l}\text { Luminous } \\
\text { llux } \\
\text { (4) }\end{array}$ & $\begin{array}{l}\text { Luminous } \\
\text { intensity } \\
\text { (5) }\end{array}$ & $\begin{array}{l}\text { Luminous } \\
\text { กux } \\
\text { (6) }\end{array}$ \\
\hline CSIRO (Australia) & - & - & - & 1.000 & 0.997 \\
\hline ExL (Japan) & - & - & - & 0.992 & 1.002 \\
\hline IEN (Italy) & - & - & - & 0.993 & 0.996 \\
\hline INM (France) & January 1, 1988 & +24 & +0.5 & 1.004 & 1.005 \\
\hline INTI (Rep. Argentina) & July 20,1987 & +0.9 & 0.0 & 1.000 & 0.999 \\
\hline IOM (Spain) & - & - & - & 1.002 & - \\
\hline NBS (USA) & - & - & - & 1.006 & 1.010 \\
\hline NIM (People's Rep. China) & - & - & - & 0.998 & 0.996 \\
\hline NPL (United Kingdom) & April 1, 1987 & +0.8 & +0.3 & 1.002 & 0.559 \\
\hline NPRL (South Africa) & - & - & - & 1.007 & 1.001 \\
\hline NRC (Canada) & July 9, 1987 & +12 & - & 1.000 & - \\
\hline OFMET (Switzeriand) & August 31,1987 & +1.0 & - & 1.000 & - \\
\hline PTB (Fed. Rep. Germany) & - & - & - & 0.997 & 0.994 \\
\hline VNIIOFI (USSR) & - & - & - & 1.006 & - \\
\hline BIPM & January 1, 1987 & +1.0 & -0.7 & 1.000 & 1.000 \\
\hline
\end{tabular}




\section{Appendix B - SP250, Optical Radiation Measurements, Chapter 7}
A. Photometric Measurements

Technical Contacts:

Yoshi Ohno

Tel: (301) 975-2321

E-mail: ohno@garnet.nist.gov

Mailing Address:

A320 Metrology

National Institute of Standards and Technology

Gaithersburg, MD 20899-0001

Test No. Items

37010C Luminous Intensity and Color Temperature Standard Lamps

37020S Special Tests for Luminous Intensity and Color Temperature of Submitted Lamps

37030C Color Temperature Standard Lamps

37040C Each Additional Color Temperature for 37030C

37050S Special Tests for Color Temperature of Submitted Lamps

37060S Special Tests for Total Luminous Flux of Submitted Incandescent Lamps and Fluorescent Lamps

37070C Opal Glass Luminance Coefficient Standards

37080S Special Tests for Submitted Luminance Sources and Transmitting Diffusers

37090S Special Tests for Submitted Photometers, Illuminance meters, and Luminance meters

37100S Special Photometric Tests

General Information

Calibration services in this area provide access to the photometric units realized and maintained at NIST. Lamp standards of luminous intensity, luminous flux, and color temperature as well as reference photometers and materials as described below are issued or calibrated on a routine basis. 


\section{Luminous Intensity and Color Temperature Standard Lamps (37010C)}

NIST will issue to the customer $1000 \mathrm{~W}$ modified FEL quartz halogen lamps calibrated for luminous intensity (candela) and color temperature (kelvin). The lamps have a double coil filament with a clear bulb, and are potted on a medium bi-post base. The lamps are usually operated at approximately $7 \mathrm{~A}(85 \mathrm{~V}) \mathrm{DC}$, at a color temperature of $2856 \mathrm{~K}$. The relative expanded uncertainty $(k=2)$ of the luminous intensity of these lamps is $0.6 \%$, and the expanded uncertainty $(k=2)$ of the color temperature is $8 \mathrm{~K}$ at $2856 \mathrm{~K}$ with respect to the SI units.

Special Tests for Luminous Intensity and Color Temperature of Submitted Lamps (37020S)

NIST will calibrate the luminous intensity and color temperature of incandescent lamps with a medium bi-post base submitted by customers. The inside frosted lamps, the airway beacon lamps, and the $1000 \mathrm{~W}$ FEL lamps previously issued from NIST can be submitted for recalibration. Customers can either specify the lamp current or the color temperature of the lamp (normally $2856 \mathrm{~K}$ ) for calibration. The uncertainty of calibration is described above.

\section{Color Temperature Standard Lamps (37030C)}

NIST will issue to the customer $1000 \mathrm{~W}$ modified FEL quartz halogen lamps as described in $37010 \mathrm{C}$ calibrated for color temperature. The lamps are usually calibrated for a color temperature of $2856 \mathrm{~K}$. The expanded uncertainty $(k=2)$ of the color temperature of these lamps is $8 \mathrm{~K}$ at $2856 \mathrm{~K}$ with respect to the SI units.

\section{Each Additional Color Temperature for 37040C}

The color temperature standard lamps requested for $37030 \mathrm{C}$ can be calibrated for additional color temperature points in a range from $2000 \mathrm{~K}$ to $3200 \mathrm{~K}$. The expanded uncertainty $(k=2)$ of this calibration is $4 \mathrm{~K}$ to $11 \mathrm{~K}$ in the range from $2000 \mathrm{~K}$ to $3200 \mathrm{~K}$.

Special Tests for Color Temperature of Submitted Lamps (37050S)

NIST will calibrate the color temperature of incandescent lamps with a medium bi-post base submitted by customers. The inside frosted lamps, the airway beacon lamps, and the $1000 \mathrm{~W}$ FEL lamps previously issued from NIST can be submitted for recalibration. The expanded uncertainty $(k=2)$ of this calibration is $4 \mathrm{~K}$ to $11 \mathrm{~K}$ in the range from $2000 \mathrm{~K}$ to $3200 \mathrm{~K}$.

Special Tests for Total Luminous Flux of Submitted Incandescent lamps and Fluorescent Lamps (37060S)

NIST will calibrate the total luminous flux (lumen) of incandescent lamps and fluorescent lamps submitted by customers. The standard lamps previously issued from NIST can be submitted for recalibration. Miniature lamps may also be accepted. Customers should contact NIST before submitting lamps. The relative expanded uncertainty $(k=2)$ of this calibration, which depends 
on the reproducibility of test lamps, is typically $0.8 \%$ for incandescent lamps and $1.8 \%$ for fluorescent lamps, with respect to the SI units.

\section{Opal Glass Luminance Coefficient Standards (37070C)}

NIST will issue flashed opal glasses, $51 \mathrm{~mm} \times 51 \mathrm{~mm}$, calibrated for luminance coefficient (ratio of luminance / illuminance, unit: $\mathrm{sr}^{-1}$ ) for CIE Illuminant A ( $2856 \mathrm{~K}$ source). The glasses, masked with a circular aperture of $25 \mathrm{~mm}$ in diameter, are calibrated for the luminance within a circular area of $1 \mathrm{~cm}$ in diameter in the center of the aperture. The relative expanded uncertainty $(k=2)$ of this calibration is $0.5 \%$.

Special Tests for Submitted Luminance Sources and Transmitting Diffusers (37080S)

NIST will calibrate the luminance $\left(\mathrm{cd} / \mathrm{m}^{2}\right)$ of submitted sources and luminance coefficient $\left(\mathrm{sr}^{-1}\right)$ of submitted transmitting diffusers including opal glasses previously issued from NIST. Customers should contact NIST before sending sources or diffusers. The relative expanded uncertainty $(k=2)$ of the luminance calibration is $0.7 \%$ with respect to the SI units.

Special Tests for Submitted Photometers, Illuminance meters, and Luminance meters (37090S) NIST will calibrate photometers, illuminance meters, and luminance meters submitted by customers. Calibration is usually made with the CIE illuminance A $(2856 \mathrm{~K}$ incandescent source) in a range from $0.001 \mathrm{~lx}$ to $3000 \mathrm{~lx}$ for illuminance and $0.1 \mathrm{~cd} / \mathrm{m}^{2}$ to $4000 \mathrm{~cd} / \mathrm{m}^{2}$ for luminance. The relative expanded uncertainty $(k=2)$ of calibration is $0.5 \%$ for illuminance and $0.7 \%$ for luminance at normal levels, which will increase at low levels. As an option, NIST can measure the relative spectral responsivity of submitted instruments and calculate spectral mismatch correction factors for a source of known spectral power distribution.

Special Photometric Tests (37100S)

NIST can provide special tests for sources, detectors, and photometric instruments other than those stated above under limited conditions with special arrangements of the NIST facility. Customers should contact NIST for consultation. 


\section{REPORT OF CALIBRATION}

Luminous Intensity and Color Temperature of Standard Lamps 37010C

for

One 1000 watt type T6 FEL lamp \# NIST0000

Supplied to:

ABC Company

123 Calibration $\mathrm{Ct}$.

Measurement City, MD 00000-0000

(See your Purchase Order No. ABC000 dated January 1, 1996)

\section{Calibration Item}

One 1000 watt type T6 FEL lamp was calibrated for $2856 \mathrm{~K}$ color temperature and luminous intensity. The lamp has a tungsten coiled-coil filament in a clear quartz bulb and a medium bi-post base. The lamp designation (NIST0000 as well as its polarity are indicated on the lamp base plate.

\section{Description of the Calibration}

The luminous intensity measurement is based on the NIST detector-based candela [1] realized in 1994 and therefore on the international definition of candela in effect since 1979. The color temperature measurement is based on the international temperature scale of 1990 (ITS-90).

The test lamp was placed on a photometry bench in the base-down position with the lamp designation number facing away from the photometer. The lamp orientation was accomplished by aligning the lamp socket so that the lamp posts were held vertical and so that the plane formed by the center lines of the posts was perpendicular to the optical axis of the photometer. A lamp alignment jig (a mirror set parallel to the plane formed by the center lines of an identical bi-post base) was used in combination with a laser (positioned to duplicate the optical axis of the photometer) to facilitate this alignment. The lamp was aligned horizontally so that the center line between the center lines of the posts intersects the optical axis. The height of the lamp was aligned so that the optical axis was $9.5 \mathrm{~cm}$ (3.75 inches) above the bottom of the posts. The distance origin of the lamp was the center of the lamp posts. 
The operating current of the test lamp was first determined so that the lamp produced a color temperature of $2856 \mathrm{~K}$. The color temperature of the lamp was measured, using a spectroradiometer, by comparison with two $2856 \mathrm{~K}$ color temperature working standard lamps (NBS10000 and NBS10005) which were calibrated in the NIST Facility for Automated Spectroradiometric Calibrations (FASCAL) described in reference [2].

After determining the lamp current, the luminous intensity of the lamp was measured with three of the NIST standard photometers which embody the NIST illuminance unit [3]. The lamp was operated on DC power with the electrical polarity as marked on the lamp bulb near the positive post. The lamp current was slowly ( 30 seconds) ramped up to the prescribed current and allowed to stabilize for at least ten minutes before luminous intensity measurements were made.

The standard photometers measured the illuminance of the test lamp at a distance of approximately $3.5 \mathrm{~m}$. The luminous intensity was determined from the measured illuminance and the exact distance between the lamp and the photometer. Measurements were made for three lightings of the test lamp to check its reproducibility, and the average values were reported. The details of the calibration procedures are described in reference [2]. The total operating time of each lamp was approximately 40 minutes. The room temperature was $23{ }^{\circ} \mathrm{C}$ and relative humidity was $18 \%$ at the time of calibration.

\section{Results of the Calibration}

The results of the calibration are shown in Table 1. The relative expanded uncertainty (with coverage factor $k=2$ and thus a two standard deviation estimate) of the luminous intensity value is $0.52 \%$. The expanded uncertainty $(k=2)$ of the color temperature value is $8 \mathrm{~K}$. The uncertainty budget is shown in Table 2 . The NIST policy on uncertainty statements is described in reference [3].

Table 1. Results of Calibration

\begin{tabular}{ccccc}
\hline $\begin{array}{c}\text { Lamp } \\
\text { No. }\end{array}$ & $\begin{array}{c}\text { Current } \\
\text { DC } \\
{[\mathrm{A}]}\end{array}$ & $\begin{array}{c}\text { Voltage* } \\
\text { DC } \\
{[\mathrm{V}]}\end{array}$ & $\begin{array}{c}\text { Color } \\
\text { Temperature } \\
{[\mathrm{K}]}\end{array}$ & $\begin{array}{c}\text { Luminous } \\
\text { Intensity } \\
{[\mathrm{cd}]}\end{array}$ \\
\hline NIST10000 & 7.201 & 85.09 & 2856 & 964.5 \\
NIST10001 & 7.203 & 8554 & 2856 & 989.9 \\
\hline
\end{tabular}

*Voltage is for reference only. 


\section{General Information}

The lamp should be carefully aligned in accordance with the procedures described above. The lamp should be operated on DC power at the reported current and at the prescribed polarity. Photometric measurements should be made after the lamp has stabilized (approximately 10 minutes after turn on).

Further details of the NIST photometric units, calibration procedures, and uncertainty analysis are described in reference [3].

The Calibration Report shall not be reproduced except in full, without the written approval of NIST.

Prepared by :

Approved by :

Yoshihiro Ohno

Optical Technology Division

Physics Laboratory

(301) 975-2321
Joseph L. Dehmer

For the Director,

National Institute of Standards and Technology

(301) 975-3216

\section{References:}

[1] C. L. Cromer, G. Eppeldauer, J. E. Hardis, T. C. Larason, and A. C. Parr, "National Institute of Standards and Technology detector-based photometric scale," Applied Optics, 32-16, 2936-2948 (1993)

[2] NBS Special Publication 250-20 (1987), Spectral Irradiance Calibrations

[3] NIST Special Publication 250-15 (1995), Photometric Calibrations

[4] B. N. Taylor and C. E. Kuyatt, "Guidelines for Evaluating and Expressing the Uncertainty of NIST Measurement Results," NIST Technical Note 1297 (1993). 
Table 2. Uncertainty budget for this luminous intensity calibration

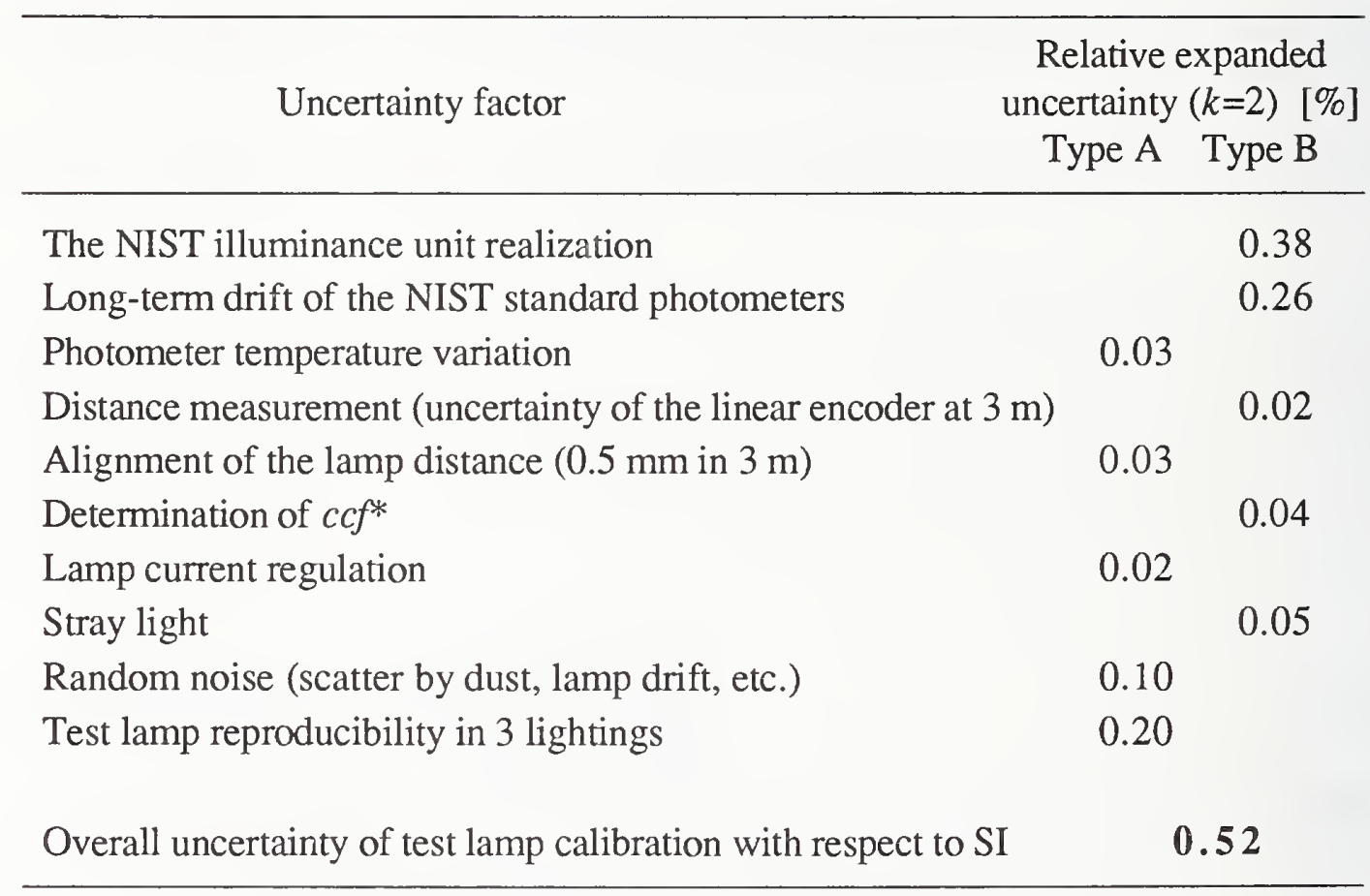




\section{REPORT OF CALIBRATION}

Special Test for Luminous Flux of Submitted Lamps 37060S

for

Three Incandescent Lamps with s/n: 000-001, 000-001, 000-003

Submitted by:

ABC Company

123 Calibration $\mathrm{Ct}$.

Measurement City, MD 00000-0000

(See your Purchase Order No. ABC123 dated January 1, 1996)

\section{Description of Calibration Item}

Three $1000 \mathrm{~W}$ gas-filled, frosted-bulb incandescent lamps with designation numbers; 000-001, 000-002, and 000-003 were calibrated for total luminous flux.

\section{Description of Calibration}

This total luminous flux measurement is based on the NIST luminous flux unit [1] realized in 1995 which has been derived from the NIST detector-based candela [2] realized in 1994 and therefore based on the international definition of candela in effect since 1979.

The test lamps were calibrated in a $2 \mathrm{~m}$ integrating sphere by comparison with the $60 \mathrm{~W}$ total luminous flux working standard lamps (TF6-1, TF6-2, and TF6-3). The working standard lamps are calibrated periodically using the integrating sphere against the NIST primary total luminous flux standard lamps (40 W, TF4 Group). The primary standard lamps are calibrated using the procedures described in reference [1]. The details of the $2 \mathrm{~m}$ integrating sphere system are described in reference [3].

The lamps were operated in the base up position. The operating current for each lamp was first determined for a color temperature of approximately $2856 \mathrm{~K}$ by measuring the relative spectral irradiance in one direction using a spectroradiometer. The total luminous flux measurements were Calibration Date: January 1,1996

NIST Test No. : 844 / 00000-96 
made in three runs. Each run consisted of measurements of standard lamps and the test lamps. The current of the lamp was ramped up slowly to the prescribed value, and stabilized for 10 minutes. The lamp current, the lamp voltage, and the photometer output signal were recorded together with the data on the environmental conditions. Corrections were made for the dark readings, the self-absorption effects, and the spectral mismatch correction factors to calculate the total luminous flux of the test lamps. The mean values of each test lamp in the three runs are reported. The variations of luminous flux values in the three runs (in a two standard deviation estimate) are included in the uncertainty of this calibration. The room temperature was $23{ }^{\circ} \mathrm{C}$ and relative humidity was $28 \%$ at the time of calibration.

\section{Results of Calibration}

The results of the calibration are shown in Table 1. The relative expanded uncertainty (coverage factor $\mathrm{k}=2$ and thus a two standard deviation estimate) of the reported luminous flux values is $1.0 \%$. The uncertainty budget is shown in Table 2 . The relative expanded uncertainty $(k=2)$ of the current values is $0.01 \%$. The NIST policy on uncertainty statements is described in reference [4].

Table 1. Results of Calibration

\begin{tabular}{ccccc}
\hline $\begin{array}{c}\text { Lamp } \\
\text { Designation }\end{array}$ & $\begin{array}{c}\text { Lamp } \\
\text { Current } \\
{[\mathrm{A}]}\end{array}$ & $\begin{array}{c}\text { Lamp } \\
\text { Voltage* } \\
{[\mathrm{V}]}\end{array}$ & $\begin{array}{c}\text { Color } \\
\text { Temperature* } \\
{[\mathrm{K}]}\end{array}$ & $\begin{array}{c}\text { Total } \\
\text { Luminous Flux } \\
{[\mathrm{lm}]}\end{array}$ \\
\hline $000-001$ & 7.570 & 104.8 & 2856 & 13350 \\
$000-002$ & 7.590 & 105.0 & 2856 & 13420 \\
$000-003$ & 7.590 & 104.1 & 2856 & 13980 \\
\hline
\end{tabular}

* Lamp voltage and color temperature are for reference only.

Prepared by :

Yoshihiro Ohno

Optical Technology Division

Physics Laboratory

(301) 975-2321
Approved by :

Joseph L. Dehmer

For the Director,

National Institute of Standards and Technology (301) 975-3216 
REPORT OF CALIBRATION

The Calibration Report shall not be reproduced except in full, without the written approval of NIST.

\section{References:}

[1] Ohno, Y., "Realization of NIST 1995 Luminous Flux Scale using Integrating Sphere Method", (to be published in J.IES, Winter 1996 Issue)

[2] C. L. Cromer, G. Eppeldauer, J. E. Hardis, T. C. Larason, and A. C. Parr, National Institute of Standards and Technology detector-based photometric scale, Applied Optics, 32-16, 2936-2948 (1993)

[3] NBS Special Publication 250-15, Photometric Calibrations (1995)

[4] B. N. Taylor and C. E. Kuyatt, Guidelines for Evaluating and Expressing the Uncertainty of NIST Measurement Results, NIST Technical Note 1297. (1993)

Table 2. Uncertainty budget for this total luminous flux calibration

\begin{tabular}{|c|c|c|}
\hline \multirow[t]{2}{*}{ Uncertainty factor } & \multicolumn{2}{|c|}{$\begin{array}{l}\text { Relative expanded } \\
\text { uncertainty }(k=2) \text { [\%] }\end{array}$} \\
\hline & Type A & Type B \\
\hline NIST luminous flux scale (primary/working standard lamps) & & 0.53 \\
\hline Aging of the working standard lamps between calibrations & & 0.30 \\
\hline \multicolumn{3}{|l|}{ Transfer from working standards to test lamps: } \\
\hline Geometric differences & & 0.50 \\
\hline Self-absorption correction & 0.10 & \\
\hline Spectral mismatch correction & & 0.10 \\
\hline Reproducibility of test lamps (typical) & 0.20 & \\
\hline Overall uncertainty of test lamp calibration with respect to SI & \multicolumn{2}{|c|}{0.83} \\
\hline
\end{tabular}

Calibration Date: January 1, 1996

NIST Test No. : 844 / 00000-96 







\section{SP 250-1 Spectral Radiance Calibrations PB87179883 \\ SP 250-2 Far Ultraviolet Detector Standards PB87227609 \\ SP 250-3 Radiometric Standards in the Vacuum Ultraviolet PB87227625}

SP 250-4 Fricke Dosimetry in High-Energy Electron Beams PB88110374 SP 250-5 Alpha-Particle Calibrations
PB88168620

SP 250-6 Regular Spectral Transmittance PB88108550

SP 250-7 Radiance Temperature Calibrations PB88123674

SP 250-8 Spectral Reflectance PB88109905

SP 250-9 Calibration of Beta-Particle-Emitting Ophthalmic Applicators PB88108535

SP 250-10 Radioactivity Calibrations with the " $4 \pi$ " Gamma Ionization Chamber and Other Radioactivity Calibration Capabilities PB88123708

SP 250-11 Dosimetry for High Dose Applications PB88201587

SP 250-12 Neutron Personnel Dosimetry PB87227617

SP 250-13 Activation Foil Irradiation with Californium Fission Sources PB88217443

SP 250-14 Activation Foil Irradiation by Reactor Cavity Fission Sources PB88217435

SP 250-15 Photometric Calibrations PB88153747

SP 250-16 Calibration of X-Ray and Gamma-Ray Measuring Instruments PB88211826

SP 250-17 The NBS Photodetector Spectral Response Calibration Transfer Program PB88201595

SP 250-18 Neutron Source Strength Calibrations PB88211818

SP 250-19 Calibration of Gamma-Ray-Emitting Brachytherapy Sources PB89193858

SP 250-20 Spectral Irradiance Calibrations PB88123781
SP 250-21 Calibration of Beta-Particle Radiation Instrumentation PB88201579

SP 250-22 Platinum Resistance Thermometer Calibrations PB88138367

SP 250-23 Liquid-in-Glass Thermometer Calibration Service PB89128888

\section{SP 250-24 Standard Cell Calibrations} PB88123690

SP 250-25 Calibration Service for Inductive Voltage Dividers

SP 250-26 NBS Phase Angle Calibration Services PB88225636

SP 250-27 AC-DC Difference Calibrations PB892222616

SP 250-28 Solid-State DC Voltage Standard Calibrations PB88168703

SP 250-29 Traceable Frequency Calibrations PB88168364

SP 250-30 GOES Satellite Time Code Dissemination: Description and Operation PB88168760

SP 250-31 Mass Calibrations PB89153894

SP 250-32 A Calibration Service for $30 \mathrm{MHz}$ Attenuation and Phase Shift PB88238324

SP 250-33 A Calibration Service for Voltage Transformers and High-Voltage Capacitors PB882252903

SP 250-34 High Vacuum Standard and Its Use PB89193841

SP 250-35 The Calibration of Thermocouples and Thermocouple Materials PB89209340

SP 250-36 A Calibration Service for Current Transformers PB91216770

SP 250-37 Photometric Calibrations

SP 250-38 NIST Leak Calibration Service PB92149772

SP 250-39 NIST Pressure Calibration Service

SP 250-40 Absorbed-Dose Calibration of Ionization Chambers in a ${ }^{60} \mathrm{Co}$ Gamma-Ray Beam SN003-003-03034-1 \$2.00

\footnotetext{
* Entries containing a stock number (SNOO3-003-) and price can be purchased from the Superintendent of Documents, U.S. Government Printing Office, Washington, DC 20402. GPO will accept checks, money orders, VISA, and MasterCard. For more infomation, or to place an order, call (202) 512-1800. Be sure to cite the stock number on ail orders.

Entries containing PB numbers can be purchased from the National Technical Information Service, Springfield, VA 22161. NTIS will accept American Express in addition to the payment methods listed for GPO. For more information call (703)487-4650; to place an order call (800) 553-6487. Fax: (703) 321-8547. Be sure to cite the PB number on all orders.

Entries without stock or PB numbers are in preparation.
} 


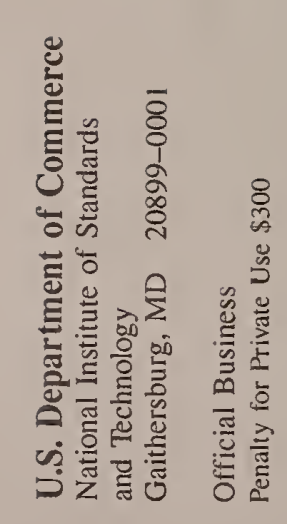

